Identity and Meaning Making of Student Veterans Transitioning to College

$$
\text { By }
$$

Leigh A. Green, B.S., M.Ed.

A Dissertation

In

\title{
COUNSELOR EDUCATION AND SUPERVISION
}

Submitted to the Graduate Faculty

Of the Texas Tech University in

Partial Fulfillment of

The Requirements for

The Degree of

DOCTOR OF PHILOSOPHY

Dr. Loretta Bradley, Committee Chair

\author{
Dr. Gerald Parr \\ Dr. Lee Duemer \\ Peggy Gordon Miller \\ Dean of the Graduate School
}

August, 2012 
Copyright, 2012 


\section{Acknowledgements}

I would first like to thank my doctoral committee: Dr. Loretta Bradley, Dr. Gerald Parr, and Dr. Lee Duemer. Without your guidance, I would not have been able to finish such a task. Dr. Bradley, thank you being a wonderful example and leader in the field of counselor education. Dr. Parr, thank you for the insight you provide about veterans' needs and for encouraging me to pursue this particular topic. The time you took to help me discover this as my true passion let me pursue this meaningful topic. Dr. Duemer, thank you for guiding me through the qualitative research process. I am grateful for your constant calm the times that I was 'wound up like an eight day clock.'

I am so thankful for my friends and family that have supported and guided me through this process. For my dear friends, thank you for understanding what this process consists of and letting me tell of my trials and tribulations over the past year. I will always cherish those those moments when I told you that I finished a chapter and you cheered with me. I am blessed to have such wonderful parents, Bill and Sarah, who have always supported me in every way. From horses, to sports, to school to more school and back to horses, the love and constant support you gave me inspires me to greatness. You always knew that I was capable of completing such an accomplishment; it just took me a couple of years to figure it out myself. I would also like to thank my parent's in-law, Ricky and Rhonda, for your continued encouragement during my Master's and Doctoral work.

Most importantly, I would like to thank my husband, Wade. Throughout the entire process, it was your constant encouragement, unfailing understanding of those late 
nights, and dedication to our relationship that I have made it here today. I am eager to begin the next chapter of our lives together.

Finally, I would like to thank the men and women of the United States Military, including my father, Wade, and extended family. It is because of your duty and service to our country that I am able to write this dissertation to honor you. I hope that this dissertation serves as an addition to the literature that will help each and every service member to ease the transition to the university based on your unique experiences. 


\section{Table of Contents}

Acknowledgements ii

Chapter I. Introduction

Introduction

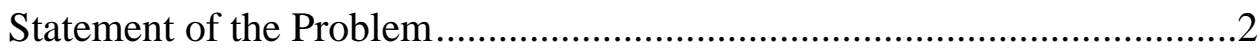

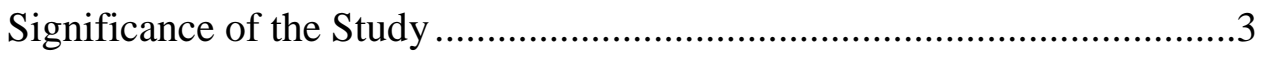

Purpose of the Study ............................................................................

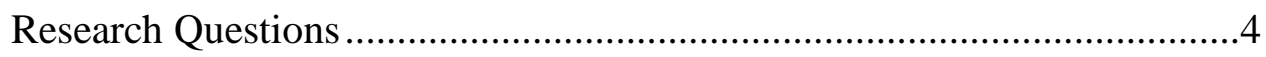

Theoretical/Conceptual Framework............................................................

Assumptions

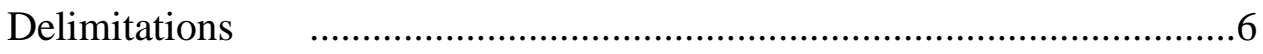

Limitations of the Study......................................................................

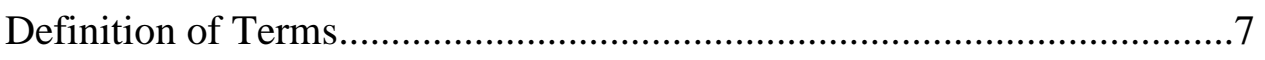

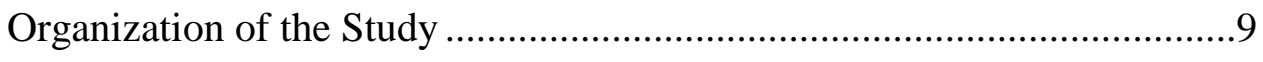

Chapter II. Review of Literature .................................................................... 10

Introduction

History of Veterans in College ………………………..........................10

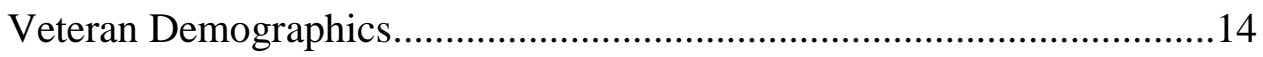

Student Veteran Demographics .............................................................14

Transition Issues of Nontraditional Students ............................................15

Transition Issues of Student Veterans...................................................22

College Student Identity Development ...................................................27

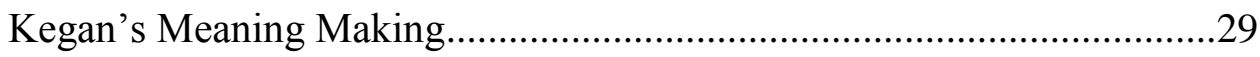


Theoretical Framework 32

Summary

Chapter III. Method .35

Organization 35

Purpose .35

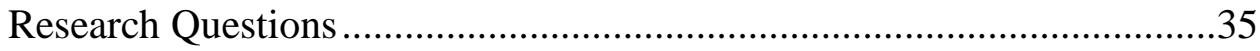

Rationale

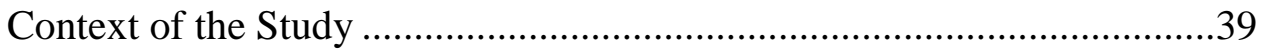

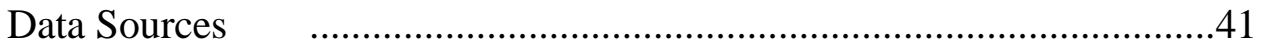

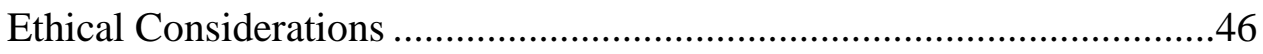

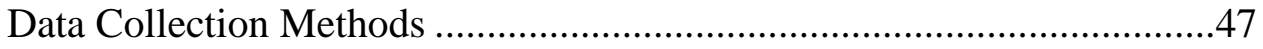

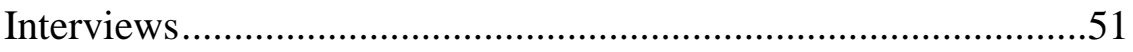

Data Management and Analysis .....................................................55

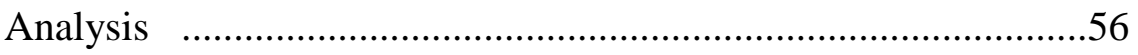

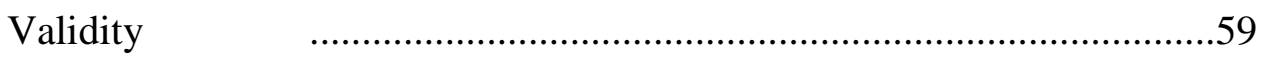

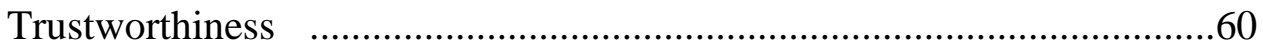

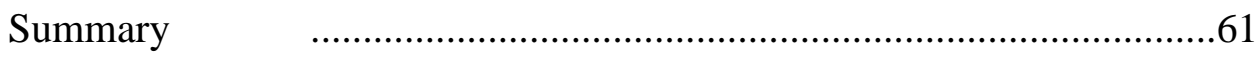

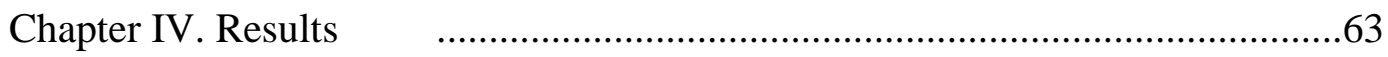

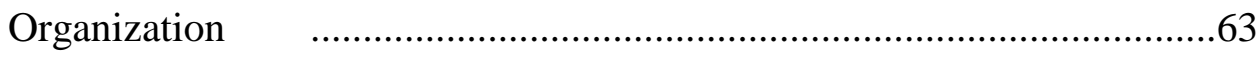

Restatement of the Problem .........................................................6

Description of the Participants ..........................................................64

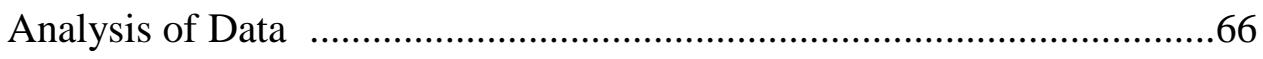

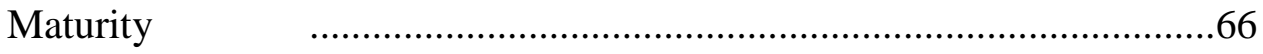




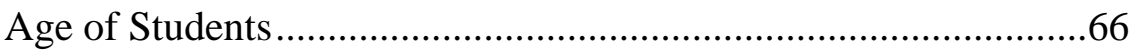

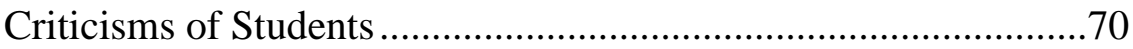

Dealing with Stressful Situations...........................................71

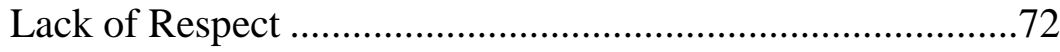

Valuing the Little Things ........................................................

Camaraderie

Feeling Toward Non Combat Veterans ...........................................

Frustration with the College Experience......................................................8

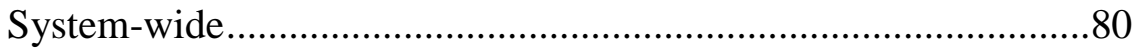

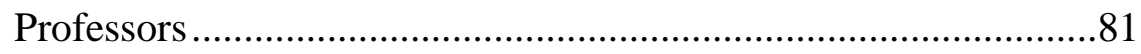

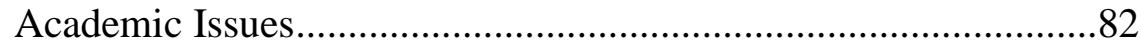

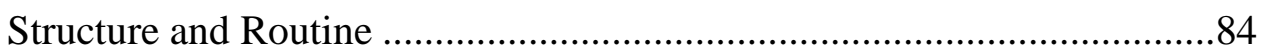

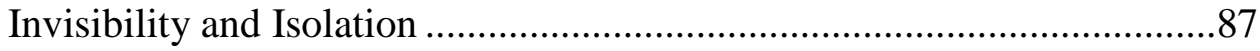

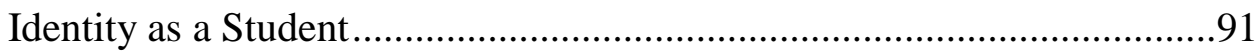

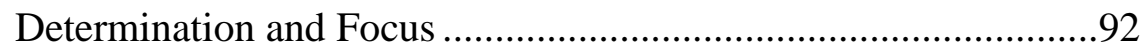

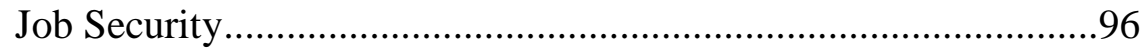

Military as Opportunity for College …………………………....... 98

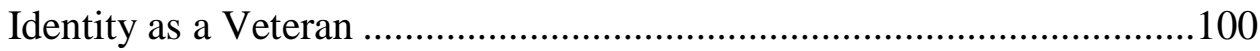

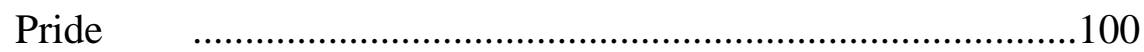

Returning to the Military ..............................................................103

Encouraging Military and Civic Service........................................104

Separation from Self-Perception as a Veteran ..............................105

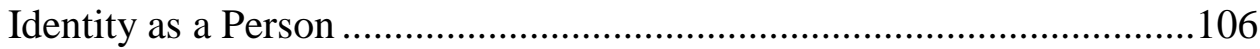




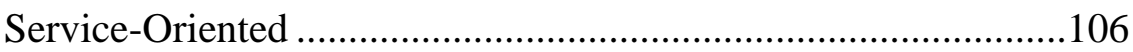

Positive Perceptions .....................................................................109

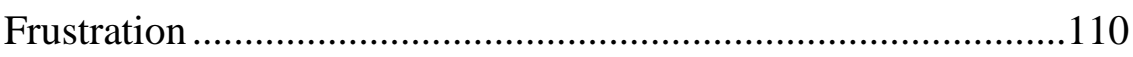

Kegan's Orders of Consciousness .........................................................111

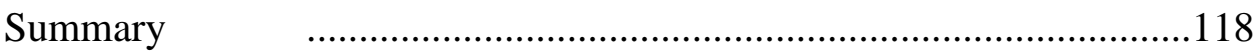

Chapter V. Summary, Implications, and Recommendations..............................119

Summary

Implications for Theory and Practice....................................................122

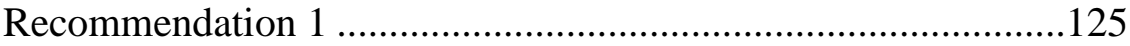

Recommendation 2 ..............................................................127

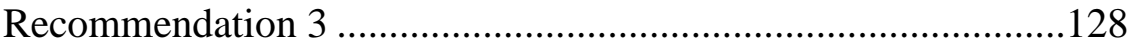

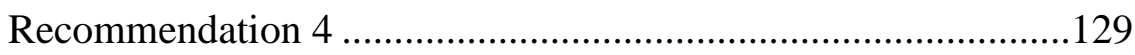

Unanticipated Findings and Implications ...............................................131

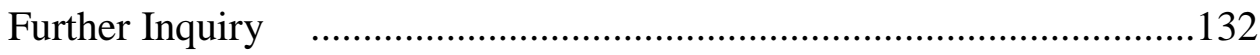

Summary

References

Appendix

A. E-mail to Participants.....................................................................146

B. Flyer

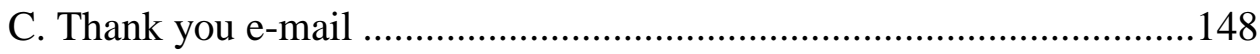

D. Institutional Review Board ...............................................................149

E. Research Information Sheet ...............................................................150

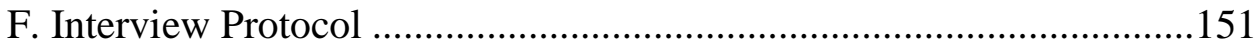




\begin{abstract}
Student veterans are returning to higher education institutions in increasing numbers with the advent of the Post 9/11 G.I. Bill. With over 1.64 million veterans of Operation Iraqi Freedom (OIF) and Operation Enduring Freedom (OEF) eligible to enter higher education, the campus community needs more information on the needs of enrolling veterans. The purpose of this study is to increase the knowledge base of the identity and meaning making of student veterans as it relates to their transition into university life. Research questions focused on transition issues, identity and meaning making of student veterans as they transitioned from combat deployments to college. Participants included veterans who had been deployed as combat veterans during the OIF and OEF campaigns and were attending the research institution at the time of the study.

Qualitative research methods were utilized to gain a personal understanding of the participants' perceptions of their transition, identity, and meaning making experiences. Grounded research directed the methodological basis for the research since it dictates a constant comparative method when analyzing data. Kegan's Order's of Consciousness guided the interpretation on the student veterans' perception of their meaning making structure.

Results concluded that student veterans viewed themselves as separate from the campus community. The perceptions of transition issues from this study are divided among the following five themes: (1) Maturity, (2) Camaraderie, (3) Frustration with the College Experience, (4) Structure and Routine, and (5) Invisibility and Isolation. Additionally, student veterans illustrated the third and fourth stage of Kegan's Order's of viii
\end{abstract}


Consciousness. Recommendations for future practice include educating the campus community on the needs of student veterans, promoting programs that assist the transition of student veterans to campus, investigating the needs of female veterans, and incorporating the multicultural counseling competencies into interactions with student veterans. 


\section{Chapter I}

\section{Identity and Meaning Making of Student Veterans Transitioning to College}

\section{Introduction}

With the advent of the new Post-9/11 G.I. Bill, student veterans are becoming increasingly present on college campuses across the nation. Currently, there are over 660,000 veterans within the United States attending postsecondary educational opportunities with 329,000 of those utilizing their educational benefits (National Center for Educational Statistics 2011a; Radford, 2010). With these numbers, almost four percent of U.S. undergraduate students are veterans (Radford, 2010) with 38 percent of the veterans utilizing their veterans' educational benefits. It is a given that there could be many more veterans on college campuses since the report does not include benefitsineligible veterans or those veterans who are not utilizing their benefits.

Secretary of Veterans Affairs Eric K. Shinseki understands that "veteran-students transitioning from active duty service to civilian educational pursuits face unique challenges entering the college setting” (Rumann \& Hamrick, 2009; U.S. Department of Veterans Affairs, 2011). Additionally, President Barack Obama has supported the transition of veterans by expanding funding for transitional programs in his 2012 budget (U.S. Department of Veterans Affairs, 2011). Accordingly, colleges and universities are asked to increase tailored services, including counseling, to ease the transition of veterans to campus (Ackerman, DiRamio, \& Garza-Mitchell, 2009; O’Herrin, 2011; Rumann \& Hamrick, 2009). In addition, universities are encouraged to provide "mental health staff who understand veterans' issues" (Radford, 2010, p. 5). 
For those veterans returning, one of the areas of concern is managing "serviceconnected injuries" (Radford, 2010). In fact, it is speculated that nearly 18 percent of those soldiers returning from "Operation Enduring Freedom and Operation Iraqi Freedom suffered or are currently suffering from psychological problems such as post-traumatic stress disorder (PTSD) and depression" (Cook \& Kim, 2009, p. 22-23).

\section{Statement of the Problem}

Counselors, student affairs professionals, and university officials lack information about the identity and meaning making in transition issues of veterans, a situation that could hinder their academic experience. Because of the lack of research on this particular subset of returning veterans, student affairs personnel are unable to provide specialized services concerning first-time student veterans' transition needs as they enter the higher education setting. Since student veterans are not seeking the specialized services for which they are eligible, the research reported herein could result in student veterans not having their university transition needs met, which in turn could lead to increased dropout rates for many veterans.

Additionally, Rumann and Hamrick (2010) suggested that further research should focus on "veteran sense-making related to multiple dimensions of identity could reveal a great deal about how student veterans construct and achieve more complex senses of self that incorporate their experiences of the social identities of service member and veteran" (p. 454). Abes, Jones and McEwen (2007) suggested:

Knowing the relationship between meaning making capacity and identity perceptions provides professionals who work with college students a deeper awareness of how students understand themselves. In turn, this knowledge allows 
professionals to more effectively engage in meaningful and individualized educational partnerships with students to help them develop a more complex understanding of their identity and the power associated with defining identity for oneself. (p. 19)

\section{Significance of the Study}

In an era of increased funding-related issues for institutions of higher education, university and governmental officials expect students who enroll in institutions to graduate in six years (NCHEMS Information Center for Higher Education Policymaking and Analysis, 2009). As of 2011, less than 26 percent of veterans over 25 years of age have earned a bachelor's degree (U.S. Census, 2009); therefore, colleges and universities are obligated to provide an environment conducive to student success.

In recent years, researchers identified the necessity of examining veteran transition from combat to college life. Researchers have taken an interest in exploring the challenges veterans often encounter as they strive to obtain higher education (Ackerman, DiRamio \& Garza-Mitchell, 2009; Cook \& Kim, 2009; Livingston, 2010; Rumann \& Hamrick, 2009; Van Dusen, 2011). Although some research has been conducted, there is a deficiency in research conducted specifically to explore the identity development and meaning making as it relates to the transition issues experienced by veterans of the Afghanistan and Iraq conflicts that received educational benefits from the Post-9/11 G.I. Bill. Resulting from the lack of current research and the recent implementation of the latest G.I. Bill program, the issues that may be experienced have not been identified. 
Given the increasing number of veterans taking advantage of the new Post-9/11 G.I. Bill as they enter college, it is imperative that colleges and universities become more aware of their specific needs to provide appropriate services. Student veterans arrive at college with unique identity and meaning making that influence their transition issues, issues that need to be addressed to enhance their retention and ultimate graduation from institutions of higher education. Given the need to spend resources wisely, it is important that the money spent on student veterans be utilized in the most appropriate and beneficial way for both the student veteran and the taxpaying citizens who support the Post-9/11 G.I. Bill.

\section{The Purpose}

Given that there is a lack of data in this area, the purpose of this study is to build a better understanding of the identity development and meaning making as it relates to student veteran transition into university life. The secondary purpose of this study is to increase the knowledge base of enrolling student veterans in the university setting. This study is expected, therefore, to assist counselors and university personnel in their instruction, support, and attention toward student veterans.

\section{Research Questions}

- What perceptions of meaning making do student veterans have of their military identity?

- In comparison, what perceptions of meaning making do student veterans have of their student identity?

- What is the role of meaning making in the construction of veteran identity and its 
interaction with other dimensions of identity, namely student identity?

\section{Theoretical Framework}

Two main frameworks will be used in this study, social constructivism and grounded theory. Social constructivism (Piaget, 1967) posits that persons construct meaning from their experiences and ideas. With each new experience that a person encounters, that person forms an idea that is stored in the person's mind to be used to later view new experiences. Piaget (1967) used the concepts of assimilation and accommodation to explain the differences in how people understand and interpret meaning to the events happening around them. Assimilation is the process through which a person takes information from the environment that is viewed in terms of their existing schemata. Accommodation then is the change made through the process of assimilation. Social constructivism is the process through which each individual understands his or her identity through historical, political, social and cultural lenses on both institutional and individual levels.

The purpose of grounded theory is to "demonstrate relations between conceptual categories and to specify the conditions under which theoretical relationships emerge, change, or are maintained" (Charmaz, 2002, p. 675). Founded by Glaser and Strauss (1967), grounded theory begins with data collection, which is then organized through a series of categories. It is through these categories that theory can be developed. Thus, in grounded theory "one generates conceptual categories or their properties from evidence; then the evidence from which the category emerged is used to illustrate the concept" (Glaser \& Strauss, 1967, p. 23). To illustrate the concept and develop a theory, the emphasis is on the data, and each theme and interpretation originates directly from the 
data. The use of a constant comparative method is used consistently throughout grounded theory research in different forms (Glaser \& Strauss, 1967). Grounded theory thus provides me a guideline to "understand people's experiences in as rigorous and detailed a manner as possible by identifying categories and concepts that emerge from text and link these concepts into substantive and formal theories" (Denzin \& Lincoln, 2005, p. 782).

\section{Assumptions}

Several assumptions were evident in the formation of this research study. First, it was assumed that identity development and meaning making in relationship to transition issues would be present for student veterans matriculating to institutions of higher education. Secondly, it was assumed that these transition issues associated with student veterans would differ from those of other students. In addition, it was assumed that because student veterans would be nontraditional students, there would be unique identity development and meaning making relating to transition issues associated with this aspect of their college experience. Finally, it was assumed that because enrolling student veterans are nontraditional, their transition issues would more closely resemble that of the adult population than those of traditional student transition.

\section{Delimitations}

One of the research delimitations occurred because the research is being conducted on student veterans from one public institution in the Southwest. Because it is only one public institution, the research findings may not be transferable to other institutions, as only student veterans at the participating institution were interviewed. 
Another delimitation to this study involves the data collection procedures. Data were gathered through an interview that relying on the participants' openness and honesty in providing in-depth information based on their experiences to the interviewer.

\section{Limitations}

Several limitations that could impact the findings are inherent in this research study. First, the data was collected by self-report of the veterans, which could lead to biased results related to the fact that the research is being conducted in an area of the country that values rugged individualism. Secondly, based on interactions with the veterans, I could have a bias in favor of veterans. Third, since I have worked in various settings facilitating the transition of students into the higher education setting, the work experience could influence how I differentiate between traditional student transition and student veteran transition. Fourth, as with any research, I could make methodological mistakes. Fifth, because the participants will be volunteers, I cannot ensure that all branches of the military are represented. Finally, a limitation to the research is related to the utilization of purposeful sampling methods. The convenience associated with purposeful sampling methods also limits the sample that will have the opportunity to participate in the research. Specifically, I will be studying those student veterans who are located at the particular institution, which decreases the transferability to other institutions.

\section{Definitions of Terms}

Afghanistan Conflict-- The invasion of Afghanistan by the armed forces of the United States of America, the United Kingdom and the Afghan United Front (Northern Alliance) on October 7, 2001. 
Identity-- "comfort with body and appearance, comfort with gender and sexual orientation, sense of self in a social, historical, and cultural context, clarification of selfconcept through roles and life-style, sense of self in response to feedback from valued others, self-acceptance and self-esteem, and personal stability and integration" (Chickering \& Reisser, 1993).

Iraq Conflict-- The invasion of Iraq by the United States beginning on March 20, 2003. It can also be referred to as Operation Iraqi Freedom (OIF) and later Operation Enduring Freedom (OEF).

Meaning Making-- The way a person constructs meaning based on their identity and interactions with their environment (Kegan, 1982, 1994).

Nontraditional Student-- According to St. John and Tuttle's (2004) definition, the nontraditional student is: "anyone who did not go to college within two years after high school" (p. 3).

Perception-- The way a person understands individuals and groups in his or her social world (Smith \& Mackie, 2000).

Post 9/11 G.I. Bill-- The reauthorization of the G.I. Bill for veterans who were on active duty after September 10, 2001. The bill went into effect on August 1, 2009.

Traditional Student-- Students between the ages of 18 and 22 who come to college directly from high school with parental support constitute only 40 percent of college students (Choy, 2002).

Transition-- Transition will be defined utilizing Schlossberg's (1995) definition as "any event, or nonevent, which results in changed relationships, routines, assumptions, and roles" (p. 27). 
Veteran-- An individual who has served and was discharged from some branch of service in the United States Military.

\section{Organization of the Study}

The overall study consisted of five sections: introduction, review of literature, methods, results, and discussion. The review of literature section includes the following: introduction, transition issues of adult learners, transition issues related to student veterans, and a conclusion. The methodology section consists of the research questions, rationale, context of the study, data sources, data collection methods, data analysis, and data management plan. The results section includes the participant demographics, interview information, field notes, data analysis, coding strategies, member checking, and themes produced by the research. The final discussion section includes implications for theory, both social constructivism and grounded theory. 


\section{Chapter II}

\section{Review of Literature}

\section{Introduction}

Throughout the United States, following the advent of the Post-9/11 G.I. Bill, student veterans are becoming increasingly present on college campuses across the nation with the advent of the current legislation. Currently, there are more than 660,000 veterans within the United States attending postsecondary educational opportunities with over 329,000 utilizing their educational benefits (Radford, 2010). Veterans have a unique history spanning back to World War II that has shaped their identity development and meaning making as they return home and either enroll for the first time or re-enroll. In a university, these veterans develop a separate identity that protects them while they are in the military that in turn may contrast with their identity as a student, and in turn, this can influence how they make meaning in various situations. The review of literature includes the history of the veterans in college, student veteran demographics, transition issues of veterans, transition issues for nontraditional students, college student identity development, Kegan's Order of Consciousness and the theoretical framework.

\section{History of Veterans in College}

Student veterans have long been a part of the United States system of higher education; however, it wasn't until the enactment of the G.I. Bill that veterans began to 
enter in larger numbers. It was in 1944 that President Franklin Delano Roosevelt signed into law what has often been called the most significant piece of legislation ever produced by the U.S. government, the G.I. Bill, also known as the Serviceman's Readjustment Act. The first incarnation of veteran's benefits began following World War I, when soldiers received approximately \$60 allowance and a train ticket home (Loane \& Smole, 2008; Today's G.I. Bill, 2011). Many of those soldiers faced difficulty assimilating into the civilian workforce and faced myriad challenges during the Great Depression (Today's G.I. Bill, 2011). In seeing the difficulties associated with readjustment, Congress tried to make it smoother by passing the Adjusted Compensation Act of 1924 or the Bonus Act. The Adjusted Compensation Act of 1924 provided soldiers with a bonus based on the amount of time that they spent in the service; however, many would not receive any of the money for 20 years (Today’s G.I. Bill, 2011).

During World War II, the United States Congress realized that it needed to do something more for the soldiers who were returning to facilitate their readjustment to civilian life. Specifically, the G I. Bill was developed. Despite its need, there was controversy and lack of support for the bill. Specifically, there were disagreements between members of Congress over the addition of an unemployment provision along with the higher education assistance and home loan benefits. In addition, some members of Congress deplored the idea of paying unemployed veterans $\$ 20$ a week because they thought it diminished their incentive to look for work while others questioned the concept of sending battle-hardened veterans to colleges and universities, a privilege then reserved for rich people (Today's G.I. Bill, 2011). Eventually, with the help of Harry Colmery of the American Legion, the G.I. Bill was passed and enacted. Reviewing the legislation, 
President Franklin D. Roosevelt stated that it gave "emphatic notice to the men and women in our armed forces that the American people do not intend to let them down" (Today's G.I. Bill, 2011).

The first provisions under the World War II G.I. Bill included \$300 mustering out pay, financial assistance for higher education and training, a weekly unemployment allowance of $\$ 20$ for 52 weeks, and federally-guaranteed loans of up to $\$ 2,000$ at four percent interest (Loane \& Smole, 2008; Today’s G.I. Bill, 2011). After three years, the G.I. Bill increased the number of veterans who went to college with over 49 percent of college admissions coming from student veterans (Today's G.I. Bill, 2011). By the end of this incarnation of the G.I. Bill, approximately 7.8 million of the 16 million World War II veterans utilized their G.I. Bill benefits in either an education or training program (Today's G.I. Bill, 2011). It was higher education and the ability to own one's own home that represented the American Dream for the veterans. Unfortunately, the G.I. Bill entered an atmosphere of reduced support for veterans.

By the time that Korean veterans were ready to take their turn realizing the American dream with the support of the G.I. Bill, the Veterans Adjustment Act of 1952 had removed much of the money. The Korean G.I. Bill combined the educational expenses and the subsistence allowance into one benefit that was paid directly to the veteran. It was the belief of the U.S. Department of Veterans Affairs (VA) that "requiring the veteran to contribute to the costs of his/her education would encourage more careful spending" (Loane \& Smole, 2008, p. CRS-3). The Korean G.I. Bill ended on January 31, 1965. Although the creation of the new Post- Korea and Vietnam G.I. Bill was intended for Korean and Vietnam veterans, it was not as generous as previous 
programs. It allowed for veterans to receive $\$ 100$ per month for every month they were in active service (Loane $\&$ Smole, 2008), which was reduced from the $\$ 110$ during the Korean G.I. Bill. The decrease in educational benefits continued for veterans and reached a record low in the 1960s with the Vietnam War.

During the interlude between the Vietnam War and the conflicts in the Middle East and the continuing fight against terrorism, the Post-Vietnam Era Veteran's Educational Assistance Program (VEAP) was established under Title IV in 1976. The VEAP's purpose was to recruit members for the Armed Forces during peacetime. The VEAP, for the first time, required participants to contribute to their educational fund during their military service (Loane \& Smole, 2008). Program participants agreed to contribute between $\$ 25$ and $\$ 100$ each month, and their maximum educational benefit could not exceed what they had already contributed to the matching federal contribution (Loane \& Smole, 2008).

In 1984, Mississippi Congressman Gillespie V. “Sonny” Montgomery revamped the bill to allow veterans to acquire their benefits through the federal government. The Department of Defense enacted the Montgomery G.I. Bill (MGIB) in 1985 as a threeyear pilot program consisting of both the MGBI- Active Duty (MGIB-AD) and the MGBI- Selected Reserve (MGBI-SR). As in the past with other incarnations of the G.I. Bill, the benefits for the Montgomery Bill also began to wane. The September 11, 2001, terrorist attacks on the United States and the subsequent influx of service member in and out of the military and into higher education precipitated the need for an update to the previous G.I. Bill. 
The Post-9/11 Veterans Educational Assistance Act, which became effective in August 2009, expanded the educational benefits available to those who served in the military after September 11, 2001. The new G.I. Bill allowed for 100 percent tuition and fee coverage, a monthly housing stipend, up to $\$ 1,000$ annually for books and supplies, and the ability to transfer benefits between one or more immediate family members (Today's G.I. Bill, 2011).

\section{Veteran Demographics}

As of September 2011, there are approximately 22.6 million veterans in the United States (United States Department of Veterans Affairs, 2011). Women consist of 7.5 percent of those veterans (United States Department of Veterans Affairs, 2011). Sixty percent of the nation's veterans live in urban areas, and six states account for about 36 percent of the total vet population; they are California, Florida, Texas, Pennsylvania, New York, and Ohio (United States Department of Veterans Affairs, 2011). The veteran population is quite diverse with Caucasian comprising 80.0 percent, African American 10.9 percent, Asian/Pacific Islander 1.4 percent, Hispanic 5.6 percent, American Indian/Alaska Natives 0.8 percent, and other 1.3 percent (United States Department of Veterans Affairs, 2011).

Veterans who served in each branch of service are as follows: 43 percent served in the Army, 22.5 percent served in the Navy, 18.2 percent served in the Marines, .09 percent served in the Coast Guard, and 4 percent served in the National Guard or Reserves (United States Department of Veterans Affairs, 2011). In addition to the overall number of veterans, the state of Texas is home to approximately 1,693,800 veterans (U.S. Census Bureau, 2012). 


\section{Student Veteran Demographics}

Approximately 85 percent of student veterans are 24 years old or older (O'Herrin, 2011; Radford, 2010; Van Dusen, 2011). Student veterans tend to be more likely nonwhite than veterans in general, which differs from the traditional undergraduate population (American Council on Education, 2011; Radford, 2010). Additionally, women make up 27 percent of the student veteran population in contrast to the 14 percent of veterans (American Council on Education, 2011). Student veterans make up less than 25 percent of veterans over the age of 25 that have a bachelors (4-year) degree (U.S. Census, 2009). Despite the 25 percent increases from the utilization of the G.I. Bill (Student Veterans of America, 2011), veterans represent only approximately 4\% of all those enrolled in postsecondary education (Radford, 2010). Radford (2010) further concluded that student veterans utilizing their benefits are 15-times more likely to enrollfull time than are those student veterans who are not utilizing their benefits.

\section{Transition Issues of Nontraditional Students}

Most readers would agree that military veterans rarely act or look like traditional college students. Not only are student veterans older in age, but also "veterans are, by definition, nontraditional students" (O’Herrin, 2011, p. 4). Even if these differences may at first seem advantageous, each carries with them their own set of challenges. Therefore, the premise of this section is to provide an exploration of the nontraditional student while simultaneously highlighting many of the contributing factors that may influence nontraditional college students. The positive contributing factors to be covered include the students' socioeconomic status and their feeling of a sense of belonging and motivation. The section will conclude with the negative factors as well as a summary. 
According to the National Center for Educational Statistics (1996) and Compton, Cox, and Laanan (2006), a nontraditional students is characterized by one of the following delayed enrollment past the same calendar year as their high school graduation, attends part-time or only part of the academic year, works full-time or more than 35 hours a week, financially independent as determined for eligibility for financial aid, has dependents other than a spouse, a single parent who is either not married or separated with dependents, or does not have a high school diploma. In addition, nontraditional students must also make adjustments to his or her academic, social, and cultural environment (Locks, Hurtado, Bowman, and Oseguera, 2008). For example, for nontraditional students, socioeconomic status has been identified as a contributing factor of delayed enrollment in higher education Goldrick-Rab (2006). Goldrick-Rab (2006) used national longitudinal data from postsecondary transcripts to investigate whether there is social class variation in college attendance patterns. Social class was found to play the most significant role in student engagement in attendance patterns. The most likely group of students to have a break in their college attendance included men, Hispanics, Blacks and lower socioeconomic status students.

Another contributing factor that plays an instrumental role in the success of nontraditional students is the student's sense of belonging at the institution. While this may be surprising to some, given the sense of camaraderie that is built during his or her time in the military, the same sense of belonging is critical to the success of student veterans on campus. A stronger sense of belonging was more evident in those students who spent more time socializing with their peers. Locks et al. (2008) wrote that "it is not only important to interact frequently with one's peers but also to engage with a diverse 
range of peers in a substantive manner" (p. 277). They thus concluded that the sense of belonging in college is directly related to the importance placed on high-quality interactions with diverse peers on (Locks et al., 2008).

One factor that has a positive effect on retention of nontraditional students is motivation. Bye, Pushkar, and Conway (2007) compared traditional and nontraditional undergraduate students and the effect of affective and motivational components on academic life. When undergraduate students encountered an increase in positive effect, researchers found that nontraditional students "maintained a higher threshold for intrinsic motivation to learn (p. 152). To facilitate the intrinsic motivation and positive effect, Bye et al. (2007) encouraged nontraditional students to "enjoy the process of mastering new skills in the classroom" (p. 155) to achieve so they can achieve and maintain the important balance between intrinsic and extrinsic forms of motivation.

Eppler and Harju (1997) examined the motivational goals of nontraditional students in relation to their academic performance. The study utilized the Dweck's model of "achievement motivation to determine the relationship between goal orientation and academic performance in 262 undergraduate students grouped by nontraditional vs. traditional status" (p. 557). In Dweck's model it is suggested that learning goals encourage a person to persist when obstacles are presented, whereas, with performance goals the goal is to avoid negative evaluation of one's performance (Eppler and Harju, 1997). Researchers found that nontraditional students rated themselves higher with learning goals than performance goals. In fact, those nontraditional students that had a break in enrollment which suggested a higher commitment to the learning goal orientation than the traditional age student. The nontraditional student was also more 
likely to combat learned helplessness based on their life experiences that allowed them to be more resistant to this phenomenon in their academic life. In addition, Dill and Henley (1998) suggested that nontraditional students have a "greater desire to learn or a higher enthusiasm for learning" (p. 30).

In addition to the positive factors that contribute to the success of nontraditional students on the college campus, Bozick and DeLuca (2005) studied the "antecedents and consequences of the timing of the transition from high school to college" (p. 531). According to the researchers, some of the academic and socioeconomic factors for a delayed enrollment are that "they come from families with few socioeconomic resources, they have performed poorly on standardized tests, they have dropped out of school, and they have exited high school with a GED” (p. 531). Even when the researchers controlled for academic and socioeconomic factors researchers, they found that "students who delay postsecondary enrollment have lower odds of bachelor degree completion" (p.531). Because of the delayed enrollment and various life commitments, it could make it impossible to fully invest in higher education.

The researchers focused their study on twelfth-grade interviews (1992) and eightyear post-high school graduation interviews (2000). This survey of over 24 thousand eighth graders reviewed the relationship between family, school, and academic performance. The goal of the study was to develop an assessment to track postsecondary educational attainment into early adulthood. Because of a lack of confidence in the social connection the students may be hindered from seeking assistance from faculty or administration. This perception also influences how university representatives interact with most nontraditional students. Additionally, because of the fear of being unable to 
afford the cost and not having parents who understand the application process for financial assistance, many will seek immediate placement in the workforce with the end result being that as time progresses, they lose connection with the academic culture. According to Bozick and DeLuca (2005), such students who do not feel academically ready are at a disadvantage because they are not properly prepared for the selection processes that four-year institutions employ versus two-year institutions.

Additionally, two-year schools are more inclusive of students with part-time and/or full-time positions as well as those with dual roles, either familial or professional. Depending on funding from the G.I. Bill many student veterans supplement his or her income through addition of a part-time or full- time position. In contrast, four-year universities organize their curricula and social resources around the lives of traditional students with most classes during the day and limited nighttime services for off campus commuters. Bozick and DeLuca (2005) suggested that more research needs to be conducted to understand how the experiences and responsibilities of young adults who have delayed college enrollment after the completion of secondary schooling affect the student's transition and successful matriculation through college.

Compton, Cox, and Laanan (2006) further addressed institutional commitment to the effective transition of nontraditional students in their study of the characteristics relevant to adult learners including: pursuing a program leading to a vocational certificate or degree, having focused goals for their education, considering themselves workers not students, more likely enrolled in distance education, and finally, more likely to leave college without a degree. The researchers suggested six recommendations for institutions interested in creating a student-centered environment that accommodate and serve adult 
learners. First, institutions should reduce the effort needed to enroll in the institution. Second, administrators need to review the instructional delivery system and office structure to ensure that class services are available to adult learners as needed. Third, because adults focused on career-oriented goals, the course work should have practical application. Fourth, institutions should creatively engage adult learners to be more integrated into the social life of the institution. Fifth, counseling centers need to be available to help adult learners deal with stress and the means for managing it effectively. Finally, institutions should be proactively inquiring about the needs of adult learners, instead of waiting until they have dropped out.

In addition to the study and recommendations by Cox et al. (2006), Taniguchi and Kaufman (2005) examined the reasons that numbers of degrees completed by nontraditional students is lower than those completed by traditional college students. Researchers identified prolonged enrollment, human capitol theory, and family and school responsibilities as leading factors that hinder nontraditional college students from matriculating through their degree and ultimately graduating from a particular institution.

Taniguchi and Kaufman (2005) examined the first factor of prolonged enrollment and found that the increased time in college impacts the student's motivation because of the extended time that it takes to complete the degree plan. The researchers determined that prolonged enrollment was directly affected by the nontraditional student's part-time status. The prolonged enrollment can also lead to a strain on the students' finances. With the decrease in available funds through scholarships, assistantship positions, tuition waivers and student loans, nontraditional students then begin taking classes on a parttime basis that extends the amount of time required to complete their degree even further. 
Human Capitol Theory (Taniguchi \& Kaufman, 2005) was the second factor contributing to the lack of completion among nontraditional students as they seek a college degree. Human Capitol Theory posits that students will invest time and money into school because it builds their skills, which, in turn, will assist them in transitioning successfully to the workforce upon graduation (Taniguchi \& Kaufman, 2005).

Nontraditional students, who are older, are less likely to complete the rigors of a college degree because they are already in the workforce and the amount of time spent obtaining the degree would not be worth the limited amount of time that remains for them on the workforce (Taniguich \& Kaufman, 2005). In addition researchers found that the lowered cognitive ability and unequal resources could affect the students' ability to attain the degree.

The final factor, identified by the researchers, was family and school responsibilities. Taniguchi and Kaufman (2005) posited that nontraditional students often transition to the college experience with a nuclear family, including dependents, when they arrive at college. The marriage for the nontraditional student "promotes degree completion" (p. 925) whereas, divorce negative affects degree completion. Young children, also, negatively affected the degree completion for both men and women. In addition to the family factors, Eppler and Harju (2007) found that the most troublesome role for the nontraditional student was one of worker. The nontraditional student in this study typically worked three times as many hours as the traditional student. Therefore, their work hours were "negatively correlated with both study time and GPA for this group" (p. 570) which would suggest that even with an increased belief in learning goal orientation work commitments worked against this advantage. However, they noted that 
no empirical data validated this claim. Family factors, including marriage and parenthood, contributed as another one of the factors that influenced the lack of completion among nontraditional college students. Although the time at work and with family was distracting for nontraditional students, Dill and Henley (1998) suggested that because of the outside influences they "cushioned themselves from stressful academic events by gaining high self-appraisal in other roles" (p. 30). Thus there seem to be positives and negatives in the amount of outside influences that the nontraditional student manages in his or her day to day life.

\section{Transition Issues of Student Veterans}

Veterans who enroll in higher education are a subgroup of nontraditional students (Brown \& Gross, 2011; Cook \& Kim, 2009; Ford, Northrup \& Wiley, 2009; O’Herrin, 2011; Persky \& Oliver, 2011; Rumann \& Hamrick, 2009). The increasing number of veterans who are utilizing their G.I. Bill has brought in a multitude of veterans to college campuses across the nation (Brown \& Gross, 2011; O’Herrin, 2011). When they return, student veterans encounter a vast array of transition issues as they arrive on the college campus. Issues range from role incongruities, maturity issues, relationships, and identity renegotiation (Rumann \& Hamrick, 2010). Role incongruities consisted of "military and academic life, the incompatibilities of lingering stress and anxiety with returning to college, and enacting aspects of the student role during deployment and aspects of the military role during college" (Rumann \& Hamrick, 2010, p. 440). Maturity was enhanced for all of the participants in the Rumann and Hamrick study as each said that they were more motivated to complete their degrees after they had returned from service. In terms of relationships, Rumann and Hamrick (2010) found that returning veterans 
found difficulty in maintaining previous relationships because of the time lapse where nonveteran students had become several semesters older than the student veteran.

In addition to maintaining relationships, student veterans experienced difficulty initiating new relationships because of the emotional and social maturity that they had developed while being deployed. With the difficulty in initiating and maintaining relationships, some veterans feel a sense of isolation because they can share their experiences only with a selective number of others, namely other veterans (Brown \& Gross, 2011; DiRamio, Ackerman, \& Garza-Mitchell, 2008; Rumann \& Hamrick, 2010). Brown and Gross (2011) highlight that student veterans are "challenged by the adjustment in moving from a command and control environment to the openness of a college campus" (p. 46). Because of this, many student veterans can feel a sense of frustration because of the "daunting and unfamiliar bureaucracy of higher education" (DiRamio, Ackerman, \& Garza-Mitchell, 2008; O’Herrin, 2011). O’Herrin (2011) pointed out that the military is a complex structure, but soldiers are trained from the beginning of their careers to navigate that system.

Soldiers are indeed educated in the military; yet, their military education does not transfer to institutions of higher education as such (Brown \& Gross, 2011). The American Council on Education suggests that the credits that they earn should receive credit consideration but many times it does not and the veteran is placed at a lower academic level (Brown \& Gross, 2011). Military service members and veterans are thus in courses that are "far below their competency level and being required to take courses that cover the same or nearly the same material that they have already mastered through 
their training schools" (p. 47). The lack of understanding and acceptance of their military education could be a contributing factor towards noncompletion (Brown \& Gross, 2011). Recent research, (Brown \& Gross, 2011; Cook \& Kim, 2009; Ford, Northrup \& Wiley, 2009; Livingston, 2010; O’ Herrin, 2011; Persky \& Oliver, 2011; Rumann \& Hamrick, 2009; Van Dusen, 2011) highlights the need for colleges and universities being leaders in raising awareness of the needs of student veterans as a first step in developing effective support services. Hassan, Jackson, Lindsay, McCabe, and Sanders (2010) suggest that student veterans "deserve to belong to a campus with good role models, accessible student advisors, and engaged faculty and staff with military savvy" (p. 31) to further the student veterans capacity for an "occupational future, with skills and abilities related to teamwork, sacrifice, courage, perseverance, and future mindedness" (p. 31). Veterans affairs staff members, especially trained counselors (Persky \& Oliver, 2011), serve a critical role in helping veterans in their transition back to college, but with the increasing number of veterans, from the G.I. Bill, they may become overextended (Persky \& Oliver, 2011; Rumann \& Hamrick, 2009). Although student veteran transitions are not novel for colleges and universities, the roles of student, service member, and veteran have become "less clear cut and bonded and are often experienced simultaneously as well as sequentially" (Rumann \& Hamrick, 2009, p. 32). Because of this, Rumann and Hamrick (2009) suggest "establishing proactive and working partnerships to help create a more seamless environment for students who need to successfully navigate multiple agencies, organizations, and bureaucracies to help create or find supportive individuals and environments to facilitate the transitions of student veterans" (p. 32). Servicemembers and student veterans can teach campus 
administrators through their "own experiences, concerns, and questions" (p. 32) and should be treated as "pioneers and invaluable sources of information" (p. 32) to inform practice. Additionally, Brown and Gross (2011) suggest that universities should utilize the resources that are currently available to them such as the American Association of State Colleges and Universities (AASCU), the Department of Defense (DOD), and the Servicemembers Opportunity Colleges (SOC).

DiRamio, Ackerman, and Garza-Mitchell (2008) examined the transition issues that affected veterans of the Iraq and Afghanistan conflicts. Participants consisted of 25 student veterans who had served in Iraq or Afghanistan from 2003 to 2007. The Schlossberg, Waters, and Goodman (1995) and Schlossberg, Lynch, and Goodman (1989) "Moving In, Moving Through, and Moving Out" model was used as the framework for DiRamio et al. (2008) to understand how student veterans transitioned in the military and also in college. When veterans transitioned to college, DiRamio and associates (2008) found that the issues were as follows: "connecting with peers, blending in, faculty, the campus veterans' office, finances, students with disability, and mental health and PTSD" (p. 80).

DiRamio et al. (2008) explained how each stage affected the student veteran through personal accounts and then described the implications for student affairs administrators. Namely, the implementation of a personalized holistic approach by administrators would aid veterans in their transition. "Financial aid, counseling, student organization, disabilities offices, academic advising, faculty, and institutional research" (p.93) were offices identified the most pertinent offices utilized by veterans where a designated and trained liaison could be the point of contact for the veteran. Training 
could be provided to the entire campus that encouraged mentors to facilitate a veteranfriendly atmosphere. DiRamio et al. (2008) also highlighted the, often overlooked, female veteran as another component to the transitioning student veteran population. DiRamio and Jarvis (2011) reported that 14 percent of active-duty military personnel are female. Female student veterans experienced higher levels of financial strain and are susceptible to being victims of sexual assault (DiRamio et al., 2008).

In addition to DiRamio et al. (2008), the American Council for Education devised a report on how universities and colleges were structuring the various services that they offered to student veterans in transition (Cook \& Kim, 2009). The purpose of the focus group was to determine the level of preparedness of higher education institutions in educating student veterans. Of those surveyed, more than half of the institutions had some type of veterans' program (Cook \& Kim, 2009). The majority of those schools that had any program for student veterans were with public universities and community colleges.

Cook and Kim (2009) found that student veterans were concerned with:

Currently available campus services and programs, including a lack of flexibility of some campus programs with respect to military students' sometimes unpredictable deployment schedule in the armed forces; uncertainty about campus recognition of civilian courses taken while in the military or formal training or college courses obtained as a service member; and lack of strong guidance about navigating the maze of G.I. Bill education benefits. (p. 14)

Finally, Student Veterans of America (2011) highlighted the following issues related to student veterans returning to colleges: inflexible / bureaucratic administrative structures and lack of preparation by university systems; unique social barriers with student body as result of age and experience; loss of sense of purpose, teamwork, and 
camaraderie experienced while serving; need for cohesive interaction with "true" peers; and significant mental health barriers as a result of military service.

\section{College Student Identity Development}

Chickering's identity development model is located within seven vectors (Chickering \& Reisser, 1993), in his developmental model of college students. Development of college student identity involves the following: comfort with body and appearance, comfort with gender and sexual orientation, sense of self in a social, historical, and cultural context, clarification of self-concept through roles and life-style, sense of self in response to feedback from valued others, (6) self-acceptance and selfesteem, and personal stability and integration (Chickering \& Reisser, 1993).

In addition, identity development encompasses four of Chickering and Reisser's (1993) other vectors including: competence, emotional maturity, autonomy, and positive relationships. Competence is divided into the three parts of intellectual, physical and natural, and interpersonal. Intellectual competence includes the skill of using one's mind through "mastering content, gaining intellectual and aesthetic sophistication and most important, building a repertoire of skills to comprehend, analyze, and synthesize" (para. 2). Physical competence involves athletic and artistic achievement through use of the body. Interpersonal competence consists of the skills of listening, cooperating, and communicating with the ability to "tune into another person and respond appropriately, to align personal agendas with the goals of the group, and choose from a variety of strategies to help a relationship flourish or a group function" (para. 3). 
Emotional maturity is the second vector that is a facet of identity development. To achieve emotional maturity, students are aware of their emotions as they happen instead of suppressing or ignoring them (Chickering \& Reisser, 1993). Emotional maturity is developed when "students learn appropriate channels for releasing irritations before they explode, dealing with fears before they are immobilized, and heal emotional wounds before they infect other relationships" (para. 6).

The third vector related to identity development is autonomy. Autonomy for college students entails "learning to function with relative self-sufficiency, to take responsibility for pursuing self-chosen role, and to learn to be less bound by others' opinions" (para. 9). To achieve autonomy a student must have movement in both their emotional and instrumental independence. Emotional independence involves freedom from the constant need for reassurance or approval and is achieved with a diminishing need for peer support and increased willingness to pursue self-interests (Chickering \& Reisser, 1993; Erickson, 1959). Erickson conceded that through the use of peer groups, clubs, and organizations, youth can experiment with new roles to integrate their identities into one well-integrated identity. Through this experimentation, college students are able to define and develop their own identities. Instrumental independence, on the other hand, consists of not only making critical decisions and carrying out focused actions but to also move between places without assistance. Through both emotional and instrumental independence, students are able to develop their autonomy while understanding the delicate balance with inclusion.

Last, when students are developing their identity, they are also developing more mature interpersonal and positive relationships with their peers. According to Chickering 
and Reisser (1993), steps in developing mature interpersonal relationships include both tolerance and appreciation for differences as well as capacity for intimacy. The main premise of tolerance and appreciation for differences is that a college student can view people as they are without the interference of stereotypes. With a sense of tolerance, students can then be open for more intimate relationships. Development of identity in this area involves "more in-depth sharing and less clinging, more acceptance of flaws and appreciation of assets, more selectivity in choosing nurturing relationships, and more long-lasting relationships that endure through crises, distance, and separation" (Chickering \& Reisser, 1993, para. 11). Through each of the vectors, Chickering and Reisser (1993), highlight how identity development is an all-encompassing venture of students in college.

\section{Kegan's Orders of Consciousness}

Kegan's (1994) social constructivist theory provides a framework for understanding the interrelation of different identities to development and helps describe the way humans evolve over their adult lives. Specifically, Kegan (1994) posits five orders of consciousness where the individual makes increasingly more complex meaning from his or her life experiences. Meaning making are the assumptions that a person makes of whether their identity is externally constructed or internally constructed (Kegan 1982, 1994).

In Kegan's (1994) five orders of consciousness, the mind moves qualitatively by shifting meaning making and complexity from the order preceding it. The shift occurs in the relationship between the Subject and the Object. The Subject refers to "those elements of our knowing or organizing that we are identified with, tied to, fused with, or 
embedded in" (Kegan, 1994, p. 32). On the other hand, the Object refers to "those elements of our knowing or organizing that we can reflect on, handle, look at, be responsible for, relate to each other, take control of, internalize, assimilate, or otherwise operate upon" (Kegan, 1994, p. 32). The Subject is immediate and a person cannot " be responsible for, in control of, or reflect upon that which is the subject" (p. 32). Kegan (1994), however, suggests that the Object is distinct enough from us that we can do something with it. It is in the movement from Subject to Object that each increasingly complex Object that a person is able to transition to an even more complex principle. Berger, Hasegawa, Hammerman and Kegan (2007) have suggested that the most profound example is "when gradually, over time, entire meaning making systems move from Subject to Object which then gives form to the five orders of mind" (p. 2).

The first and second stage of Kegan's Orders of Consciousness consist of young children being made up of their perceptions. In the first stage, the child's perception is his or her reality. For example, a quantity of water that looks different to her or him, perhaps because it is in a differently shaped container actually is different (Berger et al., 2007). Piaget's (1967) concept of conservation, when the child understands that the quantity doesn't change, then that the child moves into the second Order of Consciousness. The second Order is characterized by durable categories (Kegan, 1994). The child is able to "coordinate his or her changing perceptions across time to conserve concrete qualities" (Berger et al., 2007, p. 4). It is in this early stage that children understand that each individual views the world differently.

In the third stage of Kegan's Orders of Consciousness, people are able to use the principles of durable categories and the coordination of concrete qualities to integrate 
with the larger social structure (Berger et al., 2007). Cognitively, the third stage is characterized by ability to use abstractions, inferences, hypothesis, ideals and values (Kegan, 1994). The person is aware of his or her consciousness and is able to internalize a sense of mutual reciprocity in relationships with others. It is in this order that "people are responsible for their own role within a larger social structure" (Berger, et al., 2007, p. 5). However, those in the third stage are often torn by the expectations of others leading to internal distress and conflict about which external influence should be followed (Abes \& Jones, 2004; Kegan, 1994). Berger, et al. (2007) suggested that most adults make meaning through their interpretation that others exist and social relationships based on mutual reciprocity are critical for success.

The Fourth Order of Consciousness or the Self-Authoring Order of the Mind occurs when adults "coordinate their multiple roles and the different expectations others hold for them within their own self-generated, relationship-regulating frameworks" (Berger et al., 2007, p. 5). During the Self-Authorship stage, the person has a larger perspective on the world in which they not only view what others are doing but also how they are reacting to the situation (Abes \& Jones, 2004; Kegan, 1994). In this critical stage, only 50 percent to 75 percent of adults, can take responsibility for their internal reactions and begin to mediate between them (Kegan, 1994; Berger, et al. 1997).

The final and smallest, Fifth Order of Consciousness, occurs when a person is able to understand his or her own personal system in conjunction with the historical, cultural, psychological, and personal forces that are also occurring in the experience (Kegan, 1994). In the Fifth Order of Consciousness "conceptual frameworks in this view embrace contradiction and paradox" (Berger et al., 2007, p. 6). The person is able 
to self-transform by understanding and interinterpretation of the self and how it interacts with the world around them (Kegan, 1994).

\section{Theoretical Framework}

Two main frameworks will be used in this study: social constructivism and grounded theory (Denzin \& Lincoln, 2005). Social constructivism (Piaget, 1967) posits that persons construct meaning from their experiences and ideas. With each new experience that a person encounters, that person forms an idea that is stored in the person's mind that helps him or her construct and understand the world around him or her which then defines the person's identity and interpersonal relationships (Kegan, 1982, 1994; Piaget, 1954). Piaget (1967) developed the concept of cognitive adaptation to account for the interaction of an organism with the environment (Miller, 2002). The complementary processes of assimilation and accommodation explain the differences in how people understand and interpret meaning of the events happening around them. Assimilation is the process through which a person takes information from the environment that is viewed in terms of the individual's existing schema. In every encounter with an object there is a "bending or distorting of experience as people attempt to incorporate, understand, or interpret this experience" (Miller, 2002, p. 64). Accommodation then is the change made through the process of assimilation. Accommodation occurs when "current structures have failed to interpret a particular object or event satisfactorily" (p. 64). Through both assimilation and accommodation, new cognitive structures are developed that influence how a person views the world 
around himself or herself. Miller (2002) wrote that: "each accommodation makes new accommodations possible the future and this spiral continues in our moment-to-moment encounters with the environment throughout development" (p. 66). Social constructivism then is the process through which each individual understands his or her identity through historical, political, social and cultural lenses on both institutional and individual levels (Miller, 2002).

The purpose of grounded theory is to "demonstrate relations between conceptual categories and to specify the conditions under which theoretical relationships emerge, change, or are maintained" (Charmaz, 2002, p. 675). Founded by Glaser and Strauss (1967), grounded theory begins with data collection, which is then organized through a series of categories. It is through these categories that a theory can be developed. Thus, in grounded theory "one generates conceptual categories or their properties from evidence; then the evidence from which the category emerged is used to illustrate the concept" (Glaser \& Strauss, 1967, p. 23). To illustrate the concept and development of a theory, the emphasis is on the data and each theme and interpretation springs directly from the data. The use of a constant comparative method is used consistently throughout grounded theory research in different forms (Glaser \& Strauss, 1967). Grounded theory thus provides the researcher a guideline to "understand people's experiences in as rigorous and detailed a manner as possible by identifying categories and concepts that emerge from text and link these concepts into substantive and formal theories" (Denzin \& Lincoln, 2005, p. 782).

\section{Summary}


Student veterans have a long history of attending an institution of higher education. From the early 1900's, the United States of America offered educational benefits to support the transition of soldiers to citizens. Currently, more than 2.2 million service members compose the volunteer force of the U.S. military with more than 660,000 attending postsecondary educational opportunities. Student veterans are faced with a number of transition issues as they attend institutions of higher education. Some of these issues related to adult transition issues include lack of socioeconomic resources (Goldrick-Rab, 2001; St. John \& Tuttle, 2004), poor academic achievement in high school (Bozick \& DeLuca, 2005; Locks et al., 2008), school vs. work and family responsibilities (Tanicguchi \& Kaufman, 2005) and institutional commitment (Compton et al., 2006; O’Donnell \& Tobbell, 2007). Specifically to veterans (Cook \& Kim, 2009; Ford, et al., 2009; Livingston, 2010; O’ Herrin, 201; Persky \& Oliver, 2011; Rumann \& Hamrick, 2009; Van Dusen, 2011), all identified issues associated with veteran transition to student life. Identity issues were highlighted as one of the most important issues related to student veteran transition (Rumann \& Hamrick, 2010). Additional issues include relationships (Persky \& Oliver, 2011; Rumann \& Hamrick, 2010), academic issues (Olson, 1974), and university commitment (Ackerman, et al., 2009; O’Herrin, 2011; Van Dusen, 2011).

Additionally, the college student's identity development model by Chickering and Reisser (1993) is highlighted along with Kegan's $(1982,1994)$ Order of Consciousness. Chickering and Reisser (1993) posited that college student development consists of the following vectors: comfort with body and appearance, comfort with gender and sexual orientation, sense of self in a social, historical, and cultural context, clarification of self- 
concept through roles and life-style, sense of self in response to feedback from valued others, self-acceptance and self esteem, and personal stability and integration. Kegan $(1982,1994)$ presented a five-stage outline of how a person makes meaning from experiences and then how that interpreted meaning influences a person's identity.

\section{Chapter III}

\section{Method}

\section{Organization}

The method section consists of the research questions, rationale, context of the study, data sources, data collection methods, data analysis, data management plan, and the trustworthiness of the research.

\section{Purpose}

The primary purpose of this qualitative study was to understand the complex phenomena of identity development of transitioning student veterans in the college setting (Newman, Ridenour, Newman, \& DeMarco, 2003) and to understand how veterans make meaning based on their identity (Kegan, 1994) during college. The secondary purpose was to increase the knowledge base concerning student veterans entering the college setting. Research focusing on the college setting will enhance the growing field of research being conducted on the experiences of student veterans. This study will assist university personnel and counselors in their instruction, support for, and attention to student veterans. Because of the lack of information about identity and meaning making of student veterans, a qualitative method will be employed to develop themes. Qualitative data will add to the knowledge base (Newman, et al., 2003) of 
identity development and meaning making that student veterans have about student veteran's transition into university life as they seek counseling services.

\section{Research Questions}

- What perceptions of meaning making do student veterans have of their military identity?

- In comparison, what perceptions of meaning making do student veterans have of their student identity?

- What is the role of meaning making in the construction of veteran identity and its interaction with other dimensions of identity, namely student identity?

\section{Rationale}

A qualitative research design was selected for this study based on the lack of research pertaining to identity development and meaning making of college student veterans. Qualitative inquiry allows the researcher to understand the purposes influencing individuals. Berg (2009) concluded that qualitative research "seeks answers to questions by examining various social settings and the individuals who inhabit these settings" (p. 8). Glesne (2011) suggested that inasmuch as the goal of research is "interpreting the social world from the perspectives of those who are actors in the social

world, it follows that the research-methods include interacting with people in their social contexts and talking with them about their perceptions" (p. 8).

Based on roles, symbols, and rituals, the purpose of this inquiry was to explore how humans arrange themselves and their surroundings. The goal of qualitative research is to determine how such themes are inherent with identity development and meaning making of student veterans. An additional strength of utilizing qualitative data to study identity development and meaning making is that it "provides means for accessing 
unquantifiable facts about the actual people researchers observe and talk to or people represented by their personal traces (such as letters, photographs, newspaper accounts, diaries, and so on)" (Berg, 2009, p. 8).

One disadvantage of utilizing qualitative research includes the fact that its findings transferable yet not generalizable to populations as are those of a quantitative research project. Transferability suggests the "degree to which inferences and recommendations are applicable to other people" (Teddlie \& Tashakkori, 2009, p. 312) unlike generalizations in which the research can be generalized to the greater population both "time- and context free" (p.93). Additionally, it is important for the researcher to maintain a sense of objectivity while conducting this type of research because of the intimacy that is developed during the process. Logically, researchers study a topic because of their interest that topic, and because of the nature of qualitative data to find rich description, researchers must be constantly aware of their possible bias (Berg, 2009). In addition, qualitative research can be perceived to have lenient standards when in fact, good qualitative research is quite rigorous because of the specific procedures put in place to ensure its credibility (Berg, 2009).

Qualitative data is uniquely able to help researchers answer the research questions of identity development and meaning making on transition issues of student veterans because of its ability to develop a rich description of the data. Student veterans will be able to share, in their own words, those areas that they feel are most important to their identity as both students and veterans. In addition, student veterans should be able to explain how they attach meaning based on their identity. By utilizing qualitative research techniques, student veterans will have a venue for sharing ideas on how they construct 
their identity and how identity is associated with the meaning that they have for it.

Following the social constructivist paradigm, grounded theory will be developed because of the lack of information and literature about identity development and meaning making among student veterans.

The purpose of grounded theory is to "demonstrate relations between conceptual categories and to specify the conditions under which theoretical relationships emerge, change, or are maintained" (Charmaz, 2002, p. 675). It is through these categories that a theory can be determined. Thus, in grounded theory "one generates conceptual categories or properties from evidence; then the evidence from which the category emerged is used to illustrate the concept" (Glaser \& Strauss, 1967, p. 23). To illustrate the concept and development of a theory, the emphasis is on the data and each theme and interpretation evolves directly from the data. A constant comparative method is utilized consistently throughout grounded theory research in different forms (Glaser \& Strauss, 1967).

According to Charmaz (2005), grounded theory methods:

Consist of simultaneous data collection and analysis, with each informing and focusing the other throughout the research process we use these focused data to refine our emerging analyses. Grounded theory entails developing increasingly abstract ideas about research participant's meanings, actions, and worlds and seeking specific data to fill out, refine, and check the emerging conceptual categories. Our work results in an analytic interpretation of participant' worlds and of the processes constituting how these worlds are constructed. (p. 509)

The main strength of using grounded theory in understanding student veterans' identity and meaning making structures is that there is little research on the topic. Grounded theory allows the researcher to develop theory directly from the participants instead of placing a theory onto their perceptions. Grounded theory can help forestall the 
opportunistic use of theories that have dubious fit and working capacity (Glaser \& Strauss, 1967). Resulting from the lack of information related to identity development and meaning making of student veterans, grounded research is needed to add to the knowledge base about this particular subset of the population. However, with the increase in general knowledge about student veteran transition, some conclusions are already being drawn and implemented on college campuses without any overt information on their identity development and meaning making (Rumann \& Hamrick, 2010).

Supporting grounded theory, social constructivism theory will provide a second theoretical framework for this study. Social constructivism (Piaget, 1967) posits that individuals construct meaning from their experiences and ideas. With each new experience that an individual encounters, an idea forms that is stored in a person's mind to be used to later view new experiences. Piaget (1967) used the concepts of assimilation and accommodation to explain the differences in how people understand and interpret the meaning of the events happening around them. Assimilation is the process through which a person takes information from the environment that is viewed in terms of their existing schemata. Accommodation then is the change made through the process of assimilation.

\section{Context of Study}

The study reported herein was conducted at a large four-year public institution in the Southwestern United States, a Division I university with more than 150 baccalaureate degrees, 100 master's degrees, and 50 doctoral degrees. According to the university fact book for spring, 2011 (Texas Tech Fact Book, 2011), the student body comprises 29,604 students with 23,550 consisting of undergraduate students and the remaining 6,054 being law and graduate students. By ethnicity, the student population breakdown consists of 67 
percent Anglo, 15 percent Mexican American, seven percent non-resident alien, five percent African American, and three percent Asian American. The university student gender distribution consists of 55 percent female and 45 percent male, which is consistent with the national averages where, in 2009,59 percent of university students were female students while just 41 percent were male (National Center for Educational Statistics, 2010). Full-time students constitute 83 percent and part-time students are 17 percent of the total university population. These numbers are in contrast with the national average, where 55 percent are full-time and 45 percent are part-time. The ages of 79 percent of the undergraduate, graduate, and professional students are between 18 and 24 while 18 percent are between the ages of 25 and 45 . Most students, 88 percent, are residents from within the state while six percent are out of state and five percent are foreign. Two important facts need to be pointed out about the in-state and out-of-state population numbers. First, of the foreign students, more than 77 percent are graduate and law students. Secondly, the home state of the research institution has an agreement with surrounding states that students who are residents of counties or parishes bordering the home state are allowed to attend at the in-state tuition rate and be considered in-state students (Texas Higher Education Coordinating Board, 2011).

Specifically concerning the student veteran population at the research institution, a total of 979 students are utilizing veterans' educational benefits at the research institution, including veterans and their dependents. Of the 341 student veterans who responded to a recent survey administered through the Military and Veterans Program on campus, 52 percent characterized themselves as Anglo, with 12 percent as Mexican American, three percent as African American, and two percent as Asian. It is to be noted 
that 31 percent of respondents either left this question blank or marked as unknown. Eighty-eight percent of student veterans self-identified as male students while 12 percent self-identified as female. 68 percent of student veterans indicated that they were between 24 and 25 years of age while, the ages 18 and 24 are at 18 percent and 35 and 44 constituted of 12 percent of those responding to the survey.

The institution was selected for this study because of my ability to access the population needed for the study and the lack of information about community college transition issues. Much of the research (DiRamio, et al., 2008; Livingston; 2009; Rumann \& Hamrick, 2010) has been conducted at large public institutions on the East coast and Midwestern sections of the United States. Each site, including the site for this study, has a history of being open to military personnel on campus. Because of the setting and the values associated with the culture, the findings need to be understood in that context. The particular area in which the study was conducted is conservative with strong support for the military. With that being an overarching principle associated with this particular population, the findings are different from those expected from a more liberal area. Using a veteran-friendly university, the findings are shaped by the theory gleaned from this particular type of university. In addition to the conservative nature of the setting, the university in this study has enacted a specialized program for military and veteran students in attendance and for those seeking admission to the university. With this program being housed in the Office of Student affairs, research on identity and meaning making is critical for counselors who only may have indirect contact with those veterans.

\section{Data Sources}


The population researched consisted of student veterans enrolled and attending the university. The primary source of data was from individual interviews with participants. The secondary source of information was the literature pertaining to student veteran transition issues, identity, and meaning making of college students. Interviews in qualitative research are widely used because they provide a vast amount of information that comes directly from the perceptions of the participants (Perakyla, 2005; Taylor \& Bogdan, 1998).

Perakyla (2005) posited that "the topic of the research is not the interview itself but rather the issues discussed in the interview" (p. 869). Because of the nature of qualitative data and the empirical materials that are part of the research, I was more aware of the participants and the topic being studied (Perakyla, 2005). The primary advantage associated with interviews was the flexibility that allowed me to delve into the participants' perceptions. Another advantage was that I was able to understand the participants understanding of transition and identity. A disadvantage was that the research participants may not be saying what they are really thinking or misrepresenting themselves (Taylor \& Bogdan, 1998).

As Taylor and Bogdan (1998) suggested, to obtain in-depth information about participants, I conducted the interviews where the participants perform their day-to-day business. I accomplished this concept because each student veteran was interviewed on campus in my office. The ability to utilize my office was beneficial inasmuch as it is a closed environment in a building with many student services. By doing this, the setting promoted the student veterans' willingness to be open and feel comfortable, because they were in a confidential space. The setting and the familiarity provided a safe place for 
student veterans to share their feeling about their transition issues, identity, and meaning making as it pertains to their transition to the university level.

The samples were selected purposefully because utilizing this approach leads to "selecting information rich cases for study in depth ... that a researcher can learn a great deal about issues of central importance to the purpose of the research" (Patton, 2002, p. 46). By selecting purposefully, I anticipated that the volunteers had knowledge of their population and were willing to share their unique experiences to investigate the research questions. Each participant shared his or her experiences generously with me. Within the types of purposeful sampling, I planned on utilizing both convenience sampling and snowball sampling in my study. However, based on the overflow of responses from one of my recruitment techniques, I utilized convenience sampling. Convenience samples are those that: "are available-- those who are close at hand or easily accessible" (Berg, 2009, p. 50). Berg (2009) further suggested that convenience samples are "an excellent means of obtaining preliminary information about some research question quickly and inexpensively" (p. 50). In this study, I contacted the Military and Veterans Program Director and asked that he send one e-mail to all of the veterans on campus. Convenience sampling allowed me to easily gain access to the population but restricted the transferability of the results (Patton, 2002) because the participants were narrowly defined.

For this project, I learned more about identity and meaning making in transitioning student veterans. The essence of grounded research and the use of purposeful and convenient sampling (Patton, 2002) provided me with an adequate view of student veteran transition up to the data saturation threshold. By overtly focusing on 
student veteran identity and meaning making as the sample, I studied a unique aspect of a population that has previously been ignored in the literature.

Participants included 11 student veterans currently attending the university. The specific demographics varied among the participants. Because this study focused mainly on those student veterans deployed during the OIF/OEF conflicts, the age range was between 27 and 33. Because the majority of OIF/OEF veterans are men, eight of the participants were men. The other two participants were female. All of the participants identified themselves as veterans of the military. As mentioned, all veterans interviewed were in attendance at the university in the Southwestern United States, but the birthplace and childhood experiences of each participant varied. Within the participant population, six veterans identified their race as Hispanic. The remaining veterans identified as Caucasian. Two participants were in Law School with the remaining participants pursuing their undergraduate education. The religion and socioeconomic status of the participants varied among the participants

Although a specific number of participants is not stated in Strauss and Corbin (1990), various other studies in qualitative research have utilized approximately the same number of research participants on topics ranging from student veteran transition to identity development and meaning making. In their research, Rumann and Hamrick (2010) interviewed six student veterans on their transition experiences following their return from war zone deployments and their re-enrollment into college. In his dissertation, Livingston (2009) interviewed 15 student veterans on their transition issues in the university setting. Abes and Jones (2004) utilized narrative inquiry to determine meaning making capacity and identity development with 10 lesbian college students. In 
addition, Altman, Inman, Fine, Ritter, and Howard (2010) conducted research on 10 participants in an exploration of their Jewish ethnic identity. A strength of this particular population is first-hand intimacy with how they integrate their identity and make meaning in the university setting.

The exact number of participants was determined by the number of student veterans that met the following criteria:

- Attending the university in the research study,

- Enrolled full-time at the time of data collection,

- Self-identified as a veteran,

- Deployed during the Operation Iraqi Freedom (OIF) or Operation Enduring Freedom (OEF) conflicts.

Request for approval to conduct this study was submitted to the research site's, Institutional Review Board (IRB), the primary purpose of which is to assess the potential harm to human subjects and ensure that adequate informed consent policies are stringently followed (Berg, 2009). Four potential risks were identified while conducting qualitative research in the health care field. Those risks included: anxiety and distress, exploitation, misrepresentation, and identification of the participants in published papers (Richards \& Schwartz, 2002). However, because this particular research topic asked student veterans generalized questions about their identity and meaning making in the university setting, concerns about harm were mitigated. The IRB and I focused on the dignity of each participant, so any potential harm to participants was minimized. In the informed consent document, student veterans were given the contact information for the 
Student Counseling Center, the Vet Center, and the Veterans Administration Outpatient Clinic should the interview reignite any negative memories.

I contacted the Director of the Military and Veterans Program through e-mail asking if he would send out the e-mail to all of the student veterans in his list. A copy of the e-mail recruitment can be found in an appendix (See Appendix A). The director was very accommodating and sent my e-mail out to his e-mail list that same day. He also allowed me to place a flyer in the main area of the Military and Veteran Program. I have included a copy of flyer in an appendix (See Appendix B). The email and flyer contained information about the research study, participant criteria, and contact information of the researcher. The flyer also included the contact information for my dissertation chair and sponsor should the participants need additional information. As mentioned previously, the response from the e-mail was overwhelmingly positive. In the first day and through both forms of recruitment, I made 10 appointments for interviews.

After I had made my appointments, every student veteran who contacted me through e-mail was sent a response that thanked them and informed them that I was no longer accepting participants. A copy of my e-mail can be found in the appendix (See Appendix C). During the course of the research, two participants canceled their appointments. Consequently, I went into back to the e-mails from people writing to participate that I had to decline and asked if they would be willing to participate. I was able to obtain one interview through this process. After most of my interviews were completed with men, I received e-mails from two potential female participants. In order to ensure that appropriate information about the identity and meaning making of student veterans, the two female participants were interviewed. 


\section{Ethical Considerations}

I followed a routine set of steps to ensure the participants were treated in an ethical way. First, I submitted all proper documentation to the Institutional Review Board (IRB) at Texas Tech University for their approval. It was only after I received approval that I commenced any research involving student veterans (See Appendix D). All participants were e-mailed an information sheet about the contents of the research study to assure that each participant was aware of the purpose of the research, the interview process, how confidentiality would be protected, and contact information for the researcher and sponsor. A copy of the research information sheet can be found in appendix (See Appendix E). In addition to sending e-mails to the participants with the research information sheet before our meeting, I also printed off a copy and reviewed the sheet before each interview started. All research was conduced on a volunteer basis, and there were no consequences for those who chose not to participate or were declined participation for the reason mentioned above.

In addition to the standards stipulated by the IRB, I proceeded in an ethical and professional way by always adhering to the American Counseling Association Code of Conduct (2005). The ACA Code of Conduct acts as a guide for all professional counselors in their ethical decision-making process. The welfare of the participants was of principal importance throughout the completion of the research study.

\section{Data Collection Methods}

The primary source of data collected qualitatively was interviews of student veterans. By using interviewing as the qualitative method, I employed the constructivist theory in which "accounts [shared stories] are part of the world they describe" 
(Silverman, 2001, p. 95). Taylor and Bogdan (1998) described qualitative interviewing as "repeated face-to-face encounters between the researcher and informant directed toward understanding informants' perspective on their lives, experiences, or situations as expressed in their own words" (p. 88). Accordingly, student veterans were interviewed face-to-face to determine their understanding of their identity and meaning making as it relates to their transition in college.

The format was the use of an in-depth, semi-standardized interview structure (Berg, 2009) that allowed for probing questions when they were warranted. Semistandardized interview structure allowed "flexibility by allowing interviewers both to ask a series of regularly structured questions, permitting comparisons across interviews, and to pursue areas spontaneously initiated by the interviewee" (Berg, 2009, p. 109). Berg (2009) stressed that this type of interviewing provides a more textured set of accounts than either standardized or unstandardized interviews. In addition, in-depth interviews were particularly helpful for me because I was interested in gaining an understanding of the participants' perceptions of phenomena (Taylor \& Bogdan, 1988).

As I was conducting the research, I found the flexibility of the semi-standardized interview structure to be beneficial in answering each research question. However, a flaw in interviewing is that it did not allow for a completely accurate view of the situation (Perakyla, 2005). Participants were able to represent themselves in the way that they best see fit in an interview process. In addition, the amount of time it takes to conduct each interview, transcribe the interview, and then analyze the data is time consuming with this process. With the particular study reported herein, student veterans are able to represent themselves as they wish without any proof being given of the participant criteria. 
Interview questions were formulated utilizing previous research studies including the study by Abes and Jones (2004) on identity and meaning making, the Altman et al. (2010) study of Jewish identity development, and the Rumann and Hamrick (2010) study of student veteran re-enrollment. The questions were formatted to stay neutral while simultaneously eliciting a breadth and depth of information for proper qualitative research to be conducted (Lincoln \& Guba, 1985). Interview questions are to be based on the underlying theory (Glesne, 2011) of social constructivism. To follow Glesne's (2011) suggestion, interview questions were based on the cultural reality of the student veterans. It is important for me to remember that each participant has both an understanding of the identity of student and of veteran as well as other aspects of their identity. Each veteran is equally important, and the questions will elicit information regarding the student veterans' lives. One of the most important concepts of interview questions is that they are meaningful to the student veterans, whereby the veterans provided me with pictures of the unseen, expand the understanding of their lives, and offer insight into the research topic (Glesne, 2011).

The interview questions that were asked of each student veteran are the following:

1. What are your perceptions on the transition issues that you faced from being in the military to a student on this campus? Please give specific examples where possible.

2. What are the differences between your military and university experiences? Please give specific examples where possible

3. Thinking of both your student identity and veteran identity, describe who you are as a person. 
4. How do you view your military and student identity in relation to your other identities, e.g. social class, sexual orientation, race, etc.?

A copy of the interview protocol can be found in Appendix G.

Questions were designed based on the research questions and deciding on a method that would most appropriately and fully provide data that would inform the primary research questions. In addition to making the questions meaningful, I followed Berg's (2009) suggestion for ordering the questions. Because I wanted to gather the most authentic data about each research participant, I ordered the questions so that they would naturally build on themselves and give the student veteran a clear line to follow.

The semi-standardized and open-ended interview allowed me to develop a sequence of each question to gather optimal information about the participants. Each participant was asked identical questions in the identical order, which ensured expansive and easily maintained data. By having the interviews conducted in identical order, the analysis of data was much easier. I combatted a potential threat to flexibility by utilizing the probing questions that I had developed before the interview began. I also relied on my skills as a counselor to ask nonthreatening questions as follow-up and probes for additional information.

Much of the work on the interviews was completed before the interview process began, including selection of the probes and prompts to use if more information about a particular participant was needed. In addition to the questions being asked, it was of paramount importance that I dress correctly to enhance the student veterans' sense of confidence in me as a researcher. Because the interviews were to be tape recorded, I 
ensured that the tape recorder was both appropriate for the setting and would block out any background noise.

When the interviews were scheduled, I adjusted my schedule to fit with the student veterans' schedules, which allowed the interviews to be convenient to each participant. I chose to meet each veteran in my office on campus. In my role as the researcher, I determined this to be the most appropriate place, because it was on campus, making it easier for student veterans to travel. Further, it offered enough room and privacy, and it offered the student veteran confidentiality from other student veterans. The interview process consisted of one interview that lasted between 15 and 50 minutes. By leaving the amount of time the student veteran participated up to them, I ensured that the interview would not be too long which might lead to fatigue (Berg, 2006).

\section{Interviews}

I initially focused the first moments of the interviews on rapport building and then on his or her transition issues to college, identity, and meaning making. Rapport is critical to gathering in-depth quality data from research participants, as it promotes a lack of boundaries between the interviewer and the participant (Berg, 2009). Rapport is a positive feeling of common and shared interests between the participant and me where there is a personal relationship of mutual trust and respect based on a feeling of confidence in and security with another person (Berg, 2009). When rapport is correctly established, the student veterans' anxiety levels decreased while their depth of responses increased, thus providing valuable data (Berg, 2009). By demonstrating a "benign, accepting, and curious (but not inquisitive) individual who is prepared and eager to listing to virtually any testimony with interest” (McCracken, 1988, p. 38) 
To build on rapport and to promote a feeling of safety and security, I made sure that the door to my office was closed so as to promote a sense of confidentiality and discretion. In addition to the confidential space, I paid close attention to the student veterans' appearance and description of credentials (Dundon \& Ryan, 2009). The first perceptions of my demeanor and characteristics usually indicated how the participant consequently responded to the research process. I made sure to appear professional and thankful for their participation in my research study. I also built rapport thought revisiting the purpose of the research and orienting the student veteran to the process (McCracken, 1988).

The interview consisted of rapport building, a review of the interview process, and asking the research questions. For initial rapport building, I shared with the research participant how the research came to fruition and the personal interest I have in their story (McCracken, 1988). I shared my personal connection to the military and to those veterans who are making the transition to college. In addition, during the review of the interview process we discussed how his or her anonymity would be maintained through the use of a self-selected pseudonym and how I would send the themes to him or her after the research was completed for any feedback they might have about the research. I informed each student veteran that participation with reviewing the themes would be completely voluntary.

At the beginning of the interview process, I also asked basic demographic data about each student veteran. Demographic information included; race, gender, year enrolled/ reenrolled in college, military service branch, duration in theatre, and activeduty status. I anticipated that the first five minutes of the interview would allow the 
participant and me to interact, to build rapport, and to explain the purpose of the research and answer any questions that the participants may have about the research or the research process. However, the initial part of the interview typically lasted between two and four minutes.

After the demographic profile sheet was completed, I began by asking an overarching question about their transition process. Thinking about the transition process allowed the student veteran to acclimate to the research process and posed a question that did not involve much internalized processing. I then focused on asking some of the more important and essential questions while always focusing on a single concept or topic (Berg, 2009). By maintaining a single topic, I gathered a depth of knowledge on that particular concept. If needed, after the essential questions, I asked more intimate questions through the use of probing to examine the meaning behind the responses of the student veteran. After each concept was ferreted out, I focused on to the next topic through the use of a transition question.

During the interview Berg's (2009) ten commandments of interviewing were closely monitored. They included never beginning an interview cold, remembering your purpose, presenting a natural front, demonstrating aware hearing, thinking about appearance, interviewing in a comfortable place, not being satisfied with monosyllabic answers, being respectful, practicing, and being cordial and appreciative (Berg, 2009).

Throughout the interview, I was sensitive to the identity and meaning making in reference to transition issues such as increased anxiety and adjustment that they are currently experiencing. The relationship was one where the student veteran feels safe to have a frank and open discussion (Gordy \& Potter, 1976). Taylor and Bogdan (1998) 
also suggested "the in-depth interview is modeled after a conversation between equals rather than a formal question and answer exchange" (p. 88). During some of the interviews, I utilized a technique developed by Dundon and Ryan (2009) where I focused the topic from what is being studied to something that can be leisurely talked about for a couple of minutes during the interview. This type of tactic is risky and the "respondent has to be able to engage in a genuine way with its substance" (Dundon \& Ryan, 2009, p. 7). To manage the potential risks, I relied on my training as a counselor to engage the participants through active listening skills. Taylor and Bogdan (1998) wrote that "Far from being an impersonal data collector, the interviewer, and not the interview schedule or protocol, is the research tool" (p. 88). By utilizing these skills, such as nodding and verbal and nonverbal encouragement, I was able to maintain rapport and trust with each student veteran. In addition I posed nonthreatening questions, which included; tell me more ... I invite you to share more on that subject ... would you be willing to share an example. Each question was designed to elicit trust and authentic responses from each student veteran.

The feminist model suggests that the interviewer must be willing to disclose personal insights in order to develop a genuine relationship beyond boundaries of the interviewer and interviewee, where the interviewer understands the inherent power differential of the relationship (Berg, 2009). Accordingly, by understanding the military culture of hierarchy assisted me in navigating potential power differential considerations. The participatory model implores me to also understand the power differential but to understand that the interview is the participant's story to tell and not mine to manipulate (Berg, 2009). Finally, to maintain rapport with student veterans, I consistently checked 
for awareness that both researcher and participant are part of an interaction that encourages reflexivity and self-exploration (Morse \& Field, 1996). It was my continued commitments to have student veterans understand that I truly cared about their experiences and was thankful of their participation.

\section{Data Management and Analysis}

The time frame that I developed for the management of the data was to recruit and select participants after I received approval from the Institutional Review Board, after Winter Break, and the start of the spring semester. By plotting out the exact time in advance, I allowed time for the student veterans to get settled into the semester while avoiding the first round of examinations. In addition to the qualitative time delays, it was also important for me to remember that student veterans are busy with school and other activities such as family, friends, and work obligations. Because of this and a suggestion from the IRB, each participant was contacted during the time of the semester when they are typically less busy.

The recruitment, interview, and transcription process took approximately four weeks to complete. The information gathered consisted of basic demographic information and the data from the interview itself. All of the information from each of the interviews was tape-recorded to ensure the accuracy of the transcription. Because of the timing of each interview and my hectic schedule, I worked intermittently to transcribe all the interviews onto a Microsoft Word document. The last interview was transcribed immediately after it was completed and thus ended my data collection. Once all of the interviews were completed, I printed out each one and went line by line and made brief notes on the side of the page where I used an open coding method. In addition to this 
initial open coding, other methods of coding and developing themes were employed at the beginning. Such methods include handwritten notes and discussions with the committee. After the initial coding and other methods were employed, I uploaded the documents into NVIVO 9 for further analysis.

After the data were uploaded, it took approximately one week to further code all of the information and develop initial themes. Because the focus of this study is on both identity and meaning making of student veterans, the amount of data collected from each interview far exceeded expectations and allowed for an in-depth analysis. Therefore, the use of the NVIVO 9 program to support the analysis was vital because it allows for open coding, axial coding, hyperlinks to nontextual data, coding according to demographics, and the exploration of ideas visually (Bringer, Johnston, \& Brackenridge, 2006).

\section{Analysis}

Grounded theory is a comparative method in which the researcher compares data with data to form categories and then compares the categories (Charmaz, 2002). The most important feature of analyzing qualitative data is to code the data correctly, so it can be transferred into groups thus exposing a broader perspective (Creswell, 2009). Both the inductive and the deductive approach were used in conjunction with each other in order to both present the perceptions of others in the most straightforward manner and allow me a process for developing a hypothesis (Berg, 2009). It is, however, primarily through the use of induction that I was able to ground each of the categories that I found into the data (Berg, 2009).

Glaser and Strauss (1967) suggested that in order to generate theory the best approach is an initial discovery from the social research, which will fit the research being 
conducted. In addition, because the data are put into categories laymen will understand the concepts while other researchers will understand the theory linked to the data. The constant comparison of data in grounded theory, called interim analysis (Miles \& Huberman, 1994) does not happen in a linear fashion but cyclically where the researcher collects data, analyzes the data, collects more data and analyzes them again until the last interview is completed. Glaser and Strauss (1967) outlined a four-stage method utilizing the constant-comparative method, where the researcher first starts by comparing incidents applicable to each category. The researcher then integrates the categories and delimits the theory by reducing the number of categories to where they are saturated. Finally, the researcher begins writing the theory in his or her results section.

During the analysis of the data, I followed the constant comparative method, which includes both open coding and axial coding (Strauss \& Corbin, 1990, 1998). Coding is the backbone of grounded theory. Denzin and Lincoln (2005) have suggested that coding "helps us to gain a new perspective on our material and to focus further data collection, and may lead us in unforeseen directions" (p. 515). The use of the constant comparative method allows researchers to "simultaneously code and analyze data in order to develop concepts. By continually comparing specific incidents in the data, the researcher refines these concepts, identifies their properties, explores their relationships to one another, and integrates them into a coherent theory" (Taylor and Bogdan, 1998, p. 137). Analysis of the codes proceeds by grouping the codes into themes, interrelating the themes, and utilizing a qualitative data analysis software program (Creswell, 2009). Open coding allowed me to separate the material into the form of concepts. The open coding allowed me to quickly pull out the themes in the data by focusing on participants' 
words. From there, I assigned different codes for each of the themes that emerged from the data.

When I uploaded the interview into NVIVO 9, I copied all of the themes that I had already determined into the program. By seeing the themes on paper first, the themes were more easily identified before I put all of the information into the program. I then put each of the codes into a category with other codes that were related to them in a process called axial coding. Axial coding then allowed me to reassemble the data that were separated during the open coding process (Strauss \& Corbin, 1990, 1998). Relating the codes to one another also challenged me to constantly ask how they were related to each other.

Once each of the codes was in its related group, I then went back through, divided them into subgroups, and ferreted out any codes that were not suitable for the overall category that would become my themes. It was then that I placed a name on each overarching category so that each of the initial codes and interview responses could highlight that particular code. The selective coding process allowed me to refine the categories, name the central theme, and understand the relationships between the central theme and other categories (Strauss \& Corbin, 1990, 1998).

Coding gave me "analytic scaffolding on which to build" (Charmaz, 2005, p. 517) so I could explore new data and also determine where data were missing. The process of coding the data includes assigning labels to the data (Creswell, 2009). Coding provided a way to check my assumptions about the research participants and the data through a consistent questioning of why certain codes were developed (Charmaz, 2005). 
The results of my analysis are displayed first stating each of the categories that emerged and then supporting them through the interviews that were conducted with each participant. The quotes highlight each of the themes that were developed and should help the reader gain greater understanding of the student veteran perceptions.

\section{Validity}

Validity of the data was verified through member checking, inclusion of disconfirming data, and inclusion of unanticipated results. By utilizing the technique of member checking, the researcher validates that the themes derived are an accurate reflection of the participant's experiences (Creswell, 2009; Teddlie \& Tashakkori, 2009). Once all of the themes were developed, student veterans were sent themes to share their insight into what had been discovered. Having members check the quality increases "the credibility of the researcher's interpretation of the participant's perceptions" (Teddlie \& Tashakkori, 2009, p. 213). Also by gaining the student veteran perspective from the member checks, I was able to verify that I reflected their understanding and perception, provided information about problematic areas, and helped develop new ideas (Glesne, 1999).

Participants were asked to provide confirming, nonconforming, or additional information about the themes, if they wanted to do so. I reminded each veteran in the email that participation was completely voluntary. Understanding busy schedules, I asked for feedback within one week to make sure that there was enough time to finalize the themes and submit the draft to the committee members. Within the week time frame, I had one student veteran respond to my email. It was one of the female participants who 
thanked me for letting her participate in the research and indicated that each of the themes were sufficient.

As mentioned earlier, because of the complexity of coding data, I employed the use of NVIVO 9 as a way to manage the data and provide support in the coding process. According to Creswell (2009), qualitative software programs allow the researcher:

To block and label text segments with codes so that they can be easily retrieved; to organize codes into a visual, to make it possible to diagram and see the relationship among then; and to search for segments of text that contain multiple codes. (p. 208)

According to the NVIVO 9 website, the program is a powerful tool that guides the researcher from questions to insights, helps organize and justify findings, and share work with other researchers (NVIVO 9 website, 2011). Computer programs have been widely used in qualitative research for many years as a way to manage the vast amount of data collected through the research process. However, as Bringer, Johnston, and Brackenridge (2006) concluded, some critics argue that in using computer programs, some grounded theorists do not reach their full potential and fall short of actually developing a theory with computer software. In their study of perceptions of swimming coaches of sexual relationships, Bringer et al. (2006) used NVIVO 9 to successfully move into the theorizing portion of grounded theory. The use of NVIVO 9 helped me keep all of the data in one place and avoid any lost information that will help ensure the quality and trustworthiness of the study.

Weitzman (2000) highlighted some considerations for researchers to reflect on before using a computer program with the data, including the computer literacy of the researcher, the project, the data, and the different types of analysis that I performed. It is 
the responsibility of the researcher to monitor his or her level of competency and ask these critical questions. Accordingly, the computer literacy of the researcher was evaluated as competent to adapt to the NVIVO 9 capabilities.

\section{Trustworthiness}

Trustworthiness was enhanced through the following methods: peer reviewing and debriefing, clarification of researcher bias, member checking, and rich, thick description (Creswell, 1998). Peer review allowed for a member of a similar field to review and provide feedback on the research. Clarifying the researcher bias enhanced trustworthiness by providing transparency of bias and influence upon the research. Member checking served a similar purpose in that it that allows the participants to ensure that they are representing their ideas accurately (Creswell, 1998). Writing, utilizing rich, thick description allowed the researcher access to the context in which the research is being conducted.

Trustworthiness was achieved through both prolonged engagement and persistent observation (Lincoln \& Guba, 1985). As mentioned previously in the data-collection section, I had one face-to-face encounter not only to build rapport (Fontana \& Frey, 2005) but also to gather sufficient information from each participant so that the themes reach saturation. Charmaz (2005) suggested several questions that I asked to increase the credibility of studies including topics such as intimate familiarity, data sufficiency to meet claims with range and participants, systematic comparisons, strength of logical links between gathered data, and depth of evidence to support claims. Prolonged exposure allowed me to gain an understanding of the perceptions that are present within a veteran's 
identity and meaning making while persistent observation provided a deeper understanding (Lincoln \& Guba, 1985).

\section{Summary}

The use of interviews to help develop themes led to meaningful and thorough answers to the research questions. Interviews allowed me to manipulate the interview questions to provide a breadth and depth of information to answer the research questions. From the rich information gathered, themes were identified, and thus a grounded theory was developed. The goal was to learn more information about the identity and meaning making of student veterans. In turn, the knowledge can be utilized by counseling professionals. 


\section{Chapter IV}

\section{Results}

\section{Organization}

The results chapter includes descriptions of participants and data from interview information. I will then present the themes that emerged from the data during the analysis. The themes will be reported individually through excerpts from the participants. Overarching themes included maturity, camaraderie, college experiences, military experiences, identity as a student, and identity as a veteran. Following the themes, student veteran meaning making stages will be examined through the use Kegan's $(1982,1994)$ meaning making developmental theory. From Kegan’s (1982, 1994) meaning making theory, stages three and four will be examined with the use of student veteran interview data.

\section{Restatement of the Problem}

Counselors, student affairs professionals, and university officials lack information about the identity and meaning making in transition issues of veterans, a situation that could hinder their academic experience. Because of the lack of research on 
this particular subset of returning veterans' experiences, student affairs personnel are unable to provide specialized services concerning first-time student veterans' transition needs as they enter the higher education setting. Inasmuch as student veterans are not seeking the specialized services for which they are eligible, the research reported herein could report that student veterans are not having their university transition needs met, which in turn could lead to increased dropout rates for many veterans.

\section{Description of Participants}

In this section, I will introduce each of the participants with their demographic information. To maintain their confidentiality, the information will be presented utilizing the pseudonyms that participants chose for themselves.

James. James is a 31-year-old Hispanic male. He first enrolled in college in 1998 and re-enrolled in 2011. He was deployed to Iraq from 2005-2006 for approximately one year. He was in the Army Reserves before, during, and after his deployment.

Frank. Frank is a 36-year-old Hispanic male. He first enrolled in college in 2011. He was deployed to Iraq from 2003-2004 for approximately one year. He was in the Army on Active Duty during his deployment.

Corporal. Corporal is a 28-year-old Hispanic male. He first enrolled in college in 2007. He was deployed in 2005- 2006 for approximately 16-17 months. He was in the Marine Corps on Active Duty during his deployment.

Viktor. Viktor is a 33-year-old White male. He first enrolled in college in 1999 and re-enrolled in 2010. He was deployed to Iraq in 2001-2002 and 2004-2005. He was then deployed to Afghanistan in 2008-2009. The length of his deployments ranged 
between six months and 18 months. He was both enlisted Air Force and commissioned Army on Active Duty during his deployments.

Eyob. Eyob is a 28-year-old Black male. He first enrolled in college in 2011. He was deployed to Afghanistan in 2010 for approximately one year. He was in the Army on Active Duty during his deployment.

Charles. Charles is a 27-year-old Hispanic male. He first enrolled in college in 2001 and re-enrolled in 2006. He was deployed to Afghanistan in 2008 for approximately 8 months. He was in the Marine Corps on Active Duty during his deployment.

Tony. Tony is a 27-year-old Hispanic male. He first enrolled in college in 2004 and re-enrolled in 2010. He was deployed in 2008 to Afghanistan in for approximately 10 months. He was in the Army National Guard during his deployment.

Ricky. Ricky is a 33-year-old White male. He first enrolled in college in 1997 and re-enrolled in 2011. He was deployed to Afghanistan in 2008 and 2009 for approximately 4 months each tour. He was in the Army on Active Duty during his deployments.

Wale. Wale is a 30-year-old Hispanic male. He was first enrolled in college in 2009. He was deployed to Afghanistan in 2006 for approximately 13 months. He was in the Army on Active Duty during his deployment.

Addison. Addison is a 27-year-old White female. She first enrolled in college in 2003 and re-enrolled in 2012. She was deployed to Afghanistan in 2006, 2008-2009, and 2010-2011. Her deployments ranged from seven months to one year. She was in the Army on Active Duty during her deployments. 
Jamie. Jamie is a 29-year-old White female. She first enrolled in college in 2006. She was deployed 2003-2004 to Iraq for approximately 10 months. She was in the Army on Active Duty during her deployment.

\section{Analysis of Data}

\section{Maturity}

The first theme to emerge prominently from each of the research interview questions was that of maturity. Maturity origniates from a sense that a person is more developed and therefore has more life experiences and is able to see the world more fully based on those experiences. The student veterans expressed that by going to war and experiencing what they felt was real life that they we different, thus more mature, than their fellow classmates that were of a traditional college age. Because of this student veterans, in this study, had a sense that they are overall more mature than their college classmates.

In addition to the overall theme of maturity, the student veterans were able to identify four subsets that helped each of them describe how they felt more mature than fellow classmates. Several subthemes from maturity emerged in this area; they are (1) age of the student veteran, (2) naivety of college students, (3) ability to manage stress, and (4) valuing the little things.

Age of the students. 
As noted in the literature, student veterans as nontraditional students are older than their college counterparts. The student veterans noted the age difference between themselves and those of their classmates as a way to distinguish themselves in maturity. Corporal commented on how old the students that he is now in class were when he was in Iraq stating, "I was in Iraq when they were 13, riding their bikes, just practicality just 7 years ago, you couldn't even fathom where I was at, and you know.” He shook his head in disbelief when he made the connection between the students' ages during the time that was fighting a war. In choosing the phrase "riding their bikes' he alluded to the innocence of the students he has in his classes where he was a grown man who had fought a war.

Addison commented that she felt different being in a classroom with students who were so much younger than she was. She made a point to highlight the fact that she is indeed on a different maturity level from those others in her classes.

Addison. Uh, just the fact that I am older than most undergrads, um makes it a little weird for me. I just feel like I have a different maturity level than most other college students, well not most other, but the 18-22 year olds that are normally undergrad students. I have some fellow students that are older than me, and I kinda look up to them like if they can do it, I can do it. And then the younger ones I feel like I have a step ahead of them. I've had more experience in my life and they just kinda think 'oh I can go to class and do or miss or whatever and you know....

James was frustrated that his college administrators and staff were treating him

like an average traditional-age student.

James: Uh, well me being older, uh maturity levels, the way people handle things the way people stress out too easily about things, and then at the same time not taking things that I personally think are kinda a big deal and looking at it as seriously as they should. I actually think that's how they were, especially at that other school, were basically treating me like an 18 year old kid fresh out of high school. But I know my rights I know the difference between right and wrong, and 
they are trying to pass me up like oh this is no big deal don't worry about it and I was like uh uh this is wrong and they were basically trying to smooth things over and when they knew that they weren't doing it right, trying to treat me like an 18 year old kid vs. a 31 year old, you know that's been to the military. Even here, one of the deans at the other the engineering college, one of the assistant or associate deans, was basically treating me like an 18 year old and blowing off my issues. I mean it's kinda funny when, you know, I am going to him for help saying that I have some issues I can't and can you please like reconsider letting me turn in my homework a day late please and like don't worry about it and uh.

James mentioned that in addition to being older that there would be a stigma to

him interacting with his younger classmates.

James: Like the age thing, I am kinda like in the military, I'm a minority so um, it's kinda difficult for me to make friends like me being at school I have a lot of work experiences, I am turning down jobs to stay here and so I am easily like 10 years older than most of the people that I go to class with, I mean I hang with them and like people that do want to be my friend, there aren't' that many of them because there is literally a generation gap. With the few that don't mind my age and then there are those that don't know my age and we get along and then they find out how old I am and all of a sudden I am a creep job "what is this 31 year old doing hanging out with these 21 year olds" just (nervous laugh) so. . .

Wale described his experiences about assimilating with the younger students as something that he needed to do to be successful in college and the transition. He also described that he might not have been much different from the students who are younger than him if he went to college at their age. He said that he takes both the good and the bad about students and transitions that to "taking it all in stride."

Wale: In terms of just a college life in coming from the Army, you know um, assimilating with the kids. You know the younger especially, you know me at my age, you know I have to. You know obviously I'm not 18, barely out of high school, so it's a little different, you know. You take the good with the bad and you know just there are drawbacks and rewards to everything. So you just have to take it in stride. It's all I have been doing.

Victor defined having more difficultly assimilating back and relating to the college culture and accepting his younger fellow students as part of a group that he 
wanted to socialize with outside of the classroom. But he said he managed to find some students that he could relate to at school.

Victor: Relating to people for me, some of it was coming from, I wasn't sure if it was what I came from and just doing that. A little older than main campus but I easily have 10 years on my classmates. Yeah it was the age difference compounded with the military thing. Just as you know birds of a feather kinda thing based on your experiences, you end up flocking, you're not looking for it, it just happened that way because like people initially come together in any group in any environment. In school, wherever you sit they hand out a seating chart so you know you find yourself sitting next to them for the semester and then you get to know them.

Charles also discussed that he is unable to relate to the students in his class

because of the fact that they are younger than he is, at this point saying, "being able to relate to the people, uh that weren't military about how we were going to do classwork." He goes on to say that it is the work that is most difficult because he is older. Tony reiterated the inability to relate by stating that he "I felt like I was on the outside looking in."

Jamie hoped for those students who are open to feedback from someone who is older than they are. She hinged this sense of promise to the amount of independence that the student had from his or her parents or guardians.

Jamie. It's different because I don't group them as one 'cause you definitely meet a lot of people here that are you and are motivated. The opposite side of that though, is that you can meet people that are 18 or 19 years old, and they have no direction in life. But as long as someone that age can be open to advice, you know I mean, it really depends on how they were raised on how. If their parents did everything for them or if they are willing to step up and do something for themselves, rather than depending on their parents all the time. I think it varies. I wouldn't group them all into one and say they are all "immature, traditional students that have no direction and are just spending their parents money." Because it's not like that. I definitely look at them individually. 
Conversely, Ricky discussed how his experiences with other students wasn't different from what he experienced in the Army because he was already older than most of the soldiers that he commanded in the military. He said that with dealing with younger people, he had gotten used to that. He went on to say that the other soldiers nicknamed him Grandpa because he was older than the soldiers in his unit, which reminds him of the students who are in class with him. He sees each of the students and his former soldiers as kids.

Wale also offered that despite the frustration, he enjoyed being around his fellow students. He said that he was encouraged by the interactions he had with them. He welcomed the idea that he could learn from each student on campus because of his or her unique point of view.

Wale. Oh I enjoy my fellow students. I look to learn from them, even though they are younger. I, you know, I look to those who I see have a wealth of knowledge. Even though they are younger, I respect that whomever and wherever they come from. So .... when I interact with the students, that is what I look for, just that other framework, that other viewpoint.

Wale communicated the attitude that he brings to the situation as being abrasive, but he is willing to work to see the students from their perspective and help them through his life experiences. During this part of the interview with Wale, he expressed a caring and concern for students through his nonverbal communications, such as an open position and calm voice tone.

Wale. I may be a little abrasive at times, at some points. I'm 30 years old and most of my colleagues are young, a whole lot younger. I may come like "hey you know I've been there" if I you know what I am talking about. But if I don't know what I am talking about, then I am just going to sit back and not say anything and not worry about it. But if I do know what I am talking about, I may come across like "oh you know." But other than that, I am very friendly, extremely friendly, and I am willing to help out anyone, friend, coworker, student, or anything that I 
see that needs help. Whether it be getting a ride to school or getting a ride home. Offer any help that I can.

\section{Criticism of students.}

Because of their age and maturity, student veterans view their fellow traditionalage classmates as naive about life and the world that happens outside of their college life. The criticisms of students range from the ability to manage stress, to who pays for the student's tuition to a lack of respect for the professor and fellow classmates. In addition to the previous criticisms, student veterans were also aware of the lack of value that students placed on the basic necessities that they have taken for granted. It is an obstacle for student veterans to overcome as they manage their maturity and assimilation into college life. The following are excerpts that describe the student veterans' criticisms of their fellow students.

Victor. Students seem to be naïve. I've lived in the world, I've paid bills, it's very important to me to have independence and surround myself with people that are independent.

\section{Dealing with stressful academic situations.}

Charles views his maturity to his fellow students through how he handles the stress of a situation versus the other students in his class. The comparison between the students in his class and himself proved to be a source of tension when trying to relate with them.

Charles. Especially within law school they are going to drill you, you know just to get to it; you know they employ the Socratic method, and ugh these other students say “oh, I don't think that I am ready, I heard he was a hard professor, and uh and we have to stand and he is going to grill you for like 10 or 15 minutes about what you knew about the case" and I couldn't relate as to what they were so stressed out about. I was like, it's just a professor asking questions about a case. It's not like anything is going to happen to you, that was one of those things that 
uh that really got me. I just didn't know and wasn't able to connect with some of the other students who were so insecure.

Victor also expressed concern at the amount of stress that students were placing on themselves about everything that was happening in their lives. He noted that there should, of course, be some stress but that students take it too far and let that stress seep into every part of their lives.

Victor. What is important to people, and it blows your mind, is the perception of what it means to earn something. They are, whatever it is that is going on in their lives, it's stressful, $\backslash$ and of course it is, it's supposed to be. If your academic environment isn't at least mildly stressful, then you probably aren't learning much. Um, it's like, though, this overwhelming stress to them somehow.

\section{Lack of respect.}

Student veterans were also aware of the lack of respect that they felt that students showed toward their fellow students as well as toward the professor. Coming from a culture in which respect is paramount and integral for career advancement, student veterans were particularly adamant about the lack of perceived respect. Based on his military experiences, Corporal is acutely aware of the lack of respect that the students show in a classroom environment.

Corporal. Yeah, oh yeah, everybody seems like a kid. [Tapping on his desk beat boxing.] The lack of respect, you know, when you are in the military you are not doing your own thing, you are not there spacing out. They say behoove a lot. You should be paying attention to the person that you are talking to because they may be at a higher rank, and you should respect. You know I'm talking to you so . . . . They talk before they think. Questions, it's very important to ask questions.

Eyob. When I was in classrooms, I noticed that students would just walk in and out. 
Jamie. Uh lack of discipline from other students. It's hard to concentrate in a classroom when you have people that are checking their phones, or they are whispering behind you, or um just disrespect towards a teacher.

Wale highlighted his military experiences when discussing how students don't take the university experience seriously.

Wale. Well uh you will be in class, and the teacher will be instructing and giving instruction. We are supposed to be there following their instruction and writing notes, and guys will just be talking about how many girls you know they were partying with, and all of this, while all along, when the teacher is giving us, you know, information for our test. So that, in itself, that's not going against like everybody. You know that's human nature to; it's just an overall that's how I perceive it. Like you know some children, it's like it's all handed down and so you aren't going to have the same respect for it or hold it dear like if you would have really had to work for it and go to combat for it and fight for it.

Addison reports that the military has been able to give her the maturity she needs to manage her reenrollment into the college experience. However, she expressed frustration at the money that students waste because they do not have to pay for college themselves.

Addison. One simple thing is that I sit in class and listen, because that's what I am there for. I have a goal, and you know. But this is going to sound really bad, but Mommy and Daddy aren't paying for my school and, you know, the governments paying for it, and I've got to get everything that I can. I can't afford to retake classes and that, so them talking during class kinda interrupts my learning process.

Ricky saw the differences between his younger classmates and the older classmates in the different classes. He discussed how the classes in which the students seemed more focused and respectful were also their upper division or major classes instead of the core curriculum.

Ricky. It depends on the class. I just got out of sports history or the history of sports in the U.S., and then there's definitely some 19 to 20 year old kids in there that need to grow up and shut up. And, I well, sometimes I just have to sit there (he takes a deep breath) and bite my tongue and count to ten and say: "they are 
just kinds and they don't know any better." But in some of the other classes, um, the military history or the economics classes, it's they seem to be a little bit more mature and adult. You know it's great to get along. Especially last semester, I had a modern Middle East class, and everybody in that class was very . . . . they wanted to learn and it wasn't a joke. That one was really enjoyable.

James pointed out a social situation that he felt highlighted his fellow students' lack of respect for each other. He stated that he was different and more subdued before going into the military, but since he has been out, he has been less understanding of actions that he feels are disrespectful. He recounted a situation where he had invited some classmates over for a get-together and he didn't feel that the other students were being respectful of his belongings or his home.

James. I could point out little things, honestly before I joined the military little things didn't bother me as much but now they do like saying inviting people. Like honestly a couple of things I am going to say probably wouldn't make anyone mad but I. you know, I try to make friends like hey come over and we can have a couple of beers. Oh and one dude cracks open a beer and it's foaming over. Instead of putting it over the sink or trying to slurp it up, you know, he just pours it out on my kitchen floor (laughing). I had another group of guys straight up, I won't smoke like they started to light up cigarettes in my house and like was just like "what are you guys doing" (laughing) you know little things like that. Honestly that stuff makes me mad. That's just kinda like at the house, and like they aren't even drunk yet, it's like a beer or two, and they are like that. I don't know just little things that are kinda insensitive stuff like I can take it, I can take a verbal lashing but there are just some things that just tweak me out, and I can't even think of it, or I can't even name it because at that moment I'm mad, but then I forget about it.

\section{Valuing the little things.}

Because of their time in a warzone, all of the veterans were acutely aware of the sacrifices they felt that they had made for their country. The amount of value the student veterans placed on valuing the little things was contradicted by their fellow classmates' lack of maturity in understanding this concept. 
Each of the excerpts below related the student's lack of appreciation of the time that the student veteran spent in the military. Because I interviewed combat veterans, it was through this prior knowledge of the realities of war that they shaped their understanding of what it means to value something. Charles first focused on his relationships as well as the basic comforts that nonmilitary individuals have every day, such as a shower and a warm meal.

Charles. Also, I see that students not valuing little things, for example like you know let's say someone has a girlfriend, and because grad school and whatever they got split up, you know you have someone, you know and you need to value the relationship, you know. A lot of relationships get torn apart because of deployment, you know, they get divorced, me included. Um, I have someone who has stuck around for the second deployment, you know I tend to value the little things, uh. Whether it's a personal relationship that no one, you know, they just want to argue about little things, and whereas I would rather just be happy. Uh also other little things they, they don't seem to value like a hot shower, uh, or a shower period. Uh you know even now when I'm in the shower, I'm like this is nice. I'm very lucky to shower or get 5 or 6 hours of sleep sometimes, you know, I hear other students say 'oh I only slept like 6 hours today I'm so tired, but I got 6 and I am happy. When I get 8 , I wake up and think that was 8 hours, of work that I could have been doing. Um like 'I don't know this restaurant, I don't want to go to this restaurant, um, there's nothing to eat,' and I'm like there is something to eat there are a lot of restaurants that you can go to, you are not stuck to a menu of 24 meals, you know case A of MRE's oh your like what case is it "A" and oh it's case A alright give me number 12, you already know the menu that is in there. I want the chicken noodles, you know, its just little things that really I don't get.

Victor highlighted the differences in maturity and values based, not on the age of the person but the experiences that they have already had in the world. He made a distinction between those who are young and those who are grateful. One was not contingent on the other for him.

Victor. I'm just thankful to be here, nobody shot at me today, I am going back to my house tonight. Whatever happens, it's not going to be the end of my world. The worst thing that is going to happen is that I am going to get an undesirable grade, it's not that bad. You know, whereas you find yourself in situations where, you know, I remember in the military guys saying 'what are they going to do, take 
my birthday' it already sucks you know it's kinda it's just the difference between what you are thankful for, and I don't know, so it's still young people but I went from a group of young people that were fighting and in a war to a group of young people that some get upset because their mom and dad aren't flying them out of the country this year and that's literal because I have seen and heard that and I was like "wow really." It creates a tension.

Wale made the distinction between his opinion that the Army is a real-world experience and how students don't appear to understand that, in his view, college is not as real. As before, he made a point not that it was because they were young that they were immature which is in contrast to Victor's interpretation of age and maturity.

Wale. It's real world in the Army. Its no joke, you know, and sometimes the kids here it's all a big joke, and you know it's a laughing matter and you know in the military, it's nowhere like that, you know. Not all students, you are going to have your mold of good student. You know that take everything in stride. But I am speaking in terms of, you know, those who take everything for granted: take college for granted, you know, having a car, having a nice place to live. You know taking all that for granted. You definitely see a whole lot of that, you know, because they are young and because they are immature. I'm not getting that my stance at the same, at that same time or that point, at that age that I wasn't the same way. I'm just looking on how I see it now.

Corporal further suggested that it is him who has to take a moment to look around and be grateful that he is on campus. He stated that he regularly stops to look around the campus and be in wonder of it and the opportunities that he has ahead of him.

Student veterans as a group expressed a gratefulness in their everyday life. During the interviews, each of the veterans expressed gratitude for one thing or another. Student veterans were grateful for the ability to shower, the ability to be safe in their environment, and the ability to attend college. It is through this larger worldview of what could have happened had they not returned that they expressed frustration with their fellow students about the amount of value each student places on the little things.

\section{Camaraderie}


Camaraderie is a promoted value within the military as it means to most veterans that the other members of the unit are to support and defend you during your service time. Most referred to the camaraderie they experienced during their time in the military. However, some student veterans were able to transition their sense of camaraderie to the college experience. Charles described his acceptance of the military value of camaraderie through describing how he felt different from his high school classmates but then the military taught him to embrace camaraderie. He then experienced a strong camaraderie with his battle buddies but has had difficulty transitioning that to the interactions that he has with other students.

Charles. You kinda miss the guys that you went to combat with uh, even when you were there and you hated them, you were like "I am never going to hang out with you in the real world," like in high school I would have been picking on you, like I would have said that you were an idiot or you're just not cool. But when you are in the Marine Corps and in combat, you know, all that goes out the window and all of a sudden it's I'm willing to do something to save your life, even if I was back in the real world, I wouldn't hang out with you" or I know that you are going to do the same for me and the experiences that you go through, you know they do change you, um, so you can relate to those people. Um, you can say that you can read their facial expressions, and you know especially when certain days come up where we have casualties or something uh you know you can tell what is going through their minds. Whereas, with people here, uh, you know, I will go out with them and hang out. You know, hey let's go have a beer to them means hey, let's sit next to each other, and you know I am going to be on my phone. Whereas to me it means, hey let's go have a beer means, hey lets go drink and talk about something you know. Some you know nowadays the friends that I have in school are colleagues more than anything.

Victor related the camaraderie that he felt during his time in service as a sense of belonging to something special. He noted that not everything is perfect between all members of the military. However, when he was in his unit and a wartime environment, each soldier is involved in the process.

Jamie echoed Victor's sentiment about the camaraderie that is experienced in 
soldiers who are deployed to a combat zone. She differentiated between the camaraderie she felt during her deployment versus the camaraderie that she experienced during her time stateside. In addition to her comparison about the military camaraderie she describes how she transitioned the learned skill to her college experiences.

Jamie. Camaraderie, there is very ... it's especially engrained in soldiers that are oversees. My first duty station was German. We went to Iraq from Germany and all the soldiers had were each other. Um, when I got back to the States, a stateside, unit, it was as developed. Their camaraderie wasn't as developed as someone who is oversees the entire time. I would definitely say the camaraderie is a lot different in college because everyone is competing against each other. In the military, you are fighting the same battle. You are ingrained and taught that you never leave a soldier behind. I think I bring that mentality to the university but I don't think that the students at the university are as welcoming. You know you can study together and everybody can do well, or you can try to be an individual and succeed or fail.

James also suggested the camaraderie differences between the military and the college students that he encounters on campus. He, however, concluded that the camaraderie experienced during the military was not how it was going to be during his college experiences.

James. Uh I would say camaraderie and like you know the guys that I worked with we would hang out and go have drinks together versus here where people like show up to class and then they burn off and don't want to talk to you after class is done, so I don't know.

\section{Feelings towards non combat veterans.}

Jamie mentioned the difference in the sense of camaraderie between those veterans who had been in combat situations vs. those who were either not deployed to a combat zone or those who hadn't seen combat while in theatre. This is something that others of the interview group brought to life during the course of the in-depth interviews. In addition to the overall lack of camaraderie felt between the student veterans and other 
students on campus, combat veterans shared a disconnect with student veterans who were not deployed to combat zones or even who had been in a combat zone but did not participate in combat itself. Charles explained that he appreciated the willingness for civilians to sign up for the military to help the war cause but difficulty relating to those who had not seen military combat.

Charles. Those who were military um, of course there's that, you know we are still brothers in arms, uh you know look out for everyone and we worked with Army and Naval corpsmen but experiences may vary (laugh). Especially depending on the person's job, uh, you know they are helping out the war effort, and you know they even joined during the time of war, it's great, it's admirable, uh but sometimes you really can't relate to them because they worked in an office. Even if they went to Iraq or they went to Afghanistan, they were in an office, they had AC, they got to eat at the chow hall and got to drink 7UP and their shrimp on Fridays, their steak and shrimp. And you know where we were, it was just dirt floors. Uh the most entertaining thing you could do was, uh guys had laptops, and uh just this tiny little laptop and uh like the whole squad huddled around watching a movie that we have already seen and uh you know seven times but there was nothing else to do. You know and there's that with people who are also former military, you can't really relate because they have different experiences, it's a little different.

He goes on to mention how he wasn't treated the same as those who were

stationed at a forward operations base (FOB). It was during this part of the interview that

I noticed a slight tone of frustration in the following statement:

Charles. I didn't get to eat steak and shrimp except when I got medevac twice to camp. For some surgery, um, I was like, the only time on deployment that I saw a cold Coca Cola and some steak. This Army/ Air Force camp is awesome. 'You guys have a movie theatre in Afghanistan, wow, that's cool. Um but other than that I see myself as one of those guys that, like, 'yeah, I didn't have all the comforts but I can't go around bragging because I'm not one of those guys that landed on or was one of those guys. I'm like, wow. I see myself somewhere in the middle.

James revealed that the lack of discipline IN those who have been deployed to combat situations and those who have not is "wrong." He understood the discipline that 
the active military needed for soldiers to survive was not present as strongly in the reserve soldiers who he encountered. He highlighted that common practice in the active military was for soldiers to fix themselves and make sure they are in line with what is expected. Whereas, in the reserves, he didn't find the same level of intensity and discipline.

James. So I come back to the reserve side, and, um, yeah they don't take things as seriously, like you try to speak up and correct someone for doing something wrong and, you know, you are getting talked back to, I mean that ain't right I mean. And you should be like oh yeah I'm wrong, I should fix myself and don't even question it, and that doesn't happen on the reserve side.

Wale understood the difference of being in combat situations to not being in combat situations by relating that combat veterans have a "big elephant on his or her back." He mentioned how that even if a combat veteran returns home with no physical injury, that doesn't always mean that the veteran is in the same mental health.

Wale. You know those that really saw combat that lived the front line. It's a lot harder life than those who were a dental assistant or something because that. My infantry buddies, well, most of us, we saw combat we carry...um...we carry a big elephant on your shoulder, you know, sometimes, you know. Some guys walk out of there fine with no scrapes and no damage. Other guys walk out of there, regardless of whether you could see it or not, just wounded.

\section{Frustration with the College Experience}

For Corporal, “the military isn't for everyone, and school isn't for everyone” was an overarching theme to the frustration that college life could elicit for student veterans as they transitioned to college. The college experience was unique for all of the student veterans who are either coming to college for the first time or re-enrolling from a break in their academic career. Many of the student veterans encountered both negative and positive transition issues as they came to college. Transition issues affected student 
veterans on both the system and classroom level. In addition, student veterans were expected to academically perform at the same level as traditional -age college students. The transition to college also included the differing responsibilities, in particular relation to the student's time management and freedom, the isolation that student veterans faced from other students, as well as some who encountered easier transitions.

\section{System-wide.}

James encountered a general frustration with the system of college being the paperwork, tuition, and managing other student and professors. At the other institution that he transferred to his current institution from, he perceived a discriminatory attitude toward him because he was a student veteran. Paperwork for scholarships was lost, and he eventually used some of his non-GI Bill funds to pay for school. He was forced to make complaints to the university until he was dropped from scholarships with no further explanation. He mentioned that students with lower GPA's were receiving scholarships from the university but not him. During this section of the interview, I noted a sense of frustration in how he explained the situation.

James. I had to use my tuition assistance as well, and they would lose my paperwork (nervous laugh), and at the same time, I countered and I made some counter complaints against them and they got . . . well I got dropped off of scholarship and for no reason. Like people that were a whole point lower than me were getting scholarships, and, I wasn't uh just a bunch of stuff the school basically tried to talk to me like it was no big deal and I knew it wasn't. I knew what they were telling me, they were basically misinforming me, and uh, I transferred. I signed up and came over here.

\section{Professors.}

Jamie stated that she felt frustration with professors because of the lack of focus and structure that they gave to the students in the classroom. 
Jamie. I don't like that the teachers didn't do anything about it, like they wouldn't reprimand students for acting the way they did. They took a laissez-faire approach to it.

On the other hand, James expressed frustration with the professors who were unwilling to work with him when he was on his reserve duty while back stateside. He would let them know that he had reserve training, but they were unwilling to adjust his due dates for assignments. He stated, "so I mean the professors won't listen to me; they don't give a shit." He did though, at some points, have professors that would "work with him."

James. I had some professors that, you know they were reasonable, that dealt with me, I am still in the Reserve so I have duties, and all that stuff they would understand. And I had some other professors, especially the political science professors, who were, I don't know what it is, personally I feel like they were trying to take a stab at a solider because of their political beliefs (nervous laughing). And uh like they would, I would say hey I got some reserve duty I couldn't do my homework. Well, I was actually out of town. When I first got back every other, almost every month, they were sending me and I would be gone for like a week. And some of the professors would compromise, and I would send it to them over email or online or they would just allow me to submit it late, and um. And the ones, those other ones, they wouldn't budge. You know, they are supposed, to but they wouldn't, and I didn't make a stink about it, it just wasn't worth my time. Just so frustrating, I would get mad even thinking about it and I wouldn't deal with it, and I took a hit, and it was like that for about a year and a half. Then that's actually part of the reason that I transferred over here.

James additionally felt frustrated with the Student Counseling Center when he went to see them for help with some of his transition issues. He was also dealing with some harassment issues from the university that he attended previously. He described that he felt abandoned by the university and those who he perceived should be helping him be successful and make the transition smoother. James stated, "yeah and they are supposed to give you like 8 or 10 sessions, and after two sessions, they didn't say it 
exactly the way I am going to say it, but they pretty much said that "you are too screwed up for us and they referred me outside."

\section{Academic issues.}

In the transition to college, some veterans found the subject material to be more

difficult than they remembered. Tony mentioned that the workload was one of his

biggest challenges when he first arrived from his deployment.

Tony. I think the biggest challenge when I returned from the deployment on campus was the material and with the school it was mainly with the work. I feel that I can focus but sometimes . . . I knew what the expectations where I knew exactly what I needed to do, but when I got back from the deployment, I was still on active duty. I struggled at first not because of my ability to comprehend the material; it was just I didn't put in the effort to do well. I put everything off to the last minute because I overestimated my abilities.

Wale also expressed challenges in the schoolwork because of the transition from an infantry division to the classroom setting.

Wale. Well my, my biggest transition is going from infantry, which is no schooling, there's training involved, but it's nowhere near a classroom setting. Where you are training, outside, in the elements so coming to a classroom setting from being in the infantry was the hardest ... um the hardest . . obstacle to contend with.

Charles expressed that it wasn't the difficulty of the material that he had to struggle with but the amount of the homework that he was given each night. However, he felt that he was managing the amount of work and being successful.

However, Ricky and Addison, who had been to college before and was transitioning back, found the material to be manageable. He explained that it was his specific communications duty in the military that allowed him to keep learning and thus made the transition smoother. Addison also attended college before, and was a medic in the military where learning is highly valued. 
Ricky. There was a lot of learning that I had to do in the Army. In my unit, we were a special operations unit, so we had the combat side, but I was communications. So I had to learn, I was not a computer guy going in, and I am not a computer guy now that I'm not doing it anymore. But I had to learn all of the networking and stuff like that so there was a lot of school, I guess you could say, in the Army.

Addison. The military gave me that, and um so that's one big thing. Um, I guess the fact that getting back into the college life. Cause I was there once I was at a private school, um they didn't really have dorms, and you know, that wasn't an issue but um yeah, just getting back into the studying and all that stuff.

Frank shared Ricky and Addison's ease of transition back to the university,

because he used the last couple of years of his time in the military to research how to come back to college. He explained that the last couple of years, he wasn't as busy as he had been before, which gave him more time to understand how to best transition to the university setting. In addition to relying on the university Military and Veteran Program, he relied heavily on other veterans and outside resources.

Frank. Well actually, personally I didn't find it too hard. I had a pretty good job the second half, as a pilot I had a lot of off time, so I was kinda transitioning in the last couple of years in the military. I kinda just really just sucked it up. I kinda you know, I knew that there was very little that I could do about it at that point other than just attack it, and you know adjust, and I was very fortunate that Texas Tech has a pretty good office with the MVP office that helps you with the process of going back to school, financial aid from your GI Bill, and all of that. Um, and I guess educate myself I read a lot and researched and went on the internet and kinda read some blogs about people that were retired that our age, close to our age, late 30 's or so, and read a little bit about what they did to kinda of mingle or get back into the mix with the other students, so I found the Internet pretty helpful.

\section{Structure and Routine}

Almost all of the student veterans that I interviewed found differences between the structure in the military and the structure they encountered in their college experiences. The responsibilities that the student veterans expressed having in the military were more critical to their survival and advancement in rank, whereas, in college, 
the responsibilities were individualized to the student veteran. Student veterans also noted that time management and discipline were externalized in the military, unlike their college experiences where it was an individual's dedication.

Ricky expressed that structure in the military was defined for each soldier. Ricky felt that now that he was in college, he would need to make his own decisions, and it was going to be difficult. As a student re-enrolling after a considerable duration not in a college environment, he had grown accustomed to having directions told to him by someone in a higher rank and not making them on his own.

Ricky. In the military it's you are here at this time. There is no if and's or buts, you get this done at this time. Schools just not. I have to learn to discipline myself again. Kinda whatever I wanted to do like going to class. Everything is decided for you in the Army. Now, I need to get back into making my own decisions. The military's not hard. This is hard. I can do that the military, so it wasn't difficult, it's the easiest thing you will do in your life. Because school is you, you have to, you have to do. You had to this on a smaller scale, you had homework, you had things to do, you had to do them, you had to do them, though the only effort was doing it, there was no cognitive, there was no "oh I gotta wake up and gotta to go to class," no, you have to do it. You take that away, that authority, then the authority is on yourself. It's hard to keep that authority there and continue to do it.

Tony also pointed out that the expectations in the military are very clear and they are well communicated to each soldier. He understood that his success was going to be determined by maintaining the structure that he learned in the military and applying it to his college experience.

Tony. The difference in the military the expectations are clearly structured. What you can and can't do. What the mission is. At the university you are on your own, it's your responsibility to study and go to class. There are a lot more freedoms and uh. It's the hardest that change, it kinda throws you off. You are used to structure and you can continue with that structure then you can do what you need to do. If you get away from that structure, that you have to live by, the, um, you can set yourself behind. 
Frank discussed how the military was influential in the discipline that he has now because of what he learned in the military. He, too, expressed that it was that amount of discipline and self-imposed structure were already ingrained to help him 'buckle down' and be successful during his time in college.

Frank. They've definitely given me a lot more discipline, you know, I know that. For example I know that if I have assignments or my tasks, my goal of graduating, I know that there are steps that I absolutely have to take to graduate and to do it, and I know that nobody's going to hand anything to me, and I mean it would be nice. The discipline that I learned in the military prepared myself and allows me to really buckle down and uh not procrastinate when I have assignments due and what not.

Addison expressed similar concerns about the lack of structure and increase in

freedom that she experienced in college versus what she was used to in the military.

Addison. Um, I guess the fact, the big difference, is that I can do whatever I want. I can decide to go to class and uh be late or I have freedom, whereas the military is a set structure. You will be here at a set time, and you will get out at this time.

James reenrolled in college after he was deployed to Iraq. He related the severity of not following the structure and discipline in the military to the possibility of dying. $\mathrm{He}$ expressed the idea that he felt that the military was very beneficial for him to get some experiences. In addition to the experiences, he was accountable for his actions that kept him in line with the rules.

James. And when I was in Iraq, I wasn't doing normal stuff, and when I got back on stateside, I wasn't doing normal things, and, but even then um ... we had a certain amount of discipline. I mean, when you are in Iraq and you mess up, you die. In the military, like you get a lot of experience, like, a lot of responsibility. You are expected to read and write, especially when you are in charge, I mean, like if you don't do something right, you are going to jail. So when it comes to rules and regulations, I know how to read, like I worked before I joined the military.

Charles also related his college discipline to the military by calling his college 
experiences a mission. He described how the mission is now individualized to what he has on his syllabus. The difference between the military and college, though, is navigating how to know what to do and when to do it. Even though the information for his mission is on the syllabus, he was frustrated that he didn't know exactly what was expected of him in college. The discipline that he experienced in the military, he described as being every part of his life. He didn't have to pick out what he was going to wear that day or how much effort he needed to put into an activity. The military told him everything that he needed to do and when he should complete it.

Charles. Uh whereas now I have a job to do, a mission, and it's written down in my syllabus, it's written down. I know what needs to be done, and you are on your own. Whether I do it or not, the only time that someone is going to find out is at the end of the semester. Uh though I may have a mission now, it's very individualized it all up to me and it's on my terms and what I have to do to get it done. Where as with the military you knew it needed to be done so you did it. Some things you don't know what you have to do until someone tells you to do them, uh and then there are ways to do them, otherwise someone is going to get upset. Obviously, some big differences are that life is very simple in the military. Uh, you know what you are supposed to be wearing that day, the right uniform that I am supposed to be wearing. And you know the correct way as in how I am supposed to wear it, otherwise I will get lit up by someone. Whereas, now I have to think about it. There's more, it's a little more complex out here, I think. Uh military life, especially when you are in combat, is straightforward as to what you do. Now it's up to me to decide what I am going to wear each day, whether I even want to go to class.

\section{Invisibility and Isolation}

As mentioned in the literature, student veterans have a strong sense of isolation from their fellow students, faculty members, and staff when they are on campus. Student veterans acknowledged their feeling of invisibility by choosing whom to identify as a veteran. Because student veterans are older, they are more likely to live off campus and have friends not associated with the university. 
Ricky related his feelings of isolation and invisibility by relating them back to the sense of belonging that he felt in the military. While active in the military, he said that everything happened as a unit "you know we are working on like 10-man teams" and that he couldn't hide or "fall into the background." It was in direct contrast to how he perceives his time here, where he can "sit in the back and nobody can know who I am and that's perfectly fine."

Charles also related his experiences of feeling alone to the time that he spent in the military. He described how when he was in the military, he always was around people doing work in a team effort atmosphere. The time that he has been in college, he hadn't made connections because of the format of class, where you go listen to the professor and then leave. Very little effort is put forth to encourage social activities among student veterans. He continued on in his statements to reveal how he feels isolated from his fellow students, especially when he is not included in social events that happen without him.

Charles. Uh and sometimes, well actually a majority of the time, it's a team effort. We need 10 bodies. We need 8 bodies. Uh, you know guys, go down to the warehouse to pick up some cases of MRE's. Cause you know you always had someone there. You really, you never found yourself alone, and uh, whereas in school in general, you can find yourself alone.

You know, know when you go to class, you are either going to be in mandatory formation in the afternoon where you see everyone else. You can say "hey what are you guys going to do tonight?" I guess for the undergrads, they do live on campus and go to the dorms, they do see their classmates in and around outside of class. Where, you know, grad students, you go home you don't see anyone. Until I see them the next day in the morning and "oh I didn't know that you went out last night, oh cool." Uh the teamwork aspect of it. Yeah, you could join a study group, but you know you show up, you are there for the studying, and you leave. You don't have to live with that person, whereas in the military you know, you know, when you were in, you hated that you couldn't wait to get off base. I hate all you guys. Then out here, it's I spend most of my time alone doing my homework. I will call home, call my girlfriend or my family or whatever. 
Until I go to class and I see my friend. You know I will drop comments on FB about sometimes, but you know, other than that I hardly ever see my classmates or friends outside of the classroom. Like once a week or something, but that's it.

Charles also noted that the military provided him support that was there to monitor his actions. In addition to monitoring, it was part of the military culture to bring out any inconsistencies in his actions or words in his progress reports. He didn't think that the university had any of that same support in place for students and especially student veterans.

Charles. Um, how much effort do I need to put into this work? In the military, what you put in sometimes that wasn't even enough and you are going to have someone yelling at you. You know, I don't care that you did that, I want you to do even better. There is always somebody pushing you, and out here, you are pretty much on your own. You don't have that network, that net, but in the military, you always have someone on your case, you always have someone with progress reports. You know, I've noticed that you have been late, or I've noticed that you haven't been running as hard and, uh, you've had an attitude. Uh, we are going to sit down and counsel you, "what's been going on? what's up?" Whereas here no one is going to catch that. Uh, you are alone out here.

Both Victor and Ricky chose to keep to themselves, so that it wouldn't interfere with their academic progress. Victor, again classifying college as a mission, felt that he was isolated from other students, because he is the only one that he needs to worry about right now. Victor goes on to state that the isolation he faced with his fellow classmates is based upon a predetermined set of values that he was here to complete a degree and not worry about anything or anyone but that objective. He shared that if a student wanted to "hang out" he would do so but he didn't connect with the objectives of the students that he was interacting with because of the differing military culture. Victor and Ricky both expressed the idea that the isolation they felt with their fellow students was based on the 
lack of common experiences they shared with other students. Both of men were 33 years

old.

Victor. I decided a long time ago to worry about me and don't worry about what Joe's doing don't worry about what Mike's doing just worry about you, you have a mission, worry about your mission. I am here for my mission. If somebody likes me, great, I'll hang out with you, I don't have a problem, I don't care. And with the social graces in the Army, it's ok to tell somebody they are stupid, it's ok, nobody gets hurt it's just an environment, you know and uh.

You know, it's one of I think the word deference it's . . . . I decided a long time ago to worry about me, and don't worry about what Joe's doing, don't worry about what Mike's doing, just worry about you, you have a mission, worry about your mission. I am here for my mission. If somebody likes me, great, I'll hang out with you I don't have a problem. I don't care. And with the social graces in the Army, it's ok to tell somebody they are stupid, it's ok, nobody gets hurt, it's just an environment, you know and uh. I say deference just because they don't have any effect on me and take them as they are.

Ricky. I, one of the things that I do, I find my little spot, and that's it. I don't really, I wouldn't say that I don't get along with, but I don't interact too much with the, with most of them.

In addition to the isolation from other students, Addison expressed a separation

from her professors by their communication techniques. Addison described the fact that

she didn't feel connected to her professors because they only communicated by e-mail

and not in person outside of class. She discussed how, like Charles, in the military, she

felt cared for and connected, whereas, here she is alone.

Addison. The differences, that's a lot of stuff, I mean communication in the military is pretty much face to face most of the time, one on one and obviously here, you know, your teachers some of them are like 500 student classes. So that's a big difference. Uh most communication with your professors here is done through e-mail rather than face-to-face. I guess as far as similarities goes, some of the stuff we did in the military, as far as training, was online and a lot of the homework, unfortunately, here is online.

Addison continues that the isolation she felt in class also translates to the support she receives from campus entities to her relationship with her husband in social settings. 
In the Military and Veteran Program, she expressed the idea that none of the student workers were female, which made her feel that she didn't have someone who would understand her unique needs as a female veteran. In regard to the invisibility that she feels in with her husband, both of them served in the military at the same time; however, only he gets recognized as having been in the military. They have been around other friends who assume that he, not she, was in the military. She wavered emotionally between having it affect her and being upset, to not letting it upset her, but then back again. The internal struggle was evident in the furrowed brow on her face.

Addison. I mean there are no, well there are a lot of female veterans, but I don't think they get the same representation as other vets. I guess when I go to the MVP office there's not a single female who works in there. Um, I actually thought about going in there and doing it. Um, you know, as a female vet, it's kinda hard to establish yourself as such because people still don't accept it for some reason. Actually, an example: my husband will say uh, we'll be out just talking to some random people. And he will be like "we were in the military" and they will just automatically assume that it was just him. You know, at first, it kinda got to me and then eventually, I thought whatever. I know what I did, and it's not that big of a deal, but that is one big social thing.

In addition to isolation from the campus culture that was felt by student veterans, James also found difficulty relating to the different units he was placed with during his time in the military. He initially described himself as the "redheaded stepchild" of the Army who never fully fit in with the different units. It was during this part of the interview that I noticed James was talking quickly and with more strain in his voice. He expressed his frustration that his time in the military was not valued, and that he was moved often, which caused him hardship.

James. And, um also, as far as my military career has gone, I have always $\mathrm{s}$ been like the red headed stepchild, like always been the only guy with my job. No matter when I was with a quartermaster unit in Iraq and we weren't doing quartermaster work, and then I came back to the stateside and they put me with 
another quartermaster, and it was actually with an irrigation company so I can't identify with them. I don't even know what they do. Like I know what they do; they eventually trained me, but still like it's a different culture. The Army's split up and you have different corps with in the Army that all have their own cultures you know, it's weird. And over here, I am part of a medical unit, they are actually pretty cool. But I don't get as frustrated with the medical guys as I did with the quartermasters. I was in Fort Bliss stateside, as an instructor, and uh, I belonged to an Rray unit, Calvary unit, infantry unit, artillery unit and it was like every 6 or 9 months I would get transferred to a different unit. Not because I was doing anything wrong, but that's out of need.

\section{Identity as a Student}

Student veterans have their own understanding of who they are as students and where they fit into the university setting. I asked each to describe for me how they would characterize themselves as students. Many of student veterans started off describing himself or herself as focused or determined. The time away from school made each of the student veterans more aware of the implications for their success in college. The student veterans in this study were mixed between those who were first-time college students and those who were reenrolling in college. Despite this difference, the student veterans interviewed all thought that they were more prepared based on a heightened maturity and potentially differing family situation. Addison, for example, wanted to finish college as soon as possible and stay focused, because now she has a family that is dependent on her success. Student veterans were also grateful for the time that they spent in the military that helped they understand that college was an opportunity that their military service provided for them.

\section{Determination and focus.}

Student veterans shared an increased sense of focus for their first time or return to college. Tony stated, "I am focused. I am focused now. I am dedicated, and when I put 
the effort in with my major." James was also focused and determined to be successful this semester, “academically this semester I am feeling pretty confident about it, I've got it, I can't let it go."

Victor described how determination was the key to his continuation in college. He shared that if he had come to college as a traditional student, he would not have been as focused as he is now. He also stated that he is much more serious about his education now that he is older. When he laughed, talking about being 22 years old and trying to go to school, he looked up and seemed to have a memory of what it was like and what he was doing when he was that age.

Victor. Seriously, I mean truth is, it's probably good that I am a nontraditional student. I joined the military with absolutely no college. I went to school at nights to get done, and I reenlisted to give myself some opportunities and went to some places that could have been a lot of fun. I was in a hotel room reading books and getting my degree. I went to the Army then because I could commission and stay in the same job. But this is a lot tougher academically; I wasn't ready for this at 22. I just wasn't and that's the truth [laughing]. So I'm a serious student, that's what I would say, I mean I am serious about what I am here for. I am here to accomplish something. I am here to pass. I am here trying to do a good job.

Frank echoed Viktor's sentiment that he is serious about his school work and wants to do everything he can to be successful. He expressed an understanding that going to college was a privilege and not a right for him.

Frank. Hardworking, and uh again understanding of the situations, and uh and kinda goes back to not procrastinating. I know that I am here because I want to be and, uh, it's not mandatory for me to be here, like it's not mandatory for me to appreciate the fact that I was and am allowed to do both.

Addison and Jamie, both female student veterans, expressed the idea that they are serious and motivated about their college experience. Addison was more focused on how the completion of her degree would impact her family and make it better financially. She 
was concerned that because both she and husband were without the steady income of the military, which they became accustomed to, the faster she could finish the more sound they would be to support their children.

Addison. Um, I am much more focused. And that's because of the fact that I am married, and I do have three step kids. So I have that goal that I need to. I have a family to take care of. Though the sooner I get out of school, the sooner that I can get a real job. Income was a big thing, because me and my husband both were in the military, and we are both in school right now, so um, a source income was a big, big thing.

Jamie also said that she was very motivated to do well in college and obtain her goal of graduation. Contrary to Addison, she said that she uses all of her skills learned in the military to utilize all of the resources that she has access to at the university, particularly her professors. She realized that talking to the professors would help keep her on track and she could glean much more information by being respectful.

Jamie. I'm very motivated. I have a set goal in mind that I would like to obtain. I'm dedicated to my studies and to reaching that goal. Um, I think I'm a wellrounded student that's easy to talk to. I definitely use the professor's office hours to my advantage. I mean, I think one thing in the military that they teach you is to respect. How to get something done but in a tactful way. I think that's very beneficial for people coming out of the military, because we do have a professional relationship with people on all ranks. So you kinda develop that, and you can definitely use it to your advantage in college.

Frank was similar to Addison in that he was serious about completing his degree and being successful because he had his family to provide for. He was also thankful for the opportunity to go to college and help obtain a better life for himself and his children. During the entire interview, Frank mentioned his wife and children as the backbone to who he is as a student, veteran, and person. It was his dedication to his wife and children that helped him focused on doing well and finishing college. 
Frank. I definitely, this is one of the things that I was finding difficult at first. You know, I take my education serious, for a couple of reasons, you know the GI bill gives me money to study monthly. I still look at it like it's my money, it's something that I earned, and if I don't use it, then my money does not go completely towards school, then I can use it for other reasons. I'm married, and have three kids, and I definitely take everything seriously. I put effort into it because I know that my wife and kids are depending on me to be successful here so that I can, in turn, be successful upon graduation, so I'm dedicated when it comes to school.

Ricky utilized his impending graduation date to keep him motivated for all of his classes. He was very firm and unwavering when he used the word 'responsible' to characterize how he perceived himself as a student on campus. It was through this particular word choice and the pause after that he reflected on his past experiences failing to motivate him toward the finish of the semester and impending graduation.

Ricky. Responsible. I take the notes. I show up. Uh, I'm on time, all that stuff. It's just, I know I've got, less than a semester to go before I graduate. So I've got to get this finished and that's my attitude going in; go in, get it done, and don't do what I did last time, when I was in school and ended up kinda fading out. So I am really focused on school right now.

Wale characterized himself as above average. However, he noted that it is sometimes difficult to maintain the same level of dedication to his studies throughout the semester. He is a first time college student who seemed to be struggling with the demands of university pressure. He is aware of places that he can improve his performance, but is overall pleased with his effort and the outcomes in his classes.

Wale. Well better than, an above average student. I feel like I bring to the table not only what I need to succeed but to exceed at a higher level. So that's what I attempt. Of course there are always days and times and weekends where you need to study more. And you tell yourself that "you know you could be studying more," but you know. So you know, I'm not like 100 percent always this. There are some things that I know I can improve upon myself but overall, speaking I'm very happy being a student. 
Charles, instead, found it much more difficult to keep working hard and maintaining his sense of determination throughout the semester. He reenrolled in college after serving in the military for seven years. He said that even though the material wasn't difficult for him to understand, but the study skills that he lost in those seven years affected his motivation to do the work. In addition to a lack of study skills, he goes on to say that he doesn't find himself engaged in the material.

Since going to war, he sees the types of lawsuits that are brought forward and are frivolous. He expressed a sense of frustration with the arguments that he considered insignificant, especially since he had been to war and had a realization that life was short and precious. Later in his interview, he discussed how he felt the inconsistency in his academic motivation. He was motivated to stay up all night to study and do all of his homework and turn it in the next day. However, the inconsistency prevailed and he stated that he was back to not doing his homework and ignoring his reading.

Charles. You know I'm not going to lie. Sometimes I get burnt out, um, I find myself being hardworking and doing everything that I am doing. I read, I read ahead. When I am asked a question in class, I respond, and then there are days that, like last semester, I don't know if it was because I was back at school and forgotten how to study. Or what. I pretty much messed up my last semester. I am on academic probation. I go from being top of my class in undergrad and graduating cum laude to being on academic probation for the first time in my life.

Uh there are days when I wake up and I don't know if I am burned out but uh, I don't know. This is what I wanted to do, this, I wanted to become a lawyer, and yet uh, I get in class and they are reading a case and the plaintiff is suing a person who happens to be their family about land or something like that and I can't relate to that. I can't do this. People are going to come into my office and be like, "I want to sue my brother" and my mentality now is that life is very short, very precious, and for them to be arguing over something so insignificant. I'm not engaged by the material, sometimes, and I find myself being bored and it affected me last semester. I would read something and be like "I don't give an F\$\# this" and throw and kick the books away and you know watch a movie or something. I find myself getting very angry, sometimes, because of financial 
situations. I know that I am supposed to be doing my work and, aww the hell with it. So I close the books. So I am very inconsistent.

Hard working, I would stay up, you know, actually, on Tuesday I stayed up all night working on an assignment. Turned it in on Wednesday at 11 in the morning. There are days that I can stay awake all night, dedicated, to do my work, and then there's days that I don't know if I got burnt out by the previous week or what. I just don't care. I skipped class today, all day all my classes, I skipped them. I guess it was one of those days. I woke up today and was like "man, I don't care" and then probably later that evening, I will wake up and "oh no, what are you doing, this is what I am supposed to be doing" and get back to it. I will catch up, and get ahead in my class again. So there's this struggle as a student. I am struggling and I have flash of genius where I catch up and I am hard working. I don't know if I am struggling still with the transition.

\section{Job security.}

For many veterans, going to college and graduating with a degree ensured a chance of success in the job market. James was clear in his assessment that graduating from college would provide him job security over others. He wanted to give himself a chance to be competitive when he didn't have any of the perceived characteristics that might give him an edge, such as a family. He felt that employers could easily make a decision to fire him, since he didn't have the commitments and could live on less money.

James. Uh, honestly the ultimate end goal is job security. I am more than capable of having a job, but the thing is, I'm not married, I don't have kids. So if we have another economic downturn, the guy with no kids and the guy not married with no degree is the first one to get cut. And that's, no matter how good you are, you could be better than the other guy and them be like, 'oh man, he's got like three kids to feed and this guy could go work at McDonald's and make the apartment payment and find another job so that's why I'm here. I want my degree for jobs. Whether it is that I move back up in the ranks in the military or get into what I used to do before (eco, tech writing, pols).

Ricky described a sense of relief that he would get from having "that piece of

paper" in his hand. The diploma signified that he would be safe and have the opportunity to, again, be competitive in the job market. 
Ricky. Just knowing that I need to get that piece of paper. As far as school goes, I really don't care, but other people seem to think that the degree is important, and they are the ones that are hiring. So I gotta get that.

Corporal and Jamie explained a deeper sense of fulfillment that would come from completing their education and providing for their families. By accomplishing the college experience, they would be competitive and self sufficient on their own. Jamie expressed it as not being a "burden" to her family and someone that her children could emulate. They expressed that in the military, they didn't have to worry about where the money would come from, but now they as veterans had to make those types of decisions for survival.

Jamie, in fact, shared that she joined the military for a particular job and career that she seeks following graduation. She connected her military experience directly to the job security that she would have with her top-secret clearance once she completed her service. Like the other student veterans, she recognized what she called a failing economy and that being a student made her competitive in her chosen field and occupation.

Corporal. Even hard to do for yourself, you know, when you go to the university the notion is that you are for self-fulfillment. The notion is that you are going to school for, you know, get a good job, raise a family, you know, whatever. There are common things: get a good job and education, you know. But in the military you aren't worried about "oh I'm making this money." The notion is that you have a purpose, you want to help others and serve.

Jamie. I went into the military with a set goal in mind, and um, I wanted a specific job. I wanted a top-secret clearance so that if I got out, and I didn't want to go to school, I could still make a good living. Um, but then, also, if I didn't really like that job, then I could get out and go to school and um it wouldn't be a burden to my parents or my family.

For me, being a student means, you know that I also want to be someone that my children can look up to. You have got to go to school to be competitive in this world. So a student, to me, means someone that is taking charge of their life 
and making a decision to better themselves and their family. Make themselves competitive in this failing economy.

\section{Military as an opportunity for college.}

The student veterans were thankful, in general, for the opportunity that their military service was providing for the rest of their life. Tony shared it succinctly by stating, "It's better to be a student than not be a student in college. You have more opportunities." James also articulated that, not only did he have an opportunity to see different parts of the world through his military service but also to attend college. Many veterans come from lower-income families that wouldn't have the resources to send a son or daughter to college, but military service opens that door. James also highlighted the benefits that he is now receiving, such as free medical care and retirement income that was also gained through his military experience.

James. I wouldn't say experiences, but I would say more, well there were a couple experiences, but let me get back to what I was saying before, the opportunities that I could travel, the benefits that I could get. There is no way that I could afford to go to school, my parents didn't go to school when I first came over here. So I mean, me being able to not work, and uh go to school and take a full course load like I wouldn't be able to do that without the military. As far as, um, you know, that really helps out.

Frank spent time in the military as a helicopter pilot and shared that the time in the military was completed when he wanted to go back to school. As a 36-year-old father of three, he expressed that he also sees the opportunity to be in school that his other students may not fully take advantage of. He described the opportunity as giving him a sense of purpose to complete the degree that he had set out for himself the goal of gradating. He also explained that he was aware that he was lucky for the opportunity to attend college, because not everyone has the necessary resources or desire to complete a 
Bachelor's degree.

Frank. I didn't want to continue to fly, so it was, you know, go back to work or go back to school. Well, it's meaningful because it's a great opportunity that a lot of people take for granted, especially the younger students. I find that they are here because mom and dad told them to and they don't, they aren't dedicated and uh they don't take it quite as seriously and uh. I find it meaningful because I am doing it and I am able to fund it because of the work that I did prior to get to where I am at, so I appreciate it a little more and won't take it for granted because I know that there's many people that don't have this opportunity that wish they did and there's people that do have this opportunity that wish they don't. So it's definitely the opportunity that I really appreciate.

Wale, like Frank, expressed a sense of gratefulness that being in the military allowed him to have the opportunity to come back to school. He also articulated that he saw himself completing a journey that started when he had dreams as a boy. He may not have expected the time in the military but it was because of that that he was attending the university and receiving his education.

Wale. It's very meaningful. It holds a huge meaning in my life, you know. Like coming full circle. You know, you graduate high school and then you are off to the military. And then once you have done that, then you go to college, you know. I'm kind of completing my what I figured for myself when I was younger. Maybe I wasn't planning on the military, but I knew that I wanted to go to school and, um, challenge myself. So it's definitely come around full circle. And I am thankful for it.

Addison expressed that coming from the military and now being a student allowed her the opportunity to get back to some of the causes that she is passionate about. She shared that her ultimate goal was to be a physician's assistant because she was a medic in the Army. The military provided her an opportunity to come back to school to be involved and to also fulfill her career goals.

Addison. The fact that I am actually back in school. Um, is good for me. Um, being a student, I am able to participate in organizations. I am in Habitat for Humanity, um Colleges against Cancer, um and then the Health Occupations Students of America. I want to go to PA school. 


\section{Identity As a Veteran}

Student veterans have their own understanding of who they are as veterans and where they fit into the setting. I asked each to describe for me how they would characterize themselves as students. Nearly all of the student veterans expressed a strong sense of pride in what they had accomplished in the military and what the service meant to them as they transitioned back into civilian life. In addition to pride, I determined three other distinct themes that veterans were able to share about themselves as veterans namely returning to the military, everyone should serve, and not feeling like a veteran.

Stemming from a sense of pride, some student veterans wanted to return to the military if they were not successful with their civilian aspirations. The underlying tone of a sense of pride also manifested itself in that student veterans shared that they thought that more civilians should serve in the military or some type of duty for their country to give back. Some student veterans felt that they didn't do enough in theatre to encourage the title of veteran and be considered with those who fought in previous wars.

Pride.

The sense of pride that the student veterans expressed during the interviews was palpable. All of the student veterans spoke of how their military service provided them with a feeling of pride that they answered the call to protect the country. For me, I noticed that when the student veterans spoke of the pride that they felt in being a veteran, their tone of voice would become firmer and more direct.

Frank, the 36 year old, expressed the idea that he was proud that he became an 101 
officer. He also shared that in multiple circumstances, he went above the call of his particular job description to volunteer for difficult and often dangerous missions. By becoming a sniper, he set himself apart from his fellow service members to achieve greater status in the military structure. He also set himself apart from those in the military who are in because it is their last resort to stay out of prison. He was clear that he was in the military for voluntary reasons and not because he wanted college money.

Frank. Proud, definitely proud of my accomplishments when before I became an officer and before I went to flight school, I was always to of my peers always volunteering for tougher jobs. I was sniper and a scout for my platoon for quite some time and that was a very competitive job. It wasn't some job that you could show up and say, wow I want to be a sniper. You had to do so many series of tests and evaluations, and it was a tough position to get, then once you got into it, it was very demanding and people expected a lot out of you, and uh you know, I am proud of all that. I am proud for the fact that I was selected over my peers for those jobs and positions, and a lot of that goes back to being dedicated, you know I was amongst a lot of soldiers that had the attitude "well I am here because the judge said I had to be here" or "for college money" or they were here just because they didn't have anything else to do. I was definitely there for voluntary reasons, and I was proud to be there. So I guess proud.

Jamie was also proud of the time that she spent in the military. She also expressed the desire to be associated with those soldiers who joined voluntarily for the service of the country and to grow as a person, not for college money. She had a long line of former service members in her family, and serving also provided her pride that she was carrying on the family tradition. At 29 , she was rather unique in that she joined before the Trade Center bombings on September 11, 2001. She stated that because she was figuring her life out, she didn't anticipate going to a war zone. Despite the pride in her grandfather serving, she received negative reactions from her mother in regard to her military service. 
Jamie. I take great pride in the fact that I got out of the military. I did my five years, and I got out. Some people might so that I just went to the military for college money. It's not necessarily that I went into the military for college money. I didn't know what I wanted to do when I was 18 years old.

My grandfather was in the Army, the Air Corps, and afterwards he worked for the DEA. So there were certain things that I wanted from the military. I think that I successfully completed all of those. I am doing what I meant to do. Well I joined the military before 9/11 happened so it wasn't a choice of "something bad has happened to our country so now I am going to go in and support it." Like I said, my grandfather was in the Army Air Corps, and I needed some direction. I took it upon myself to join the Army. My family was not happy about it at all. My mom was very upset. You know, before 9/11 happened, I was like "oh I'm not going to war, nothing's going to happen." Then 9/11 happened, and she was really mad at me.

Like Jamie, Wale also shared that he felt a sense of pride in his military service associated with his family traditions. He had a family member in theatre since World War II, and carrying on his family military service was a point of pride for him. He also described a sense of pride because he was able to return home where some of his unit members didn't return home. He stated that he remembers his reactions to the family members when their loved ones didn't return, and that by being proud of his military service he honors them everyday.

Wale. Everything about being a veteran is meaningful, in every sense of the word. I've had a relative be a part of a war since WWII, and I've had some uncles die. You know the Battle of the Bulge; I had an uncle die and another uncle die in Korea. That's kinda, you can't take none of this stuff with you when you die, but while I am here on earth, that is one thing that I can celebrate is like you know. It has been a part of my family and of my life since way back. I am definitely proud to be an American, you know, and every aspect of it. That's one thing that I hold near and dear to my heart just because some guys didn't come back, didn't make it back. I actually saw that, I saw their families react to that pain, you know. So I try to remember that every time, whether I'm having a good day or a bad day, you know, or whatever.

Charles and Viktor were also proud of their military service and how they were able to give back to those who either didn't fight in the war or those suffering from the 
effects of war. Charles specifically spoke to the fact that he was protecting civilian freedoms and the constitution by fighting in this particular war. He shared the sense of doing what others would not because they want to live like rock stars. He described that he was different from the average person because he protected the rights of the people, even if they may or may not be aware of them.

Charles. I feel very proud of myself. 'Cause even if it's giving them to someone that's saying something that I don't believe in I find myself being humbled because I'm like "you have that right." I didn't give it to you, but I am protecting it. I'm protecting it for those four years that I was in. Guys like us we are very, I don't know, it just feels nice to be able to secure something like that. Whereas people we just want and want and want and their thoughts and desires. They just want, want to live like people that they saw on TV who have a reality show because they are rich and famous. Um, I want to live much more simply than that. I actually care to live by the ideals that I decided to protect. I am very proud to be a vet.

Viktor shared that the time he spent in theatre allowed time to be able to bring peace to people who were caught in the crosshairs of war by no fault of their own. He expressed that he realized the risks but that those didn't matter as much because he was in those areas to complete a mission that would bring peace and diffuse live bombs.

Viktor. Proud. I felt like what I did had meaning. I would go to those places and, we went different places, and when we were in .... it's funny especially in the contemporary. You're going to get shot at, that's just part of it, and my job was to do something peaceful in that entire environment. Proud-- proud of what I did, proud of who I am, that there is something that is bigger to me.

\section{Returning to the military.}

Some of the student veterans expressed a desire to potentially return to the military after they completed their degrees. James, Jamie, and Corporal all shared that they would be interested in returning to the military. James saw the military as a potential fallback if his degree didn't work and get him a job. Once he finishes his 
degree, he will be eligible to change from an enlisted soldier to an officer. The military structure gives officers more prestige and income. As he mentioned himself, as the red headed stepchild before, he strongly explained that he would be an officer to find his niche in the military.

Jamie and Corporal also shared that both of them have given thought to returning to the military because of the structure and purpose but neither of them was as adamant as James.

James. I have absolutely thought about going back to active duty, I just want to finish my degree, yeah like I'm going to get a job or I am going to go back to the Army. I am going to stay Reserves. I still have 6 more years left on my contract, so uh. I'm going officer; they won't promote me as an NCO, so I'm going officer.

Jamie. I loved the military. I loved being in the military. Sometimes I think about going back.

Corporal. Some of the similarities that you find, having that sense of purpose so much anymore and that lasted a long time so much so that I considered going back into the military. That didn't happen.

\section{Encouraging military and civic service.}

Student veterans, in different ways, expressed that they felt that most Americans if not all should participate in either the military or some other sort of civic duty. Jamie and Ricky said that everyone should have to do some duty for his or her country. Jamie discussed how if "kids" were expected to perform some type of duty to the country, that they would have a better appreciation for what they had and also figure out what he or she wanted to do with their lives. Jamie followed the path to the military because she didn't know what she wanted to do when she was 18 and because it worked for her, it should work for everyone. Ricky, while on the same message, took a different approach by encouraging a sense of pride and camaraderie that he experienced by his military 
experience.

Jamie. So I mean it means a lot to me for people to do a civil service. Whether it's the military or the Peace Corp. I think it should be mandatory for kids getting out of high school to do a minimum two-year civil service to their country. Ultimately to grow up and mature. I don't know anybody that is 18 that really knows what they want to do. so save time and money and you can also find yourself. A sense of self in doing something productive.

Ricky. I know that I did my part. Like one thing I said a long time ago before I even started thinking about joining the military was "I think that everybody should have to serve their country in some way, military whatever. Everybody should have to do something and I know I can say that I did that."

Even though Tony did not advocate for every person to be required to participate in military or civic service, he does advocate for others to volunteer. Like Ricky, he touts the camaraderie and sense of pride that he felt when he "fought for the country."

Tony. I am glad to be part of that group to be characterized as a veteran who fought for the country. We need people to volunteer. I know it's cliché and all, but you are signing away a portion of your life. Your commitment keeps other people from being forced to fight in a war.

Charles. As a veteran, I know that I answered the call of war. You know I didn't want to fight, I don't know, I didn't want to have to die or kill someone but there's people that can't fight. There are people that won't fight, the pacifists. I needed to fight for them and I sacrificed for them, even if they don't know it. You know I will be at a bar, and they don't know, but I'm like, that's cool, you are having a beer because you can, because there's guys like me that are willing to go out there. And something that I am very proud of and I keep it to myself.

\section{Separation from self- perception as a veteran.}

Addison described how she didn't feel like she was a veteran unless it is brought

to her attention. She was able to articulate that she knows what other veterans are managing as they transition back to civilian life because she has gone through what they have in the same way. However, it was difficult for her to take the identity of veteran and apply it to her everyday life. 
Addison. I guess I don't really think of myself in a sense as a veteran. Unless, I see like that Lubbock House for Heroes and I saw that and was like "oh that is really cool, and I'd like to help with that next year." I e-mailed them and never got a response. So in that aspect, I share with them what they have gone through and you know, seeing that brings up the veteran thing. But other than that, I don't really think of myself as a veteran.

Charles described himself as a veteran; however, he didn't think that he was on

the same level as those veterans who had fought in earlier wars. The battalion he was a part of lost many of its members, but he didn't feel that he was a true veteran who had seen the same carnage of those who had gone before. He didn't see as much death and therefore in was his opinion that he wasn't a true veteran in comparison. He went on to describe how he has to be told that he did well instead of internalizing the impact that he made in Afghanistan. He expressed that the Viet Nam veterans deserved more recognition for what they experienced in war than what he accomplished.

Charles. My battalion lost 21 guys. I didn't think anything of it because of my mentality of Vietnam style where "20 guys get killed in one day" so with my mentality, I'm like, 'I'm joining, I'm joining Infantry so I'm going to get killed. I'm going to see a lot of guys around me get killed" and a lot of guys did die, but it wasn't to the level in my mind it wasn't an Iwo Jima . . . thousands of dead Marines on the beach. It wasn't like that, but so in my mind, I don't feel and I still don't feel that I, you know someone says I'm a WWII veteran and I was in Iowagima and or Okinawa. I am in awe of them they are my heroes "I'm like you guys went through some shit" and some ways, I'm in Vietnam.

As a veteran, I see myself not at their level, yet I have had people tell me when I get back, other Marines say "man what you guys did in Afghanistan," . . . it was like two years, I was about to get out, and um, some other Marines had gone as a combat replacement and had just got back and said "dude they still talk about our battalion over there, what we did, we paved the way and camp 546, oh it's camp 234, it's no longer just 12 tents, it's a mini little city from where we push out" and I'm like, wow, I was there when there wasn't any internet, and um, we had two satellite phones and one worked and one didn't so people talk to me like that are I'm like "alright, cool" I appreciate the compliments and when guys say that I am badass I'm like, "thanks I have to take it as a compliment," but at the same time I'm like, but there are guys that do deserve more recognition like the Viet Nam veterans that came back. 


\section{Identity As a Person}

\section{Service-oriented.}

Student veterans also wanted to help other veterans and their friends. The overwhelming need to help and let others know that they were available to evident in many of the student veteran interviews. As mentioned above, student veterans saw the time that they spent in the military as a way for them to give back to their country. The natural transition for veterans transitioning back was for them to continue to help and be a source of support for both other veterans and their friends and family.

Wale compared the struggles that he has seen with some of the soldiers returning from theatre to his own struggles. The sense of wanting to help his buddies who have the invisible wounds of war drives who he is as a person and how he interacts with others.

He then used the satisfaction and fulfillment from these interactions to help heal himself.

Wale. Active in the community of veterans. Always looking for, you know, to help another veteran. I'm one of those guys that you could always call. You know, whether it just to talk or whatever. I don't have no kids or no wife or no nothings or whatever so it's just me. So I am always available. I tell my buddies, "hey." I know there are some, especially my infantry buddies, you know, because, you know those that really saw combat, that lived the front line. It's a lot harder life than those who were a dental assistant or something because that. My infantry buddies, well, most of us, we saw combat we carry ... . um . . . . we carry a big elephant on your shoulder, you know, sometimes you know. Some guys walk out of there fine with no scrapes and no damage. Other guys walk out of there, regardless of whether you could see it or not, just wounded. So I think that's why it's important that every vet that I talk to I try to get sense about how, about who .... they are doing and about how they are coming across. That way I can help, to push them toward help but you know. I need help myself, you know what I mean. I just try to keep balances as much as I can myself. When talking about how combat veterans return to the states that he needs to help them in the best way that he can with his capabilities.

Addison also thought of the military when she described being a helping person.

She was a medic while she was on active duty, which lent itself well to being a helping 
and caring person in school.

Addison. Um, you know, I'm caring. As far as the military aspect, I was a medic, so that was the nature of my job as well as the nature of my future job. I'm organized. I like to think that I am pretty happy-go-lucky.

Like Addison and Wale, Ricky also attributed his helping nature to what he learned in the military. He additionally looked at helping as something that he was required to do as a job and mission in life. His helping has extended to his classmates and friends. He defined himself and was proud that he was the person to whom people in his life could turn for support and help.

Ricky. As a person, I guess, I'm the kinda guy that will take care of people. That kinda covered the military. You know, I have helped people out with notes and stuff in school. Uh that's me, I'm the guy that takes care of people. You look at my friends and ask them who is the one that always takes care of them, and the answer is me. I am the one making sure that people have a safe ride and all that. You know, that's me, that's my job.

James and Charles also defined themselves by how they help others in situations.

James shared that he would give something simple such as a pen or pad of paper or something more demanding of his time. James discussed a certain situation where he drove for eight hours to help a friend who needed a ride, and no matter what time of night he would wake up and pick up friends who needed his help. Charles also shared that he felt that he was helping his fellow classmates and making himself available to others.

James. I am real flexible I will bend over backwards for some one if a someone calls me at 3 in the morning and I am already crashed out and they need a ride, I pick them up. like you know if someone forgot their pen or pad you know I would given them my extra pen or pad, and I won't even ask for it back, I won't ask for a dollar. I mean back I mean when I was living in Corpus when I could afford it when I didn't have a truck, I had my Honda you . . . . someone know that would need me to pick them up at the airport, you know in San Antonio, like a two hour drive, and they let me know the day of you know I would do it. Yeah, I don't have anything going on, I will drive. I mean even when I was living in El Paso, like while I was in the military one guy called me, and he was on the border patrol, 
and there was a training station about 4/4.5 hours away from El Paso and he needed to get to the airport, and all the rental cars were booked because it was a town of about a hundred or something. The biggest part of the town was the border patrol training station. I drove out there, picked him up, and you know what is that like 8 hour/ 9 hours out of my day? You know, just like nothing. I gave up my sleep time so he could get on the airplane, you know.

Charles. When fellow students ask something I am very polite, "oh yeah the reading assignment is this and that," "oh sure, I will help you out;" you know print it or make copies of that, you know.

\section{Positive perceptions.}

Approximately half of the student veterans described themselves in a positive way.

Jamie used words such as honest, having integrity, honorable, motivated, and dedicated to describe her positive self-image. She, like Charles and Frank, portrayed a sense of being easygoing and having an ultimately positive perspective on life in general. Charles expressed the idea that he is able to see all sides of the issues and respects each person's point of view. He shared his desire to be a normal citizen in the world. He wanted his actions to speak for him instead of the words that he says. He discussed that he didn't want to feel different from any other person, and he was just like everyone.

Charles. Really easygoing except for some stuff that are just straight up wrong, I let things slide. People say some messed up things to me, sometimes people do some dumb things. I just let it go you know. As a person, I'm just living day by day. I have dreams and inspirations like everyone else. There's not much that I want. I want peace. All these things that I get to enjoy I want everyone in the world to be happy. I hate it when people are . . you know they say that the political climate in America right now is very hostile, and I'm like why. I'm neither Democrat or Republican. I hear both sides. I'm like 'that's a valid point...oh you are getting crazy right there and again; that's a valid point...oh you are really getting crazy right there, now shake hands." I just want things to be happy. I'm not trying to be a millionaire, but as a person I'm just normal ordinary citizen. I just hope that the few days that I do have left on this earth that people remember me for my actions, not my words, because I joke around a lot, and I poke fun at everything. I poke fun at everything. I raise eyebrows all the time, especially on my Facebook. It's not that I have lost my faith, like freedom of speech, baby. The fact that I offended you offends me, so how does that make you 
feel. So it's not my actions, I mean my words that I want people to remember me like. It's my actions. Other than that, I'm just not that much different from me or you.

Frank also shared the opinion that he was optimistic with the situation that he is in now because of the time that he spent in the military. He discussed some of the experiences in the military where he would be left out in the field for days with no support and in inclement weather. He stated that in those situations, everything would work out. Therefore, he has transitioned that thought process into his day-to-day life in how he views the world. The perspective to persevere and succeed was fostered in Frank by his service in the military.

Frank. Well, I have a perspective on life that no matter how tough it gets, it always works out. You are always going to work out. I always have that attitude. I think a lot of that has to do with my military experience and training, there were some situations where, especially when I was enlisted, and I was a sniper, we operated in two-man teams, and you know, there were times that we didn't get forgotten out there, but they couldn't get back in to uh get us out. And there were situations that we went in with supplies for a three-day mission, and for twelve, and it didn't matter how bad or cold or wet the situation got, it always worked out, we were always going to be taken care of there was always a way out and uh I guess it's made me like today uh look at life that no how bad it gets, that situation that day itself, might suck pretty bad but things always get better and things are always going to work themselves out.

\section{Frustration.}

Although half of the veterans viewed themselves from a positive viewpoint, some veterans did not have the same favorable opinion. Because of the stressors of being in the military and having to transition back to college life, both James and Wale felt frustrated and worn by the demands placed on them. James had transitioned from another school, where he was having difficulty with the faculty and staff. He mentioned how he was struggling to find a balance between the times that he is in a bad mood and 
the times where he is able to maintain healthy relationships. He admitted that most of the time, especially last semester, he was in a bad mood because of the situation that he had to endure and that he wasn't in a good place to socialize or transition to this institution. Wale also felt the burden from his military experiences in addition to his childhood experiences. He stated that he had "been through a lot" throughout his life. The time that he spent away in home from training and getting sent to war were especially difficult for him to manage.

James. Um, really depends on when you find me and how you find me, I mean you meet me in a bad mood, and I am an asshole, and - but I mean, but most of the time, last semester was a whole other story, I had just endured a whole load of crap, and I was a mess back last semester.

Wale. As a person, um I mean, it's easy, I mean, what's it called when you've been like worn, like a person who has been through a lot. That's what I have been through. Being a veteran, and um, the certain circumstances that follow, you know, being a veteran, you know, not being home a lot.

\section{Kegan's Orders of Consciousness}

As mentioned in the literature review, Kegan's $(1982,1994)$ constructivedevelopmental theory provided the framework for understanding "both the construction of an individual's understanding of reality and with the development of that construction to more complex levels over time" (Berger et al., 2007, para 1). New information is added to a person's experiences, which in turn, leads to a transformation in the way the person knows those things. Student veterans, in this particular study, are not only older than the traditional-age student but also have experienced war. Berger et al. (2007) suggested that a person's current place in the journey of transformation is based on the experiences he or she has been exposed to and how the person has chosen to pay for 
those opportunities. Those experiences have shaped the way student veterans understand their surroundings and thus make more complex meaning from the uncertain world.

Many traditional college students are in the third order of consciousness in Kegan's theory (Baxter Magolda, 1999). The third order of consciousness is categorized by the person's perceptions of how others' opinions and expectations of others impact how the person thinks, behaves, and feels (Berger, et al. 2007). Kegan characterizes the third stage as the socializing stage, through which many adults (between 5/9 to 2/3) make meaning in this stage. In this stage people are their relationships instead of having relationships. Many in this stage are concerned with being normal and fitting into others' expectations of their identity labels (Abes \& Jones, 2004). In addition, those in this stage have difficulty seeing "relationships between or among their multiple identities" (p. 619).

In Kegan's fourth order of consciousness, “adults come to coordinate their multiple roles and the different expectations other people hold for them within their own self-generated, relationship regulating framework" (Berger, et al., 2007, para. 17). This stage is characterized as the self-authorship stage. Relationships, during this stage, become part of a person's world instead of the reason for the person's world. According to Kegan $(1982,1994)$, persons are able to take ownership of their internal authority and establish their own set of values and meaning. It is important to note that no stage is inherently better or worse, but that they shed light on how a person makes meaning based on his or her understanding of where he or she is in the process of meaning making and growth. By knowing where a person is in his or her meaning making structure, we are able to examine the fit of his or her capacities to make meaning and the demands that are placed on him or her from the outside world (Berger, et al, 2007). 
Excerpts from the student veterans will highlight the third and fourth order of Kegan's theory. Student veterans varied as to which order they belonged to or if they were transitioning between the stages. Kegan posits that while his model is hierarchical it does not imply that a person is either one order or another but that they could be transitioning through one into another. The story of Charles illustrated the third order of Kegan's theory transitioning to the fourth order.

Charles stated that he interacts with other students but that he has to separate his two identities from being a veteran to being a student here on campus. He felt that both of these identities couldn't coexist because of the nature of each of the positions that he held. One was a combat situation where he was required to maintain a heightened state of awareness while the other is a university setting which is more relaxed. With the third order of consciousness, people are able to make meaning based on the mutual reciprocity between social relationships (Berger, et al., 2007) which he demonstrates by stating that he just wants to be normal as a student. He doesn't want to stand out and expose his military identity because the two are not alike for him.

Charles. My attitude, um, I am very friendly with them. I am not one of those that's like 'oh those nasty civilians, you know. I let them do what they want. I joke around with them. I blend in with them, as much as I can you know. That was a professional job that I was doing and it's you can't have that attitude out here. Uh that mentality, I'm two different people sometimes. I am Charles and the guy here in school is completely different from Lance Corporal Charles, you know, the assault man whose job it is to breach and be the point man. There is a different, you go from, I'm here, I'm a regular classmate. They are like 'oh yeah yeah you were a Marine you guys were badass and I'm like "oh yeah, yeah" and joke around and whereas when I was on patrol, I'm a different person. So the attitude that I have towards them is that I try to be as normal as a student as I can be. Um I will talk about schoolwork and I try to be just like them, not like the other side of me. So I tend to look away because there is no need for that side of me to come out because it's not war, it's class. Yeah, I joke around a lot 
Charles continues that the label of veteran came with a certain set of expectations about who he was as a person. He associated his clothing with either being a Marine or from his undergraduate institution, as enough to separate him in his identity structure. He felt as though by wearing those types of shirts, he was crossing the boundaries between the multiple identities that produced some anxiety for him. Later in the paragraph, however, he seemed to transition to the fourth order of consciousness by stating that he doesn't care what people think of him. Individuals in this stage are prone to rebelling from what is expected of them, and Charles does this by the amount of attention that he places on the opinions of his classmates. Yet, he still seems to be unable to integrate his multiple identities of a student, veteran, and family member when he talks about how different he is around his family versus the students. The identities and meanings from those that he draws are separate, and although he expressed his own authorship in that he doesn't care what others think, he is unable to transition that into integration.

Charles. It's not like I'm walking around with a very short haircut and a shirt you know that says "born to kill" on it or anything. This is how I dress, just throw on some khaki or throw on some jeans and a t-shirt. Occasionally, wear a Marine Corps shirt or hat because it's laundry day or it's the first thing I grab. I don't know, you know I'm not wearing that to remind people "oh hey I'm a Marine, watch out." No, it's just a piece of clothes. You know, I grab a shirt from my undergrad, and it's not because I am crazy about my undergrad but you know it's my alma mater, that's where I went, and you know, so I don't know if they are afraid or if they feel that stereotype. Well actually I don't care. I could care less. Let them think whatever they want. I have a mission to do and my grades and if they want to think I'm crazy. Well you know and uh then they get to know me and oh your not. And then they do get to know me, and you are who you are when you are joking around. So I'm like an onion. I have all these layers and I let them see what I want them to see. Um, for my family, I am very soft and very warm person. I am very good with my nephews and nieces. I joke around and they think I'm a big teddy bear. Classmates, you know, depending on if we are debating then you are going to think that I am this smart pants that likes to show off and like 
wants to win the argument. But my friends, when we are out at a bar, they are going to see the joke-around Charles. They will see me being goofy and being a perv just like any other 27-year-old guy. Everyone gets to see something different and, uh, and I treat them how; depending on what group they are in, in my life. If that's the group of classmates that I don't talk to, then I am just going to be quiet.

Corporal echoes Charles'statement that he doesn't feel that he is a corporal anymore, and that identity for him no longer exists in the world that he is in now. He sees other veterans who have returned from war, but those people are different from who he is now. People in the third order make meaning in part through the social relationships they feel are set by others. Corporal mirrors this when he states that veterans are on the corner, those who are disenfranchised, or those who are invisible to others. He goes on to say that he was a Marine but now he is a student. These two are separate and he didn't elaborate further on how they were connected. However, the choice of his pseudonym as the rank that he was in the military when he left would suggest that he does make meaning based on his experiences in the military.

Corporal. There are different spectrums, there are veterans that you see on the corner, you know, come help me out, and there are the unknown veterans that you are sitting next to and you don't even know it in this class. Oh I'm not anything anymore; I am not a corporal anymore. Even when I see older veterans, I think that what they went through was even tougher than what I went through, so if I am doing it they better get up and go do it. I know I wanted to be a Marine and I figured out when I got out that I don't know what I am going to do next, but I am going to go to school, and I know that much, and I will just go to school, and I will figure it out. If anything I need to do something positive, and school is that.

Corporal continues that the ties he has to the military are still there, and he makes meaning based on those, but the longer he is out of the military, he sees those fading into the background of his meaning making structure. He expressed that it was necessary for him to separate those roles so that he could take on his new role as student and ultimately 
a working professional. His age seemed to play a large role in how he developed

meaning based on his two separate roles, that 30 years old was a defining age.

Corporal. Problem is you have stronger ties to those things that are closer and have affected your life more recently. I got out, and the ties are still strong, that's it, the ties are still strong. But when you start talking about "well, it's been years" then you can't hold onto that anymore. You have to move towards something that is good. You always need a good foundation, but you can't stay on the first floor, you know you want to build, you want to add four or five stories. So it's kinda a hard line to walk when you get so far, yeah I was like I was over there and ok, yeah you did something but now you have, what now. Ok, for me, that's not it, that's not enough. OK, so you went to the military, you went to Iraq, ok cool. Now you have to move on. You are reaching 30, what now.

Ricky shares Corporal's sentiment that he is proud of the role that he served as a veteran, but that does not define him as a person. He is able to separate the different roles that he has played throughout his life and those share in making him who he is today as a person. In the transition to the fourth stage of Kegan, Ricky shares that he is able to take those different parts of his reality and self-author who he wants to be as a person. The fading away of the veteran identity, also shared by Corporal, suggests that he is adopting the student role to further make meaning from his situations.

Ricky. I think if people didn't know, or I didn't tell them, that people wouldn't know that I ever served. I mean it's I'm not; I don't like to throw it in peoples' faces and what not. I'm not, I see myself as just me. Not as a veteran or as a student. I'm the same person that I was before I joined the military. I am the same person that I am when I am out. I don't even know. It's just I did my military thing, and I'm proud of it, but that's not all who I am. I do identify with it a lot still, because I did just get out, you know. It's been only 6 months or so. I still have a lot of military mindset. But the longer that I am out its kind more of that fades away, and it's just me being me again. It's like I said, I am the same person I was before I joined and just because I served some time in the Army. Yeah, I am a veteran, but you know, it's just one more. You know, I used to be a bartender and I don't identify myself as a bartender cause that was part of my past. I used to be a lifeguard. I guess everything that I have done has made me who I am right now, but I don't see anyone of those being my identity. Just chalk it up to another one of life's experiences. 
Jamie also is in transition between the two stages. Whereas, she portrays Kegan's third order of consciousness by wanting to fit into the social structure and not have students in her classes treat her any differently. She didn't want the only thing that other students would know about her to be that she had been in the military. Her student identity was the dominant role from which she made meaning from her current situation. With the fourth order of consciousness, people are able to make meaning based on a deconstruction of the different identities that are then rebuilt to form a newer integrate meaning from their experiences (Berger, et al., 2007), which Jamie demonstrates when she discusses that she is not able to separate her two identities, and that those two experiences have influenced each other. She connects the two different roles in how they relate in a larger social structure.

Jamie. I don't think that I go out and portray first thing that I tell somebody is that I am a veteran or that I went to Iraq. It's just not something that I disclose. It's not that I am ashamed or embarrassed of it. You know I don't want them to treat me any differently because I have been overseas. I don't know. I think that as far as identity is concerned I don't separate my student identity from my veteran identity. I think that the experiences that I have had have made me the person that I am. I will continue, you know, the experiences that I get in college, will further my overall character makeup, I guess. And it just adds to it and adds to the mosaic of myself, that makes up me.

Wale also demonstrates the transition from the third order of consciousness to the forth because each of the roles he has played influenced how he is currently makes meaning. Wale expressed that being married also formulated who he was today, in addition to his military and veteran experiences. He discussed how he uses the skills that he learned in the military to help him succeed here in college. He goes on to share that the social roles that he has developed allow him to exist within a larger social structure and be happy and thankful. 
Wale. Cause you know I have been married but that didn't work out for me but that's just formulates who you are now. That formulates who it allows me to be, the student. Being the veteran allows me to be the student I am now. They kinda work hand in hand. Being a veteran and now becoming a student, being a veteran gave me all the skills outside of the classroom that I can depend on to, that allow me to succeed in the classroom. So I just built upon those skills while I was in the military, you know, and now I just utilize them in every aspect that I can, you know, from the military. When you go from such hardship of combat to, you know, to school life, you know, the hardest thing is just being able to walk into a classroom and just be happy, be content, you know. Uh, and that's what I try to do. That's what I try to do, every day I get up and go to work and go to school. I try to be happy and thankful.

Viktor is on the verge of the fourth order of Kegan's theory by saying that he cannot separate his student role from his veteran role but then realizing that both are part of how he makes meaning from the world today. They are both part of who he and, how he constructs meaning from the world. He also includes those roles that he played from before he was in the military. He reiterates Kegan's perspective, that a person's current state in the journey between stages is based on the opportunities that the person has had to shape how they make meaning from the world (Berger, et al., 2007).

Victor. Trying to separate, trying to separate my identity as a person is difficult. They are all me, and at some point I don't know. Parts of my history are written on me and that's just because they will always be, in the Army those experiences became a part of me and they always will be, you know because I think they are intermingled. You can dial it all the way back to growing up and the values that you took into the military with you and what they did with those values that make you the person.

\section{Summary}

The results of the research offered insight into the perceptions of student veterans regarding their identity and meaning making structures as they transitioned from the military to college life. The fourth chapter presented information from the in-depth individual interviews of each of the student veterans. It also included the insight of the 
researcher after the interviews were transcribed and their thoughts put into specific themes. The results identified several themes such as maturity, camaraderie, frustration with the college experience, structure and routine, invisibility and isolation. In addition, the research explored how student veteran viewed himself or herself as a veteran, as a student and as a person. Finally, the use of Kegan's Order's of Consciousness guided a review of the student veterans meaning making structure. In all, student veterans should be view as individuals at different stages of their development and different views on the campus community. In the next chapter, I will present a discussion of the findings as well as implications and potential future research.

\section{Chapter V}

\section{Summary, Implications, and Recommendations}

In this chapter, I will summarize the results of the research. This chapter will also include a discussion of implications for theory and practice. In addition, I will provide recommendations for future researchers and university officials working with student veterans.

\section{Summary}

This study was conducted on the perceptions that student veterans have of the transition issues, identity, and meaning making that they encounter on a college campus. To determine these issues for student veterans, the following questions emerged including: What perceptions of meaning making do student veterans have of their 
military identity? In comparison, what perceptions of meaning making do student veterans have of their student identity? And what is the role of meaning making in the construction of veteran identity and its interaction with other dimensions of identity, namely student identity?

The purpose of the study was to build a better understanding of the transition issues, identity, and meaning making as it relates to the transition into university life of student veterans. The secondary purpose of this study was to increase the knowledge base about student veterans in the university setting.

In order to answer the research question, the participants consisted of 11 Operation Iraqi Freedom (OIF) or Operation Enduring Freedom (OEF) combat veterans who were attending the university. Each of the participants had experienced combat situations while they were deployed and in theatre. The participants ranged in age from 27 to 33. Each of the participants resided in the Southwestern region of the United States. The participants identified themselves as Caucasian, African American, and Hispanic. Nine men and two women participated in the research.

The perceptions of transition issues from this study are divided among the following five themes: (1) Maturity, (2) Camaraderie, (3) Frustration with the College Experience, (4) Structure and Routine, and (5) Invisibility and Isolation. The first theme concerns how student veterans perceive they are more mature than their fellow students because of their age, how they deal with stressful academic situations, the lack of respect shown to others, and how traditional age students do not seem to value the little things in life. The second theme is an explanation of the sense of togetherness that student veterans perceived among each other but not with fellow students and noncombat 
veterans. The third theme describes how student veterans felt frustration with their college experience on various levels including: system-wide, professors, and academics. The next theme of structure and routine characterized how student veterans were able to transition from a structured environment with a specific routine, to college life that is more flexible with time and commitments. The fifth explores the invisibility that student veterans perceived at the university. The isolation was either internal or external. For example, either fellow students did not recognize if they were veterans or if the veteran did not disclose that they were veterans.

The findings from how a student veteran described himself or herself as either a student, veteran, or a person are divided again into themes. Student veterans described themselves as students with the themes of determination and focus, job security, and military as an opportunity for college. Theme one was described by veterans in that they were much more willing to do the work necessary to be successful, and they did not allow outside influences to affect their school work. The second theme of job security detailed how student veterans perceived that by going to college they would be more marketable when they were searching for a job. The final theme with how student veterans identified themselves as veterans was in their view that the time they served in the military provided them an opportunity to attend college.

The themes associated with how student veterans viewed their veteran status included; pride, thoughts of returning to the military, encouragement of military and civic service, and then not identifying as a veteran. The first theme of pride was communicated by a sense of self-resect that each expressed that their military service gained for them. The second theme of returning to military service stemmed from both 
the expression that they enjoyed the time they spent in the military and the security they felt in the military versus here in their college life. The next theme is that student veterans felt that others should take part in giving back to their country through either military or civic service. Lastly, some of the veterans interviewed did not constantly view themselves as veterans and perceived that phase of their life had ended.

Student veterans then described how they viewed themselves as persons with the following themes: helping, easy going, and frustration. The first theme of helping was expressed in that student veterans always wanted to help those around them whether they were fellow students, family, and/or friends. The next themes of easy going and frustrated was felt by student veterans as a perception that "everything is going to be all right' or 'things bother me more than before."

Last, student veterans' comments were evaluated based on Kegan's Orders of Consciousness. Many of the student veterans exhibited thoughts associated with a transition between the third stage and fourth stage. The third order of consciousness is categorized by the person's perceptions of how others' opinions and expectations impact how the person thinks, behaves, and feels (Berger, et al. 2007). Some student veterans expressed their thoughts that they were concerned with being normal and fitting in with the other students. Those who did not want to fit in with their fellow students were approaching Kegan's fourth stage where they began to self-author. Relationships, for these student veterans, were part of the student veterans' world but not the reason for it.

Through individual interviews, these different themes developed a clear and powerful understanding of the experiences that are felt by veterans as they attended college after their deployment experiences. The information garnered should assist 123 
counselors and university personnel in their instruction, support, and attention toward student veterans. Seeing the need for further research in this area was the stimulus for this research study. The findings from this study provide those insights about the perceptions of those student veterans.

\section{Implications for Theory and Practice}

Kegan's Order of Consciousness served as a theoretical basis for this study. The different orders of consciousness represent the different stages that Kegan theorized to explain human social development. Specifically, Kegan (1994) posited five orders of consciousness where the individual makes increasingly more complex meaning from his or her life experiences. Meaning making constitutes the assumptions that people make of whether their identity is externally constructed or internally constructed (Kegan 1982, 1994). This study confirmed the assumptions of Kegan's Orders of Consciousness. In this study, I found that most of the student veterans either were transitioning from the third stage to the fourth or were almost completely in the fourth stage. Student veterans conveyed the different stages in how they drew meaning from the world around them through their social interactions. Those in the third order demonstrated a need for social interaction where their relationships were part of who they were and how they drew meaning from their university experiences. Student veterans related their experiences to how they wanted other students to view them. Some needed the mutual reciprocity of relationships (Berger, et al. 2007), which is indicative of the third stage in Kegan's theory. Student veterans in this stage, though, were also transitioning into the fourth stage, which is defined by the ability to coordinate their multiple roles, and then determine their own self-generated, relationship-regulating framework (Berger, et al., 
2007). The student veterans in the fourth stage could understand how each role was part of the fabric of who they were as a person.

Student veterans utilized their invisibility and isolation to either share their veteran status or keep it hidden from traditional age college students. For a student veteran to want to be normal and fit in would suggest that they are choosing to isolate themselves from their fellow students. By isolating, the student veterans do not fully fit in and are not able to share their true selves, thus the transition to the fourth stage of Kegan's theory, to author their meaning from the world isn't experienced. Fellow classmates' opinions and the relationships are more valuable than the different identities inside of them, which is how the student veteran makes the meaning for himself of herself.

Despite how some of the student veterans wanted the students to think of them as normal and fit into the group, others were in transition to Kegan's fourth stage, selfauthorship. Through self-authorship, people are able to understand how the different identities that they have are intermingled but yet separate. As mentioned previously in the results section, Viktor stated that "trying to separate my identity as a person is difficult. They are all me and at some point, I don't know. Parts of my history are written on me and that's just because they will always be ... you know because I think they are intermingled." Much like other veterans he is taking those experiences and reformulating his own thoughts and ideas but understanding that he was built by those different identities. Through this, the student veterans showed that the experiences they had during their deployments had given them the tools to transition to the self-authorship stage. 
In terms of practice, this study highlighted several different implications for university officials. The new influx of student veterans encourages university officials to provide the most effective strategies to support their experiences at the university. Student veterans have various characteristics that set them apart from their traditional age counterparts which much be addressed by campus officials. The main themes discovered asserted that student veterans were aware that they were different from other students on campus. Some of those student veterans wanted to share their veteran experiences with others, whereas some chose to keep it hidden. The challenge is to help student veterans feel like they are part of the institution while navigating their various degrees of selfdisclosure.

In completing the research, four recommendations for practice emerged. First, the campus community must be educated about the unique characteristics of the student veterans. Secondly, campus programs should be advanced to support the transition of student veterans to campus. Third, the need for increased information and intervention strategies for female student veterans. Lastly, student veterans are a unique culture returning to college and thus counselors should follow the multicultural counseling competencies and standards during the counseling process.

\section{Recommendation 1: Educate the campus community.}

Knowledge is the key that opens the door for effective and efficient services for student veterans by the campus community. The more knowledge that the campus community has about the specific needs, identity, and meaning making of student veterans, the better able they will be to effectively provide services. By the campus community, I am referring to campus employees who interact with students, including 
faculty, staff, and administrators. The education process should consist of an overview of the specific issues that student veterans face as they come to college, many of which were discovered in this study.

Specifically, the campus community should be educated about how student veterans feel more mature than their traditional age counterparts. The service that the student veterans have provided their country makes them feel as though they have the right to be treated with respect. The frustration then that some student veterans felt toward their college experience stems directly from their feeling of disrespect being shown toward them. Faculty and staff understanding of these concepts will facilitate more meaningful conversations between the student veterans and the university faculty and staff members.

Additionally, it should be noted that, even though many student veterans have many similar issues, they are not all the same in how they are transitioning to the university, how they view their identity, or how they make meaning. For example, many student veterans wanted to experience the campus culture and community by fitting in and being normal. However, they continue to have a strong pride in being veterans and their former military service. These two seemingly conflicting concepts make it important for the campus community to understand how veterans are unique to themselves. Through this knowledge, the campus community members can value the unique aspects of each student veteran.

In addition to knowledge about the specific issues that student veterans face in their transition, the information for the campus community should include a discussion on the identity and meaning making structures of student veterans. Student veterans, 
overall, identified themselves as helpful, prideful, but frustrated with some of the issues that they perceive as trivial. The knowledge of the multitude of ways that student veterans identify themselves should help faculty and staff be considerate of their transition process.

Similarly, information that concerns meaning making will help the campus community interact with student veterans on their level. Baxter Magolda (1999) described that many traditional college students are in the third order of consciousness in Kegan's theory. However, as was demonstrated in this research study, many student veterans are in transition between having relationships be their main meaning making structure to self-authoring their own meaning or between the third and fourth stages. The campus community should be informed about this difference about how student veterans relate with each other and make meaning from those interactions.

\section{Recommendation 2: Further programs that support the transition of the} student veteran to campus.

University campuses across the country are beginning to fully understand the impact that student veterans have and will continue to have on their student populations. Programs have begun to form that provide support systems for student veterans as they come to and attend the university. The programs range in size from a one-person office where the campus staff person manages the student veterans' benefits to full-service offices that provide support through academic advisors, tutors, and the benefits administrator. However, with the choice of student veterans to either feel isolated or choose to be invisible, the difficulty lies in developing those programs that student veterans will seek out and utilize fully. 
Programs, such as the one at the research institution and at military friendly designated schools across, that increase interaction among student veterans should be examined to use the student veterans' sense of camaraderie. Camaraderie was one of the most prevalent themes during this research study. The student veterans expressed how the camaraderie they experienced during their military experiences was something that they continued to carry with them as they came to college. The feeling of missing a "battle buddy" and those people who have seen you at your very best and sometimes very worst was very moving for student veterans. To capitalize on this innate characteristic of student veterans, campuses could facilitate a student organization on campus that would bring student veterans together to socialize with other veterans who have experienced similar situations. The military teaches soldiers from the beginning that several together are stronger than one individual person. By developing and fostering a student group of veterans they will be able also to advocate for their rights as students on campus.

In addition to student groups, those universities that have the physical space could designate an area near the veterans office that would be a gathering spot for veterans. Again focusing on the theme of camaraderie, student veterans could use this specified space to mingle with one another and also have a place to relax or study between classes. Many student veterans live off campus and having a space on campus where they would feel safe would promote their overall well-being and positive attitude toward the university.

\section{Recommendation 3: Increase understanding of female veteran transition}

issues

Females currently consist of 15 percent of current active and 18 percent reserve 129 
military forces (Ostendorff \& Bompey, 2011). Additionally, there are "1.9 million female veterans in the United States" (Ostendorff \& Bompey, 2011). As such, more universities will see an increase of female veterans attending their universities in the future. Often times during the interviews the two female veterans echoed similar sentiments as their male counterparts including camaraderie, focus and determination on school, pride in military service and increased maturity from their fellow students, among others. Jamie even shared that she had considered going back to into the military.

However, Addison noted that her husband was the assumed veteran and not her because she was a female. She reacted to the omission as a veteran by describing how it was part of her daily life and she couldn't concern herself with it because it was out of her control. Based on her experiences, Addison went on to suggest that female veterans be visible in the veteran support offices on campus. By actively recruiting female veterans to be a member of veteran support offices, universities will send the message that they are aware and accommodating to the needs of female veterans.

In addition to involving female veterans in veteran student services offices and as part of the education of the campus community, universities should look to incorporate information about specifically about female veterans in the information that is disseminated across campus. Female veterans are similar to the overall student veteran population in that each female veteran has their own interpretation of how the military has impacted their lives. However, female veterans share being a minority population within the overall military. Understanding and sharing information about the experiences of female veterans will provide a welcoming environment for this growing population of veterans. 


\section{Recommendation 4: Student veterans are a unique culture returning to college and thus counselors should follow the multicultural counseling competencies and standards during the counseling process.}

In Sue, Arrendondo, and McDavis (1992) groundbreaking call to action article the provide the initial framework for how the counseling profession can increase multicultural competencies in their practice. For the minority client, they state "he or she is likely to approach counseling with a great deal of healthy suspicion as to the counselor's conscious and unconscious motives in a cross cultural context" (Sue, et al., 479). No truer is this statement then for student veterans and the veteran population as a whole. The cultural mindset of the military encourages strength and compartmentalization of feelings so they do not interfere with the mission at hand. Soldiers face a stigma to be hesitant in relaying any mental health concern to a professional for fear of the impact on their career. Student veterans then bring this same distrust of those outside of their culture to campus. Part of the isolation and invisibility that student veterans feel on campus was relayed during the interviews in that they couldn't relate to others and the campus couldn't relate to them and their experiences and military culture. Sue et al reiterates this point in that "counseling professionals need to recognize that counseling does not occur in isolation from larger events in our society" (p. 479). The conflicts in Iraq and Afghanistan have lasted for over a decade and will continue to impact political forces and events in the years to come.

Counselors thus have the responsibility to view the veteran population as a unique culture and thus employ the multicultural counseling competencies and standards in their practices. Arrendondo, et al. (1996) outline three overarching areas that counselors can 
follow in order to provide effective services to unique populations including; counselor awareness of own cultural values and biases, counselor awareness of client's worldview, and culturally appropriate intervention strategies. First, university counselors can seek out various training to educate themselves in the culture of the military and the impacts on that culture upon student veterans transitioning to the college setting. Counselors in this first area are also encouraged to understand how they internally view the military culture and work towards becoming understanding and adapting their identity. Secondly, counselors skills should include the knowledge of the various research related to any mental health and mental disorders associated with student veterans. Approximately 18 percent of returning soldiers have been diagnosed with PTSD (Radford, 2010) and mTBI (mild traumatic brain injury) has affected an estimated 187,539 (Defense and Veterans Brain Injury Center, 2012). mTBI has been called the have been called the signature wound of the Iraq and Afghanistan conflicts (Snell and Halter, 2010). Counselors dealing with student veterans at the university level should have a knowledge of both of these mental health issues when working with this population.

Lastly, outlined by Arrendondo, et al. (1996), counselors should have the skills available to them to utilize the most effective treatment strategies available for student veterans. Traditional talk therapy may need to be adjusted for the student veteran in the counseling process. Arrendondo, et al. state that culturally skilled counselors "are able to engage in a variety of verbal and nonverbal helping responses" (para 25). Other types of treatment modalities have been show effective for PTSD including exposure therapy, stress inoculation training, and eye-movement desensitization. Counselors should be aware that the culture of the military lends itself to these modalities. An additional skill 
for the culturally competent counselor to utilize the appropriate intervention strategies is the ability to educate the client on the counseling process. Student veterans may not have had any formal experience to a counseling experience and thus this introduction will ease the student veteran's suspicion to the counseling process.

Counselors are called to ensure cultural competence with student veterans as they return to the college campus. Counselors must take the responsibility to know their population, know themselves and the implement this knowledge in the counseling interactions that they have with student veterans. Veterans and student veterans bring a unique set of worldviews to college campuses and thus the college community should prepare accordingly.

\section{Unanticipated Conclusions and Implications}

During the study, I found the literature review to be accurate in that the transition issues of student veterans were consistent with the veterans I interviewed. The research identified that student veterans were more mature, had feelings of invisibility and isolation, had pride in their military experiences, and felt frustration with the overall transition to college. However, student veterans are unique. It is not a blanket statement that all veterans will be more mature or have pride in the military. As Addison mentioned, she did not identify herself as a veteran on a regular basis, and it was only when there was a specific veteran event that she thought about it. In addition, not all veterans think of their fellow students as naïve, but some wanted to learn from their fellow students as well.

\section{Further Inquiry}

The purpose of this study was to investigate the perceptions of transition issues, 
identity, and meaning making of student veterans, all of whom had been deployed, as they experienced college life. Although the study was able to accomplish this goal, I found many areas where future research could be conducted. First, more inquiry is needed in regard to the specific experiences that women veterans feel as they return to college. Women are a growing population among the service branches. Specifically relating to Operation Iraqi Freedom (OIF) and Operation Enduring Freedom (OEF), women are increasingly present in combat duty positions. Also, women already constitute the majority of university students at 59 percent nationwide. Further inquiry is warranted to determine the in-depth relationship that women, who have been through combat and are attending a university, experience in their transition during college.

In addition, this study focused on combat OIF/OEF veterans. However, not all of the military veterans attending college have been in combat situations. As mentioned in the themes above, within the military culture there is a bias, among those veterans who have seen combat to those who have not. Studies to determine the transition issues, identity, and meaning of noncombat veterans are also warranted in this area.

Duplication of this study could also be conducted on multiple populations, including graduate students and faculty members. Both populations have a unique insight into the transitions and meaning making of student veterans. Because of the differences in expectations and culture, graduate student veterans could offer researchers the ability to contrast their transition issues and meaning making to those who are pursuing their undergraduate degrees. Additionally, faculty members may be able to provide a varied perspective to how veterans are able to transition to college. With this perspective they would be able to share their thoughts on the issues that they find most 
pertinent to the transition process. In addition, faculty members could drive future best practices with techniques and strategies that they have utilized in the classroom during a student veterans' transition process.

Lastly, another area that would prove fruitful for future research would be a longitudinal study of student veterans and how their identity and meaning making structures shift over time. Kegan suggests that as people mature and experience more life events, they are forced to reevaluate their current situation, which moves them from one stage to another. The experience of war may impact how the transitions are made between stages and if they are quicker because of it or slower.

\section{Summary}

Chapter IV is the final chapter of this dissertation. I have summarized the findings of the study and discussed the theoretical implications of this study related to Kegan's Orders of Consciousness. I also provided three recommendations for university professionals to consider as they interact with student veterans as they transition. Last, I highlighted my recommendations for future study of student veterans. 
Texas Tech University, Leigh A. Green, August 2012

\section{References}

Abes, E. S., \& Jones, S. R. (2004). Meaning making capacity and the dynamics of lesbian college students' multiple dimensions of identity. Journal of College Student Development, 45, 612-632.

Ackerman, R., DiRamio, D., \& Garza-Mitchell, R. L. (2009). Transitions: Combat veterans as college students. In R. Ackerman \& D. DiRamio, (Eds.). Creating a veteran friendly campus: Strategies for transition and success (New Directions for Student Services), 5-14. San Francisco, CA: Jossey Bass.

Altman, A. N., Inman, A. G., Fine, S. G., Ritter, H. A., \& Howard, E. E. (2010). Exploration of Jewish ethnic identity. Journal of Counseling and Development, 88(2), 163-173. 
American Counseling Association (2005). ACA code of ethics. Alexandria, VA: Authors. Arredondo, P., Toporek, M. S., Brown, S., Jones, J., Locke, D. C., Sanchez, J., Stadler, H. (1996) Operationalization of the multicultural counseling competencies. Journal of Multicultural Counseling and Development, 24, 42-78.

Berg, B. (2009). Qualitative research methods for the social sciences (5th ed.). Boston, MA: Allyn and Bacon.

Berger, J. G., Hasegawa, B. A., Hammerman, J. K., \& Kegan, R. (2007). How consciousness develops adequate complexity to deal with a complex world: The subject-object theory of Robert Kegan, 1-8. Retrieved from terrypatten.typepad.com/iran/files/KeganEnglish.pdf

Bozick, R., \& DeLuca, S. (2005). Better late than never? Delayed enrollment in the high school to college transition. Social Forces, 84(1), 527-550.

Bringer, J., Johnston, L. H., and Brackenridge, C. H. (2006). Using computer assisted qualitative data analysis software (CAQDAS) to develop a grounded theory project. Field Methods, 18(3), 245-266.

Brown, P. A. \& Gross, C. (2011). Serving those who have served- Managing veteran and military student best practices. The Journal of Continuing Higher Education, 59, 45-49. doi:10.1080/073377363.544982

Bye, D., Pushkar, D., \& Conway, M. (2007). Motivation, interest, and positive affect in traditional and nontraditional undergraduate students. Adult Education Quarterly, 57(2), 141-158. 
Charmaz, K. (2002). Qualitative interviewing and grounded theory analysis. In J. Gubrium \& J. A. Holstein (Eds.), Handbook of interview research (pp. 675-694). Thousand Oaks, CA: Sage.

Charmaz, K. (2005). Grounded theory in the $21^{\text {st }}$ century: Applications for advancing social justice studies. In N. Denzin \& Y. Lincoln (Eds.) Handbook of qualitative research (3rd ed., pp. 507-535). Thousand Oaks, CA: Sage.

Chickering, A. W., \& Reisser, L. (1993). Education and identity (2nd ed.). San Francisco, CA: Jossey-Bass.

Choy, S. P. (2002). Access \& persistence: Findings from 10 years of longitudinal research on students. Washington, DC: American Council on Education.

Compton, J. I., Cox, E., \& Laanan, F. S. (2006). Adult learners in transition. New Directions for Student Services, 114, 73-80.

Cook, B. J., \& Kim, Y. (2009). From soldier to student: Easing the transition of service members on campus. Washington, D.C: American Council on Education.

Council for Adult and Experiential Learning (2000). Serving Adult Learners in Higher Education: Principles of Effectiveness. Retrieved February 24, 2010 from www.cael.org.

Creswell, J. (1998). Qualitative inquiry and research design: Choosing among five traditions. Thousand Oaks, CA: Sage.

Creswell, J. (2009). Research design: Qualitative, quantitative and mixed methods approaches $\left(3^{\text {rd }}\right.$ ed). Thousand Oaks: Sage. 
Defense and Veterans Brain Injury Center (2012). DoD Numbers for Traumatic Brain Injury. Retrieved from http://www.dvbic.org/sites/default/files/uploads/dod-tbi2000-2012.pdf

Denzin, N., \& Lincoln, Y. (Eds.). (2005). Handbook of qualitative research (3rd ed.). Thousand Oaks, CA: Sage.

Dill, P .L. \& Henley, T. B. (1998). Stressors of college: A comparison of traditional and nontraditional students. The Journal of Psychology: Interdisciplinary and Applied, 132(1), 25-32.

DiRamio, D., Ackerman, R., \& Garza-Mitchell, R. L. (2008). From combat to campus: Voices of student-veterans. NASPA Journal, 45(1), 73-102.

DiRamio, D. \& Jarvis, K. (2011). Veterans in higher education: When Johnny and Jane come marching to campus. ASHE Higher Education Report, 37 (3), 1-144.

Dundon, T. \& Ryan, P. (2009). The qualitative research interview: Fashioning respondent affinity. Journal of Management Research, 1(1), 1-12.

Eppler, M. A. \& Harju, B. L.(1997). Achievement motivation goals in relation to academic performance in traditional and nontraditional college students. Research in Higher Education 38(5), p. 557-573.

Erikson, E. H. (1959). Identity and the life cycle. Psychological Issues (Monograph No. 1). New York: International Universities Press.

Fontana, A. \& Frey, J. H. (2005). The interview: From neutral stance to political involvement. In Denzin, N. \& Lincoln, Y. (Eds.). Handbook of qualitative research (3rd ed., pp. 695-727). Thousand Oaks, CA: Sage.

Ford, D., Northrup, P., \& Wiley, L. (2009). Connections, partnerships, opportunities, and 139 
programs to enhance success for student veterans. In R. Ackerman \& D. DiRamio, (Eds.). Creating a veteran friendly campus: Strategies for transition and success (New Directions for Student Services, Vol. 126), 61-70. San Francisco, CA: Jossey Bass.

Gall, M. D., Gall, J. P., Borg, W. R. (2007). Educational research: An introduction ( $8^{\text {th }}$ ed.). Boston, MA: Pearson.

Glaser, B.G. (1978). Theoretical sensitivity. Mill Valley, CA: Sociology Press.

Glaser, B. G., \& Strauss, A. L. (1967). The discovery of grounded theory: Strategies for qualitative research. Chicago, IL: Adine.

Glesne, C. (2011). Becoming a qualitative researcher: An introduction (4 $\left.{ }^{\text {th }} \mathrm{ed}\right)$. Boston: Pearson.

Goldrick-Rab, S. (2006). Following their every move: An investigation of social class differences in college pathways. Sociology of Education, 70, 61-79.

Gordy, W. J. and Potter, H. R. (1976). Interview rapport: Demise of a concept. Public Opinion Quarterly, 39, 529-543.

Greenberg, M. (2004). How the GI Bill changed higher education. Chronicle of Higher Education, 50 (41), 1-10.

Hassan, A. M., Jackson, R., Lindsay, D. R., McCabe, D. G. \& Sanders, J. E. (2010, May/June). The veteran student in 2010. About Campus, 30-33.

Doi:10.1002/abc. 20020

Heppner, P., \& Heppner, M. (2004). Writing and publishing your thesis, dissertation and research. Belmont, CA: Brooks/Cole. 
Jones, S. R. (1997). Voices of identity and difference: A qualitative exploration of the multiple dimensions of identity development in women college students. Journal of College Student Development, 38, 376-386.

Jones, S. R. \& Abes, E. S. (2004). Enduring influences of service-learning on college students' identity development. Journal of College Student Development, 45, 149166.

Jones, S. R., \& McEwen, M. K. (2000). A conceptual model of multiple dimensions of identity. Journal of College Student Development, 41, 405-413.

Kegan, R. (1982). The evolving self: Problem and process in human development. Cambridge, MA: Harvard University Press.

Kegan, R. (1994). In over our heads: The mental demands of modern life. Cambridge, MA: Harvard University Press.

Lincoln, Y. S., \& Guba, E. G. (1985). Naturalistic Inquiry. Newbury Park, CA: Sage.

Livingston, W. (2009). Discovering the academic and social transition of re-enrolling student veterans at one institution: A grounded theory. Unpublished doctoral dissertation. Clemson University, Clemson, SC.

Loane, S., \& Smole, D. (2008). A brief history of veterans' education benefits and their value. Washington, DC: Congressional Research Service.

Locks, A. M., Hurtado, S., Bowman, N. A. \& Oseguera, L. (2008). Extending notions of campus climate and diversity to students' transition to college. Review of Higher Education, 31(3), 257-285.

McCracken, G. (1988). The long interview. Newbury Park, CA: Sage. 
Miller, P. H. (2002). Theories of developmental psychology ( $4^{\text {th }}$ ed.). New York: NY: Worth.

Miles, M. \& Huberman, M. (1994). Qualitative data analysis: An expanded sourcebook ( $2^{\text {nd }}$ ed.). Thousand Oaks, CA: Sage

Morse, J. M., \& Field, P. A. (1996). Nursing research: The application of qualitative approaches. Cheltenham, UK: Nelson Thornes Ltd.

National Center for Educational Statistics, Digest of Educational Statistics. (2011a). Military service members and veterans: A profile of those enrolled in undergraduate and graduate education 2007-08. Retrieved from http://nces.ed.gov/pubsearch/pubsinfo.asp?pubid=2011163

National Center for Educational Statistics, Digest of Educational Statistics 2010. (2011b). Total post baccalaureate fall enrollment in degree-granting institutions, by attendance status, sex of student, and control of institution: 1967 through 2009. Retrieved from http://nces.ed.gov/programs/digest/d10/tables/dt10_214.asp?referrer=report NCHEMS Information Center for Higher Education Policymaking and Analysis. (2009). College-Going Rates of High School Graduates: Directly from High School. Retrieved from http://www.higheredinfo.org/dbrowser/index.php?measure=32

Newman, I., Ridenour, C. S., Newman, C., \& DeMarco, G. M. P. (2003). A typology of research purposes and its relationship to mixed methods. In A. Tashakkori \& C. Teddlie (Eds.), Handbook of mixed methods in social and behavioral research (189-208). Thousand Oaks, CA: Sage.

NVIVO 9. (2011). Retrieved from http://www.qsrinternational.com/products_NVIVO 
9.aspx

O'Donnell, V. L. \& Tobbell, J. (2007). The transition of adult students to higher education: Legitimate peripheral participation in a community of practice. Adult Education Quarterly, 57, 312-328. doi: 10.1177/0741713607302686

O’Herrin, E. (2011). Enhancing veteran success in higher education. Peer Review, 13(1). Retrieved from http://www.aacu.org/peerreview/pr-wi11/prwi11_oherrin.cfm Olson, K.W. (1974). The G.I. Bill, the veterans, and the colleges. Lexington, KY: University of Kentucky Press.

Ostendorff, J., \& Bompey, N. (2011, February 28). VA scopes out medical needs of female veterans. USA Today, p. 3A.

Patton, M. Q. (2002). Qualitative research and evaluation methods $\left(3^{\text {rd }}\right.$ ed.). Thousand Oaks, CA: Sage.

Piaget, J. (1954). The construction of reality in the child. New York: Basic Books.

Piaget, J. (1967). Biology and knowledge. Chicago; University of Chicago Press.

Perakyla, A. (2005). Analyzing talk and text. In N. Denzin \& Y. Lincoln (Eds).

Handbook of qualitative research (3rd ed., pp. 869-885). Thousand Oaks, CA: Sage.

Persky, K. R., \& Oliver, D. E. (2011). Veterans coming home to the community college: Linking research to practice. Community College Journal of Research and Practice, 35, 111-120. doi: 10.1080/10668926.2011.525184

Radford, A. W. (2010). Military service members and veterans in higher education: What the new GI Bill may mean for postsecondary institutions. Washington, DC: American Council on Education. 
Richards, H. M. \& Schwartz, L. J. (2002). Ethics of qualitative research: Are there special issues for health services research? Family Practice, 19, 135-139.

Rumann, C. B., \& Hamrick, F. A. (2009). Supporting Student Veterans in Transition. In R. Ackerman \& D. DiRamio, (Eds.). Creating a veteran-friendly campus: Strategies for transition and success. New Directions for Student Services (vol. 126, pp. 25-34). San Francisco, CA: Jossey Bass.

Rumann, C. B., \& Hamrick, F. A. (2010). Student veterans in transition: Re-enrolling after war zone deployments. The Journal of Higher Education, 81(4), 431- 455.

Schlossberg, N. K., Lynch, A. Q., \& Chickering, A. W. (1989). Improving higher education environments for adults: Responsive programs and services from entry to departure. San Francisco, CA: Jossey-Bass.

Schlossberg, N. K., Waters, E. B., Goodman, J. (1995). Counseling adults in transition (2nd ed.). New York, NY: Springer.

Silverman, D. (2001). Interpreting qualitative data: Methods for analysing talk, text and interaction. London: Sage Publications.

Smith, E. R. \& Mackie, D. M. (2000). Social psychology. London, England: Psychology Press, $2^{\text {nd }}$ ed.

Snell, F. I. \& Halter, M. J. (2010). A signature wound of war: Mild traumatic brain injury. Journal of Psychosocial Nursing, 48(2), 22-28.

St. John, E. P., \& Tuttle, T. J. (2004). Financial aid and postsecondary opportunity for nontraditional age, pre college students: The roles of information and the education delivery systems. Boston, MA: The Educational Research Institute.

Strauss, A., \& Corbin, J. (1990). Basics of qualitative research: Grounded theory 144 
procedures and techniques. Newbury Park, CA: Sage.

Strauss, A., \& Corbin, J. (1998). Basics of qualitative research: Techniques and procedures for developing grounded theory (2nd ed.). Thousand Oaks, CA: Sage.

State of Texas, Education Code. (2003). Resident of bordering state or nation or participant in student exchange program: Tuition. Retrieved from http://www.statutes.legis.state.tx.us/Docs/ED/htm/ED.54.htm\#54.060

Student Veterans of America. (n.d.). Student veterans of America [Brochure]. Washington, DC: Author. Retrieved from http://www.studentveterans.org/resourcelibrary/documents/SVA\%20Brochure.pdf

Sue, D. W., Arredondo, P., \& McDavis, R. J. (1992). Multicultural counseling competencies and standards: A call to the profession. Journal of Counseling and Development, 70, 477-486.

Taniguchi, H., \& Kaufman, G. (2005). Degree completion among nontraditional college students. Social Science Quarterly, 86 (4), 912-928.

Taylor, S., \& Bogdan, R. (1998). Introduction to qualitative research methods: A Guidebook and resource (3rd ed.). New York: John Wiley.

Teddlie, C. B. \& Tashakkori, A. (2009). Foundations of mixed methods research: Integrating quantitative and qualitative approaches in the social and behavioral sciences. Thousand Oaks, CA: Sage.

Texas Higher Education Coordinating Board. (2011). College for all Texans. Retrieved from http://www.collegeforalltexans.com/apps/financialaid/tofa2.cfm?ID=444 
Texas Tech University, Office of Institutional Research. (2011). Texas Tech University fact book. Retrieved from http://www.irim.ttu.edu/FactBook/Enrollment/ENRHOME.aspx

Today’s G.I. Bill (2011). History of the GI Bill. Retrieved from http://www.todaysgibill.org/todays-gi-bill/history-of-the-gi-bill/

U.S. Census Bureau. (2012). State and County Quick Facts. Retrieved from http://quickfacts.census.gov/qfd/states/48000.html

U.S. Census Bureau. (2009). Section 10: National security and veterans affairs. Statistical Abstract of the United States. Retrieved from http://www.census.gov/compendia/statab/cats/national_security_veterans_affairs. html.

U.S. Census Bureau, Population Division. (2007). Table 1: Annual estimates of the population for the United States, regions, states, and Puerto Rico: April 1, 2000 to July 1, 2007. (NST-EST2007-01). National and State Population Estimates. http:// www.census.gov/popest/states/NST-ann-est2007.html.

U.S. Department of Veteran Affairs. (2011, March 11). Reaching out to veterans on campus through VetSuccess. VA Office of Public and Intergovernmental Affairs. Retrieved from http://www.va.gov/opa/pressrel/pressrelease.cfm?id=2070

Van Dusen, R. L. (2011). A quantitative study of student veterans' intent to persist. Unpublished doctoral dissertation, Texas Tech University, Lubbock, TX. Weitzman, E. (2000). Software and qualitative research. In N. K. Denzin \& Y. S. Lincoln (Eds.) Handbook of qualitative research ( $2^{\text {nd }}$ ed.). Thousand Oaks: Sage. 
Texas Tech University, Leigh A. Green, August 2012

\section{Appendix A}

Email script from the Director of Military and Veteran Programs

Dear OIF/OEF Student Veterans,

Ryan Van Dusen, Director of Military and Veteran Programs have sent this email to you on my behalf. My name is Leigh Green and I am currently recruiting OIF/OEF student veterans to participate in my dissertation. I am studying how you perceive both your military identity and your student identity as you transition to college. I will meet with you for approximately one hour and audiotape our conversation about your experiences in college. Meetings can be scheduled at a convenient time for student veterans, including evenings and weekends. Research participation is completely confidential. 
If you are interested please contact Leigh Green at leigh.green@ttu.edu or 806-445-3763. Dr. Loretta Bradley in the College of Education is supervising this research.

Sincerely,

Leigh Green, LPC-Intern, NCC

Doctoral Candidate

Texas Tech University

Loretta J. Bradley, PhD

Paul Whitfield Horn Professor \&

Coordinator, Counselor Education

Texas Tech University

COE Box 41071 Counselor Education

Lubbock, TX 79409-1071

Ph: office 806-742-1997x 263

$\mathrm{Ph}$ : home 806-798-2555

FAX: $\quad 806-742-2179$

\section{Appendix B}

Flyer

\section{OIF/OEF Student Veterans Wanted \\ Texas Tech University \\ Department of Counselor Education and Supervision}

I am currently recruiting OIF/OEF student veterans to participate in my dissertation. I am 
studying how you perceive both your military identity and your student identity as you transition to college.

Audiotaped meetings will last approximately one hour.

Meetings can be scheduled at a convenient time for you, including evenings and weekends. Research participation is completely confidential.

If you are interested, please contact Leigh Green at leigh.green@ttu.edu or 806-445-3763. Dr. Loretta Bradley in the College of Education is supervising this research.

\section{Appendix C}

Dear Student Veteran,

Thank you so much for being willing to participate. At this time I have been lucky to receive enough responses and am currently full. If something happens I will certainly be in touch to see if you would still be willing to participate.

Thank you again and have a wonderful day, Leigh 
Texas Tech University, Leigh A. Green, August 2012

\section{Appendix D}


Texas Tech University, Leigh A. Green, August 2012

TEXAS TECH UNIVERSITY

Vice President for Research

December 20, 2011

Dr. Loretta Bradley

Ed Psychology \& Leadership

Mail Stop: 1071

Regarding: 503211 Student Veteran Identity Perception and Meaning Making

Dr. Loretta Bradley:

The Texas Tech University Protection of Human Subjects Committee approved your claim for an exemption for the proposal referenced above on December 19, 2011.

Exempt research is not subject to continuing review. However, any modifications that (a) change the research in a substantial way, (b) might change the basis for exemption, or (c) might introduce any additional risk to subjects must be reported to the IRB before they are implemented.

To report such changes, you must send a new claim for exemption or a proposal for expedited or full board review to the IRB. Extension of exempt status for exempt projects that have not changed is automatic.

The IRB will send annual reminders that ask you to update the status of your research project. Once you have completed your research, you must inform the Coordinator of the Committee either by responding to the annual reminder or by notifying the Coordinator by memo or e-mail (donna.peters@ttu.edu) so that the file for your project can be closed.

Sincerely,

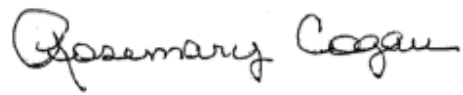

Rosemary Cogan, Ph.D., ABPP

Protection of Human Subjects Committee

Box 41075 | Lubbock, Texas 79409-1075 | T 806.742.3905 | F 806.742.3947 | www.vpr.ttu.edu
An EEO/Affirmative Action Institution 


\title{
Appendix E
}

\author{
Research Information Sheet
}

Purpose of the Research

The purpose of this study is to build a better understanding of student veteran identity perceptions and meaning making as it relates to their transition into university life. The secondary purpose is to build on the knowledge base of enrolling student veterans in the university setting. This study will assist counselors and university personnel in their instruction, support, and attention for student veterans.

During the Interview

- The interview will take approximately one hour to complete. Meetings can be scheduled at a convenient time for student veterans, including evenings and weekends.

- Information is completely voluntary.

- Questions can be skipped and the participant can stop the interview at anytime.

- Student Veterans will be asked if they wish to review the transcript to provide feedback. If yes, then I will ask them to write his or her email address.

Participants will be asked if they can be audiotaped during the interview and audiotapes will be electronically stored on the researchers external hard drive. Transcripts will then be uploaded on a software program that will help the researcher develop a theory from the themes they describe. The information will be uploaded with a pseudonym and once the research is completed the original audio will be deleted. In addition, after the research has been completed identifying information, such as email addresses, will be deleted.

Should you have any questions please do not hesitate to contact myself, Leigh Green, at leigh.green@ttu.edu or 806-445-3763 or Dr. Loretta Bradley at Loretta.bradley@ttu.edu or 806-742-1997 ext 263.

\section{Referral List}

\author{
Student Counseling Center \\ 201 Student Wellness Center \\ 806-742-3674 \\ Vet Center \\ 3106 50th st suite 400 \\ Lubbock, TX 79413 \\ 806-792-9782 Or 877-927-8387 \\ Veterans Administration
}

6104 Avenue Q, Lubbock, TX 79412 
$806-472-3400$

Interview Protocol

\section{Appendix G}

Interviewer:

Date:

Interviewee (pseudonym) :

1. The interviewer will provide the interviewee time to review an information sheet outlining:

- The research purpose to the participant, i.e. identity development and meaning making of student veterans.

- The IRB statement for the participants.

- That the information is completely voluntary.

- Questions can be skipped and the participant can stop the interview at anytime

- The participant will be asked if they wish to review the transcript

If yes, then I will ask them to write his or her email address

2. After the sheet is read the researcher will ask the participant if they can be audiotaped during the interview.

- Participants will be told that audiotapes will be electronically stored on the researchers external hard drive.

2. After the research has been completed the electronic files and identifying information, such as email addresses and original audio, will be deleted.

After the questions are finished, the interviewer will ask the participant of any other student veterans that would be willing to provide insight into how they interpret their military identity with their student identity. Please thank the participant for their 
time and insight into their perceptions. Also, remind the participant that you will be in contact with them shortly to confirm the themes that you have garnered from the data provided

4. The interviewer will ask the participants the following questions in this order.

5. How are you today? (Icebreaker question)

6. What are some of the transition issues that you faced from being in the military to a student on this campus?

- Please give specific examples where possible

7. What are the differences between your military and university experiences?

- Please give specific examples where possible

8. How would you describe yourself as a student and what makes it meaningful to you

9. How would you describe yourself as a veteran and what makes it meaningful to you

10. Thinking of your both your student identity and veteran identity, describe who you are as a person.

11. How do you view your military and student identity in relation to your other identities, e.g. social class, race, etc? 